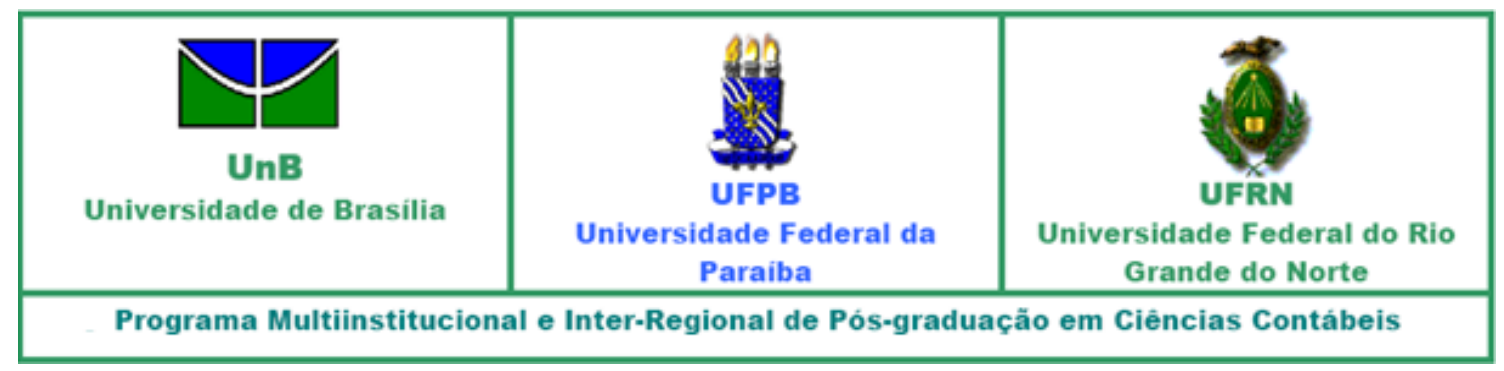

LUIZ CARLOS MARQUES DOS ANJOS

RELAÇÕES ENTRE EFICIÊNCIA TÉCNICA DAS ORGANIZAÇÕES E REMUNERAÇÃO A EXECUTIVOS À LUZ DOS IMPACTOS DA MOTIVAÇÃO E SENSIBILIDADE DA REMUNERAÇÃO AO DESEMPENHO

\title{
JOÃO PESSOA
}




\section{LUIZ CARLOS MARQUES DOS ANJOS}

\section{RELAÇÕES ENTRE EFICIÊNCIA TÉCNICA DAS ORGANIZAÇÕES E REMUNERAÇÃO A EXECUTIVOS À LUZ DOS IMPACTOS DA MOTIVAÇÃO E SENSIBILIDADE DA REMUNERAÇÃO AO DESEMPENHO}

Tese apresentada ao Programa Multiinstitucional e Inter-Regional de Pós-Graduação em Ciências Contábeis da UnB, UFPB e UFRN, como requisito parcial para obtenção do título de doutor.

Orientador: Prof. Dr. Paulo Aguiar do Monte

JOÃO PESSOA - 2016 
A599r Anjos, Luiz Carlos Marques dos.

Relações entre eficiência técnica das organizações e remuneração a executivos à luz dos impactos da motivação e sensibilidade da remuneração ao desempenho / Luiz Carlos Marques dos Anjos.- João Pessoa, 2016.

133f. : il.

Orientador: Paulo Aguiar do Monte

Tese (Doutorado) - UnB-UFPB-UFRN

1. Contabilidade. 2. Incentivos - executivos. 3. Eficiência técnica. 4. Motivação - executivos. 5. Desempenho remuneração. 
Professor Doutor Ivan Marques de Toledo Camargo

Reitor da Universidade de Brasília

Professora Doutora Sônia Nair Báo

Vice-Reitora da Universidade de Brasília

Professor Doutor Jaime Martins de Santana

Decano de Pesquisa e Pós-graduação

Professor Doutor Roberto de Goes Ellery Júnior

Diretor da Faculdade de Economia, Administração e Contabilidade

Professor Doutor José Antônio de França

Chefe do Departamento de Ciências Contábeis e Atuariais

Professor Doutor Rodrigo de Souza Gonçalves

Coordenador-geral do Programa Multi-institucional e Inter-regional de Pós

Graduação em Ciências Contábeis da UnB, UFPB e UFRN 


\section{RELAÇÕES ENTRE EFICIÊNCIA TÉCNICA DAS ORGANIZAÇÕES E REMUNERAÇÃO A EXECUTIVOS À LUZ DOS IMPACTOS DA MOTIVAÇÃO E SENSIBILIDADE DA REMUNERAÇÃO AO DESEMPENHO}

Tese apresentada ao Programa Multi-institucional e Interregional de Pós-Graduação em Ciências Contábeis da UnB, UFPB e UFRN, como requisito parcial para obtenção do título de doutor.

Prof. Dr. Paulo Aguiar do Monte

Universidade Federal da Paraíba - UFPB

Orientador

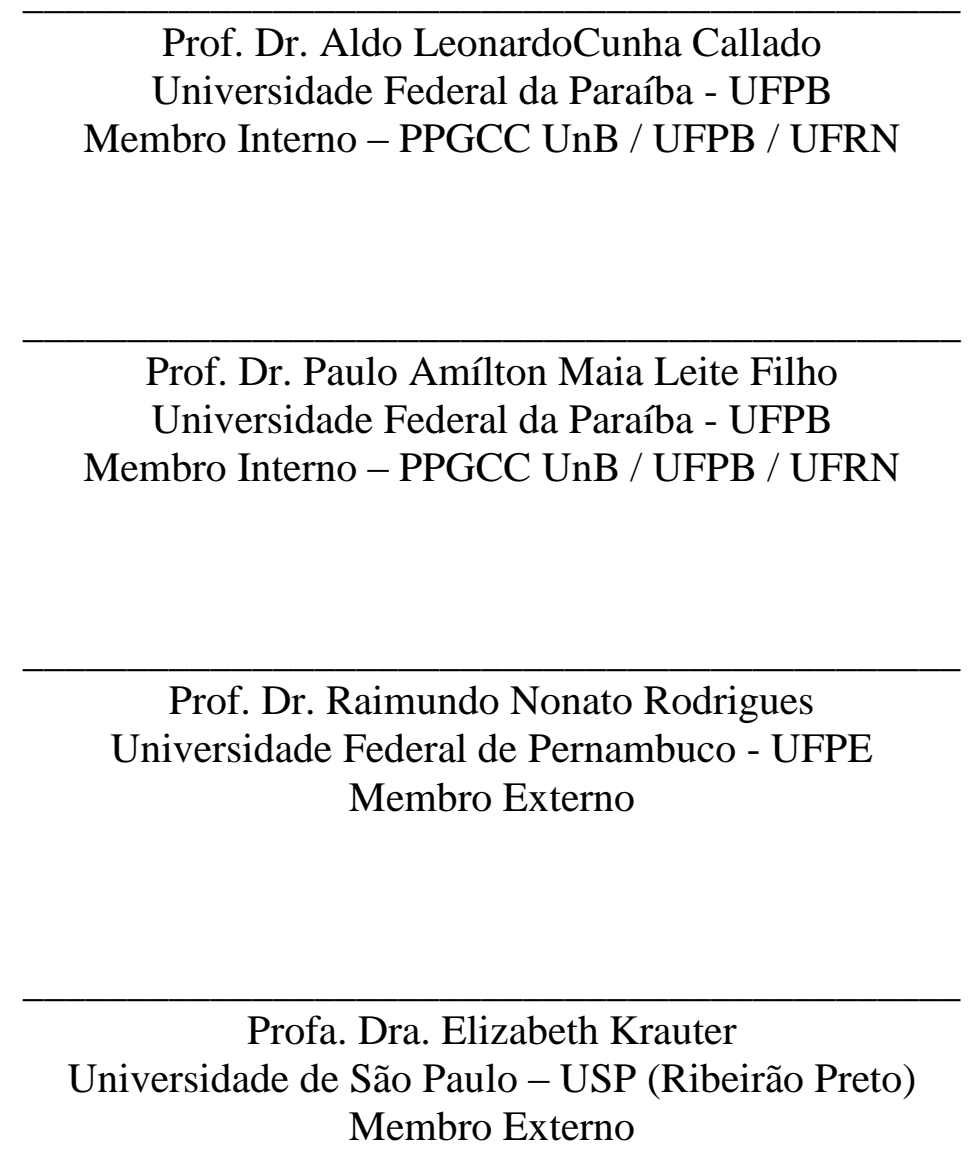

Membro Externo 
Ninguém se iluda: se qualquer pessoa entre vós se considera sábia de acordo com os padrões deste nosso tempo, então é melhor tornar-se insensata para alcançar a sabedoria. (I Co. 3:18) 


\section{AGRADECIMENTOS}

O processo de pós-graduação stricto sensu pode ser longo e doloroso, porém surgem amigos neste caminho que viabilizam sua conclusão. $O$ primeiro amigo a quem agradeço é Deus. Ele me deu esta oportunidade e esteve comigo nos momentos de dificuldade, nas horas em que me senti só, que achei que não conseguiria concluir o curso, que vivi os maiores embates da minha vida, Ele cuidou de mim e me ensinou mais sobre a vida e as pessoas. Foi por causa do que Deus fez em minha que consegui ingressar em um curso deste nível e finalizá-lo. Não foi mérito meu, e não mereço nenhum louvor por isso. Obrigado meu Deus!

Em seguida quero agradecer aos amigos que sempre estiveram do meu lado e que sofreram bastante com meus maus momentos e se alegraram e aliviaram nas horas de alegria: minha família. Minha esposa, Aline Rúbia, e meus filhos, Alícia e Davi, que compartilharam tudo que vivi, inclusive adoeceram por causa das minhas escolhas. Vocês são o alicerce que Deus colocou em minha vida. Não sei como agradecer, apenas quero dizer que os amo.

Outros familiares também foram importantes em muitas fases e quero mencionálos, assumindo o risco de esquecer alguém: Meu pai Carlos dos Anjos e meus irmãos Pollyanna, Lorena, Filipe e Carlinhos, vocês são alegria certa, Meus sogros Amaro de Freitas e Railde Ferraz, um pai e uma mãe que Deus me deu, meus cunhados Givaldo, Rivaldo, Rosinha e Rosivaldo, vocês fazem uma diferença enorme em minha vida, os agregados Regina, Ana, Fred e Karla, vocês são certeza de apoio, os sobrinhos Gabriel, Joana, Victor e Maria Amélia, sorriso certo a cada encontro, o povo "do" Goiás Vó Joana, Tio Luiz e Tia Neusa, Tio Fábio e Tia Fátima, Guilherme, Lucas, Tatiane e Bruno, família sempre presente mesmo na distância. A cada um de vocês meu muito obrigado.

Há também os amigos que encontrei durante o caminho. Quero começar pelos amigos da $5^{\text {a }}$ turma de doutorado: Adriana Steppan, Gilmara Borges, Diego Boente, Mateus Alexandre, Márcia Tavares, Josicarla Santiago, Lúcio Tozetti, Lidiane Dias, Leonardo Seixas e Daniel Falcão, a cada um de vocês o agradecimento de quem não conseguiria passar por isso sem a vossa companhia. Que essa amizade perdure. 
Os amigos dos locais de trabalho. Comecei o doutorado como professor da UFAL e não posso deixar de agradecer aos amigos Adhemar Ranciaro, Valdemir da Silva e Thierry Prates por todo o apoio nos momentos conflituosos e discussões sobre o doutoramento. Conclui o doutorado como professor da UFPE e nesta instituição devo agradecer aos professores Luiz Carlos Miranda, Jeronymo Libonati, Daniel Cardoso e Marcelo Jota por toda a preocupação e acolhida.

Aos amigos / irmãos que conheci em Recife: Luciano, Daniel Reis e Marfisa, Anderson e Lívia, Diogo e Liliane, Felipe e Bianca, Jimes e Valéria, Ewerton e Érika com quem a caminhada tem sido compartilhada. Obrigado por todo apoio e orações.

Aos funcionários do Multi: Iva, Wilma e Inês, obrigado. E aos professores que tive o prazer de ouví-los compartilhando suas experiências e conhecimentos: Jorge Katsumi, César Tibúrcio, José Matias-Pereira, Ivan Gartner, Otávio Medeiros, Paulo Lustosa, Edilson Paulo, Paulo Roberto Nóbrega, José Dionísio, Anderson Mól, Paulo Amilton, Aldo Callado, Márcio Machado e Márcia Reis.

Ao amigo irmão que a vida me concedeu e que se preocupa comigo mesmo quando eu não me preocupo, Rommel de Santana Freire. Difícil encontrar uma amizade desinteressada em contrapartidas, sincera, presente e alegre como é a sua. Obrigado por tudo.

Ao meu orientador, professor Doutor Paulo Aguiar do Monte, que sempre foi bastante acessível, preocupado com meu desenvolvimento e engajamento nas atividades pretendidas. Por toda a paciência, dedicação, compreensão e orientação, meu muito obrigado.

Por fim, agradeço a todos que contribuíram direta e indiretamente, ao longo do curso, na consecução deste trabalho. 


\section{LISTA DE FIGURAS}

Figura 1 - Função Típica de Recompensa de Healy (1985) ......................................... 26

Figura 2 - Circunscrevendo o domínio do desempenho organizacional ........................ 30

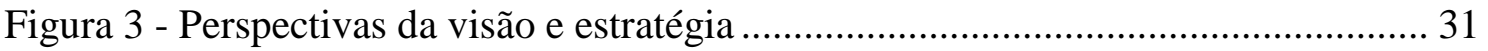

Figura 4 - Estrutura para mensuração de desempenho organizacional .......................... 32

Figura 5 - Esquema para classificar enfoques alternativos para medir o desempenho

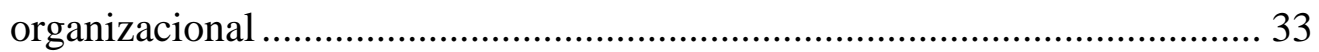

Figura 6 - Vetores na motivação de executivos ........................................................... 43

Figura 7 - Conceito de Remuneração dos Executivos ..................................................... 49

Figura 8 - Estrutura conceitual para efeitos de incentivos monetários sobre esforço e

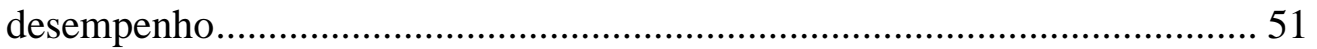

Figura 9 - Modelo Conceitual da Relação Entre Tipos de Incentivos e Compensação Baseada em Metas de Desempenho ......................................................... 69

Figura 10 - Eficiência técnica média ao longo do tempo nas amostras 1, 2 e 3. 2010 a

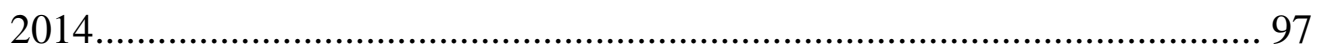




\section{LISTA DE QUADROS}

Quadro 1 - Taxonomia da motivação humana........................................................ 41

Quadro 2- Efetividade motivacional e uso de incentivos .......................................... 48

Quadro 3 - Informações Sobre Remuneração Exigidas no FR ...................................... 52

Quadro 4 - Variáveis utilizadas em estudos já desenvolvidos. .................................. 56

Quadro 5 - Relação esperada do efeito motivacional na eficiência técnica das firmas .. 74

Quadro 6 - Relação esperada da sensibilidade da remuneração à eficiência técnica das

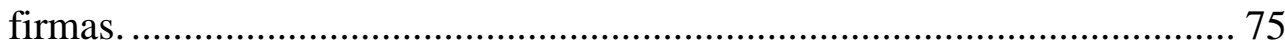




\section{LISTA DE TABELAS}

Tabela 1 - Autores e obras mais citados acerca de desempenho organizacional ........... 28

Tabela 2 - Descrição da amostra 1 - todos os setores: Distribuição das empresas por

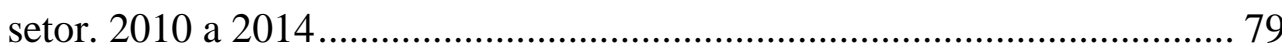

Tabela 3 - Descrição dos dados de remuneração atualizados pelo IPCA para as firmas da amostra 1 - com todos os setores. 2010 a 2014

Tabela 4 - Descrição dos dados acerca do Ativo Total das firmas da amostra 1, em Reais (R\$) - com todos os setores. 2010 - 2014...

Tabela 5 - Descrição dos dados acerca da receita das firmas da amostra 1 - todos os setores, em Reais (R\$). 2010 - 2014

Tabela 6 - Valor médio das variáveis das firmas da amostra 1 - com todos os setores. 2010 a 2014

Tabela 7 - Descrição dos dados acerca do número de funcionários das firmas da amostra 1 - todos os setores. 2010 a 2014

Tabela 8 - Teste da função de verossimilhança das funções Cobb-Douglas e Translog para as amostras 1, 2 e 3.

Tabela 9 - Estimativa para os parâmetros da função de fronteira estocástica (Battese e Coelli, 1995) em painel das firmas da amostra 1, 2 e 3. 2010 a 2014

Tabela 10 - Estimação das fronteiras formuladas por Kumbhakar (1990) e Lee e Schmidt (1993) para as firmas da amostra 1, 2 e 3. 2010 a 2014

Tabela 11 - Resumo dos resultados das estimações da fronteira estocástica com todos os setores, sem o setor financeiro e apenas com indústrias. 2010 a 2014 ....... 91

Tabela 12 - Resultados do Teste-F para variâncias das amostras 1, 2 e 3.2010 a 201493

Tabela 13 - Sumário dos logaritmos da eficiência técnica, nível e tipos de remuneração das amostras 1, 2 e 3. 2011 a 2014

Tabela 14 - Relação entre eficiência técnica e remuneração, por tipo de incentivo e nível de incentivo nas amostras 1, 2 e 3. 2011 a 2014

Tabela 15 - Sumário da variação da remuneração total e tamanho das firmas das amostras 1, 2 e 3.2012 a 2014.

Tabela 16 - Sensibilidade da variação da remuneração total ao desempenho organizacional das amostras 1, 2 e 3. 2012 a 2014

Tabela 17 Sensibilidade da remuneração variável ao desempenho organizacional das amostras 1, 2 e 3.2012 a 2014. 


\section{LISTA DE SIGLAS}

BM\&FBovespa - Bolsa de Valores, Mercadorias e Futuros do Estado de São Paulo.

CVM - Comissão de Valores Mobiliários.

DMU - Decision Making Units

ET - Eficiência Técnica.

FR - Formulário de Referência.

IPCA - Índice de Preços ao Consumidor Amplo

NYSE - New York Securities Exchange

VIF - Variance Inflation Factor 


\section{RESUMO}

O objetivo desta tese foi investigar a relação entre a eficiência técnica das firmas e a motivação dos executivos, através dos incentivos financeiros a eles concedidos. A base teórica pressupõe que incentivos concedidos no período $t$ influenciam o desempenho organizacional em $t+1$ e geram diferentes tipos de motivação. Os dados coletados abrangem o período de 2010 a 2014, porém, a não disponibilidade de dados em alguns dos períodos limitou a amostra em 239 firmas, totalizando 47.800 observações. A análise foi dividida em três partes: i) estimação de uma fronteira estocástica de produção para firmas; ii) exame dos efeitos motivacionais que os incentivos pecuniários concedidos aos executivos exercem sobre o desempenho organizacional das firmas; e iii) análise da sensibilidade da remuneração dos executivos à eficiência técnica das firmas. Os resultados permitiram inferir que: i) as firmas têm aumentado suas eficiências técnicas ao passar dos anos e a ineficiência das firmas é decorrente principalmente de fatores específicos das próprias empresas e não de fatores exógenos ( $\eta=0,1422$ e $\gamma=0,9994)$, não permitindo rejeitar a hipótese 1 da pesquisa; ii) o desempenho organizacional tem relação significativa apenas com o nível dos incentivos, porém os tipos de remuneração não influenciam o desempenho organizacional ao nível de 1\%; e iii) apenas em situações restritas (amostra sem o setor financeiro e ao nível de significância de $10 \%$ ) foi possível identificar sensibilidade da remuneração variável ao desempenho da organização, apesar que ao considerar apenas o setor industrial, ou todos os setores listados, tal relação não foi estatisticamente significativa. Concluiu-se, portanto, que, apesar da ineficiência estimada das firmas ser decorrente de fatores endógenos, as fórmulas de incentivo ainda não conseguem motivar os executivos por meio dos tipos de incentivos adotados (remuneração fixa, remuneração variável ou outras remunerações e benefícios) e que essa fragilidade faz com que a remuneração dos gestores não apresente relação significativa com a eficiência técnica estimada.

Palavras-chave: Incentivos a Executivos. Eficiência Técnica. Motivação de Executivos. 


\begin{abstract}
The objective of this thesis was to investigate the relationship between the economic efficiency of firms and motivation of executives through the financial incentives granted to them. The theoretical basis assumes that incentives in period $t$ influence organizational performance in $t+1$ and generate different types of motivation. The collected data cover the period 2010-2014, however, the non-availability of data in some of the periods limited the sample to 239 firms, totaling 47,800 observations. The analysis was divided into three parts: i) estimating a stochastic boundary production companies; ii) examination of the motivational effects that monetary incentives granted to executives have on organizational performance of firms; and iii) sensitivity analysis of executive compensation to the technical efficiency of the firms. The result showed that: i) firms have increased their technical efficiencies over the years and the inefficiency of the firms is mainly due to factors specific of the companies themselves rather than exogenous factors $(\eta=0.1422$ and $\gamma=0.9994)$, allowing not to reject the hypothesis 1 of the research; ii) organizational performance is significant only to the level of incentives, but the types of remuneration do not influence organizational performance at 1\%; and iii) only in limited situations (sample without the financial sector and at the 10\% significance level) were identified sensitivity of the variable remuneration to the performance of the organization, though considering only the industrial sector, or all of the listed sectors, such relationship was not statistically significant. It was concluded, therefore, that despite the estimated inefficiency of firms is due to endogenous factors, formulas incentive can not motivate executives through the types of adopted incentives (fixed remuneration, variable remuneration and other remuneration and benefits) and this fragility makes the remuneration of managers does not have significant relationship with the estimated technical efficiency.
\end{abstract}

Keywords: Executive Compensation. Technical Efficiency. Executive Motivation. 


\section{SUMÁRIO}

1 INTRODUÇÃO ......................................................................................................... 16

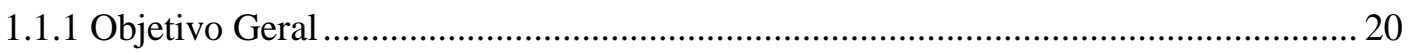

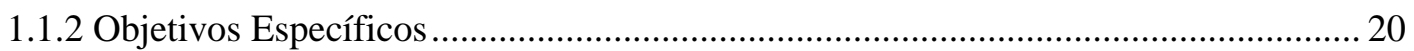

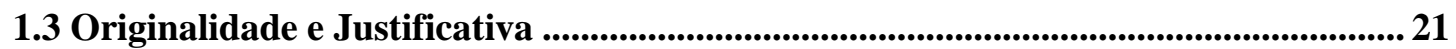

2 REVISÃO DA LITERATURA ............................................................................. 23

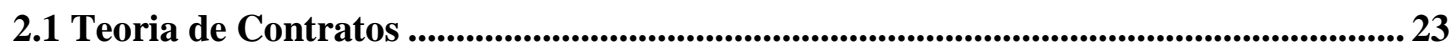

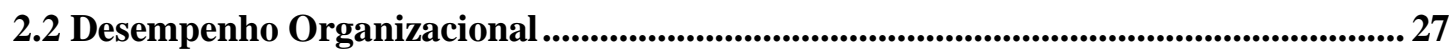

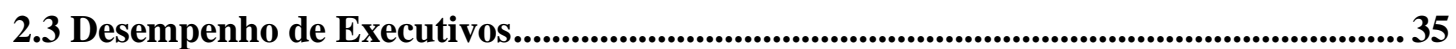

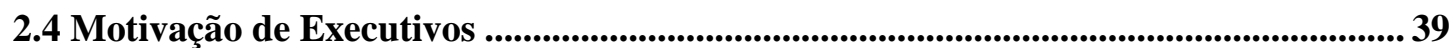

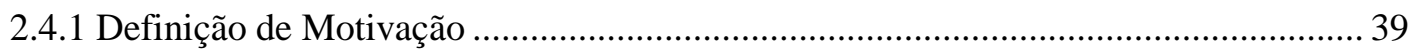

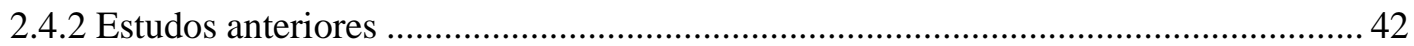

2.5 Sistemas de Incentivo e Remuneração de Executivos .......................................................45

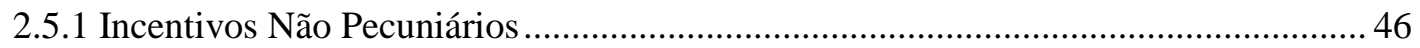

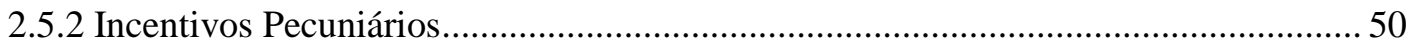

2.6 Avaliação de Desempenho ................................................................................................. 58

2.7 Análise de Eficiência e Desempenho Organizacional.......................................................... 63

2.8 Hipóteses de Pesquisa.............................................................................................................................. 66

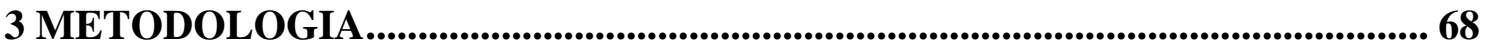

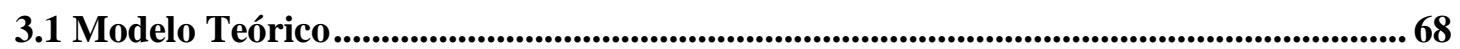

3.1.1 Estimação da Fronteira Estocástica............................................................................ 69

3.1.2 Diversificação e Nível de Incentivos vs. Desempenho Organizacional ...................... 72

3.1.3 Sensibilidade dos Incentivos a Executivos ao Desempenho Organizacional.............. 75

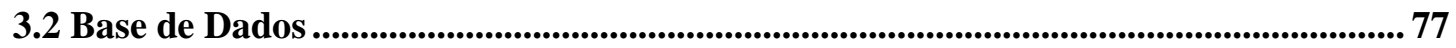

4 ANÁLISE DOS RESULTADOS ............................................................................. 79

4.1 Análise Descritiva ........................................................................................................ 79

4.2 Estimação da Fronteira Estocástica ......................................................................... 85

4.3 Desempenho Organizacional vs. Nível e Diversificação de Incentivos ........................ 92

4.4 Sensibilidade da Remuneração aos Incentivos ................................................................. 101

5 CONCLUSÕES.................................................................................................... 109

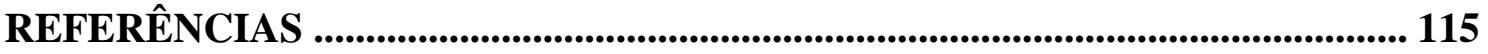

APÊNDICE A - MATRIZ DE COVARIÂNCIA DOS COEFICIENTES DA

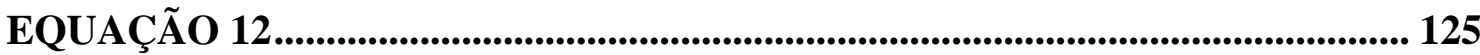


APÊNDICE B - ESTIMAÇÃO DA FRONTEIRA DE EFICIÊNCIA COM USO DA FUNÇÃO COBB-DOUGLAS.......................................................................... 127

APÊNDICE C - TESTES DOS PRESSUPOSTOS DAS EQUAÇÕES 20 E $21 \ldots 128$

Equação 20 ............................................................................................................................. 128

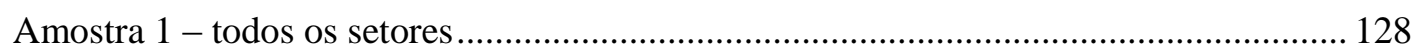

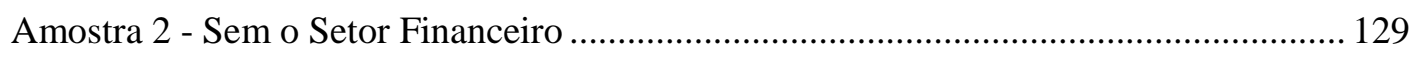

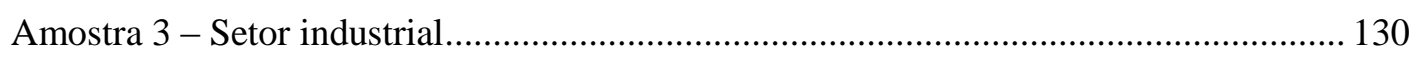

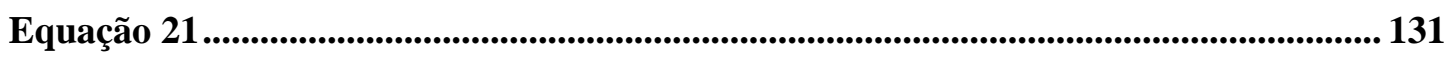

Amostra 1 - Amostra completa, com todos os setores...................................................... 131

Amostra 2 - Amostra sem o Setor Financeiro .................................................................. 132

Amostra 3 - Amostra restrita ao setor industrial.......................................................... 133 


\section{INTRODUÇÃO}

Algumas das ideias centrais que permitem melhor entendimento da contabilidade e controle nas organizações evidenciam que todas as organizações são conjuntos de contratos entre indivíduos, ou grupos de indivíduos (COASE, 1937; WATTS; ZIMMERMAN, 1986), e que a informação compartilhada entre as partes auxilia no desenvolvimento e implementação destes contratos (SUNDER, 1997). O contexto de incerteza, onde são geradas decisões sob informação imperfeita, faz com que sejam estabelecidos nos contratos pacotes de incentivos que motivem os gestores a escolherem ações que gerem resultados esperados pelos principais.

Considera-se que os resultados alcançados seriam decorrentes dos esforços que o indivíduo, ou grupos de indivíduos, exercem para levar a organização a atingir determinado desempenho. A definição de desempenho organizacional utilizada nesta tese parte das discussões de autores como Venkatraman e Ramanujam (1986) e Kaplan (2010) que afirmam que o desempenho organizacional é resultado dos esforços em áreas distintas como financeira, operacional, aprendizado interno e mercado. Para que a organização obtenha bom desempenho são criados fatores que influenciem $o$ comportamento dos executivos, no sentido de tornar a utilidade destes executivos semelhante à utilidade dos stakeholders. Estes fatores são chamados de incentivos e podem ser de caráter pecuniário, ou não (MERCHANT; STEDE, 2012)

A busca pelo entendimento de como determinado gestor responde aos incentivos que lhe são oferecidos, para que ele escolha as ações que maximizem a utilidade daqueles que lhe delegaram autonomia para tomada de decisões, tem sido estudada sob dois enfoques: (i) controles gerenciais por parte de usuários interessados no desempenho organizacional, e; (ii) avaliação do mercado sobre os resultados obtidos por este indivíduo, como forma de motivá-lo a produzir informações úteis para o próprio mercado (SCOTT, 2011; MERCHANT; STEDE, 2012). Em ambos os casos fica evidente o ambiente de avaliação dentro do qual os gestores de alto escalão (executivos) desenvolvem suas atividades profissionais. Ao agirem de forma racional, os executivos buscarão maximizar sua própria utilidade, o que pode não representar a maximização da utilidade dos principais que o contrataram, gerando assim um conflito de agência entre as partes (SCOTT, 2011; JENSEN; MECKLING, 1976). 
Por conta desse conflito, os principais desenvolvem controles para monitorar as ações dos agentes de forma a se certificarem que as ações escolhidas por estes sejam aquelas com maior probabilidade de maximizar a utilidade dos principais. Acerca deste debate, Merchant e Stede (2012) afirmam que os indivíduos deveriam ser avaliados sob a égide do princípio da controlabilidade, logo, seriam responsáveis apenas por aquilo que podem controlar. Entretanto, sabe-se que poucas (ou nenhuma) variáveis de mercado são completamente controláveis, o que pode gerar descontentamento na forma de avaliação e motivar práticas de gamesmanship. ${ }^{1}$

Autores como Healy (1985) e Guidry, Leone e Rock (1999) mostram que os gestores ao agir com tal motivação podem adotar a prática de gerenciamento de resultados que, mesmo sendo lícita, pode levar os usuários das informações contábeis a tomar decisões equivocadas. Alguns exemplos são dados a seguir: 1) os gestores que têm interesse em aumentar o resultado da organização e melhorar sua avaliação poderiam antecipar o reconhecimento de receitas a fim de aumentar o lucro; 2) os gestores que já atingiram seu resultado em determinado exercício podem postergar o reconhecimento de receitas para não complicar sua avaliação nos exercícios subsequentes; e 3) empresas com resultados muito voláteis sugerem maior risco, consequentemente, os investidores aumentariam suas expectativas de retorno o que onera o custo do capital. Desta forma os gestores utilizariam a competência como forma de "suavizar" o comportamento do lucro, tornando-o mais estável e atraindo mais investidores a um menor custo de capital (income smoothing).

O comportamento racional e oportunista do gestor pode levar investidores e proprietários a tomarem decisões que não são ótimas sob o ponto de vista da maximização de suas utilidades. Uma forma de buscar proteção contra tal comportamento do gestor seria adotar práticas de governança corporativa. Merchant e Stede (2012) afirmam que a governança corporativa se refere a um conjunto de mecanismos e processos que asseguram que as firmas estão sendo dirigidas para criar valor para seus proprietários. Logo, empresas com melhores níveis de governança estariam adotando melhores práticas, que proporcionariam maiores riquezas para os acionistas.

\footnotetext{
${ }^{1}$ Merchant e Stede (2012) utilizam o termo gamesmanship para se referir a ações que o agente pode realizar para melhorar seus indicadores de desempenho, sem produzir qualquer efeito econômico positivo para a organização.
} 
Neste sentido, o Instituto Brasileiro de Governança Corporativa (IBGC) tem buscado elencar práticas que seriam ótimas e que teriam maior transparência. Uma destas práticas seria a definição de uma política de remuneração de executivos que represente, apropriadamente, os objetivos de curto e longo prazos da organização, garantindo o cumprimento de seus planos estratégicos (IBGC, 2009). De forma similar, a Comissão de Valores Mobiliários (CVM), entidade reguladora do mercado de capitais no Brasil, através das Deliberações no 562/2008, 600/2009 e da Instrução 480/2009, aprovou a obrigatoriedade de evidenciação de informações acerca da remuneração de executivos, como forma de possibilitar ao mercado a avaliação dos resultados organizacionais com a remuneração paga aos executivos.

É possível perceber a existência de uma relação precípua onde melhores desempenhos individuais, por parte dos executivos, gerariam maiores remunerações. Porém, esta ideia inicial poderia ferir o princípio da controlabilidade conforme descrito por Merchant e Stede (2012) dado que o desempenho organizacional também está sujeito às variações macroeconômicas do período. Com base nesta reflexão, mercados mais desenvolvidos, como o dos Estados Unidos da América (EUA), exigem que as organizações divulguem a evidenciação do uso de avaliação relativa de desempenho nos contratos de compensação de executivos. Até o presente momento não foi identificado, na literatura pesquisada, evidências do uso explícito de tal prática no Brasil. A ideia geral é a de que qualquer variação macroeconômica não traz impacto apenas sobre determinada organização, mas sobre o setor ao qual ela pertence, possibilitando ao mercado identificar situações de sorte ou revés e considerar seus impactos no desempenho dos executivos (HOLMSTROM, 1982; AGGARWAL; SAMWICK, 1999; ANGELIS; GRINSTEIN, 2011).

A aprovação da Instrução CVM 480/09 (que dispõe sobre o registro de emissores de valores mobiliários admitidos à negociação em mercados regulamentados de valores mobiliários) gerou repercussão no meio empresarial brasileiro e diversas empresas buscaram na justiça o direito de não revelar os valores pagos a seus executivos e a estrutura de seus pacotes de remuneração, nos termos da referida Instrução. Segundo tais empresas, a divulgação destas informações seria uma ameaça à segurança de seus executivos. De acordo com o IBGC (2013), em 2012, cerca de 55 empresas se recusavam a divulgar tais informações. Além disso, diversas outras apresentaram informações 'inconsistentes', como: valores anuais zerados ou muito baixos 
(remuneração anual da diretoria muito baixa), ausência de diretoria estatutária, erros de preenchimento. Por outro lado, a Comissão de Valores Mobiliários (CVM) busca meios e parceiros para forçar o mercado a divulgar estas informações e fornecer maior transparência para os acionistas.

É importante destacar que, de acordo com Scott (2011), o mercado avalia constantemente o desempenho dos gestores e forma um senso comum acerca de sua reputação. Porém, as considerações sobre a reputação dos executivos não excluem a necessidade de contratos de incentivos aos executivos. Por outro lado, autores como Korman, Glickman e Frey Jr (1981) apontam falhas à teoria dos incentivos, concluindo que nem sempre "mais é melhor" e que o contrato ótimo deveria prover diferentes motivações para o gestor. Logo, para que os executivos estejam devidamente motivados seria necessário desenvolver uma política de incentivos que abranja tanto motivações extrínsecas como as intrínsecas. Krauter (2013) evidencia relações estatisticamente significativas entre incentivos não pecuniários e o desempenho da firma.

Partindo-se do pressuposto que a melhor utilidade para investidores e para a própria organização englobaria resultados de curto e de longo prazos, a mensuração da eficiência técnica de uma organização poderia permitir entender tais resultados, o que diminuiria o viés decorrente do uso de variáveis essencialmente financeiras (BAEK; PAGÁN, 2002).

Considerando que autores como Sloan (1993) e Murphy (2001) tratam o desempenho organizacional como uma função do desempenho do executivo, e que o comportamento do agente é uma variável não-observável pelo principal (JENSEN, MECKLING, 1976), pode-se inferir a carência de conhecimento mais aprofundado acerca de uma função utilidade de incentivos para executivos.

Neste contexto, o problema de pesquisa pode ser descrito como: Qual é a interrelação entre eficiência técnica das organizações e a remuneração a executivos, considerando os impactos da motivação e da definição de metas de desempenho?

Para tal, será utilizada como técnica principal a estimação de fronteira estocástica cujo produto resultante seria a receita. A partir desta será estimado o termo de eficiência técnica para cada firma em cada ano, analisando a sensibilidade da eficiência técnica (como proxy de desempenho organizacional) aos tipos e níveis de remuneração, e, por fim, analisar-se-á se o poder preditivo da eficiência técnica em relação à a executivos. 
Esse estudo compreenderá apenas empresas listadas na BM\&FBovespa devido a disponibilidade dos dados necessários para a estimação de uma fronteira estocástica. $\mathrm{O}$ período analisado compreendeu os anos de 2010 a 2014, a partir do qual será analisada a relação entre o desempenho organizacional e o incentivo a executivos.

\subsection{Objetivos}

Para estabelecer resposta ao problema levantado foram estabelecidos os seguintes objetivos:

\subsubsection{Objetivo Geral}

- Investigar a relação entre a eficiência técnica das firmas e a motivação dos executivos através dos incentivos financeiros concedidos, no período de 2010 a 2014.

\subsubsection{Objetivos Específicos}

- Definir uma fronteira estocástica para incentivos a executivos, tendo como inputs o capital e mão-de-obra investidos e como output a receita líquida da firma.

- Analisar os impactos de estrutura e nível da remuneração a executivos na eficiência técnica da organização a partir do viés motivacional.

- Analisar os impactos da eficiência técnica, como medida de desempenho organizacional, na remuneração a executivos a partir do viés da sensibilidade da remuneração às metas previamente definidas. 


\subsection{Originalidade e Justificativa}

A originalidade desta Tese de Doutorado evidencia-se na ampliação da discussão no que se refere a explicação da relação entre incentivos a executivos e desempenho organizacional no mercado brasileiro. Em linhas gerais, diferencia-se de estudos anteriores realizados no Brasil (AGUIAR, 2009; KOETZ; KOETZ; MARCON, 2011; CHIEN，2012; FERREIRA，2012; SANTOS，2012; KRAUTER，2013; VENTURA, 2013; VASCONCELOS; MONTE, 2013) por: i) testar o incentivo como um efeito motivacional e temporalmente defasado; ii) separar os efeitos dos tipos e do nível dos incentivos pecuniários concedidos; e iii) utilizar como proxy para desempenho organizacional a eficiência técnica estimada da firma. Além disso, esta proposta avança em relação aos estudos internacionais (CONYON; 1997; BAEK; PAGÁN， 2002; AMORNKITVIKAI; HARVIE, 2011; YANG; REGIS, 2011) por: i) tratar o efeito motivacional dos incentivos e a sensibilidade destes ao desempenho como um ciclo temporal e mutuamente dependente.

Esta tese busca contribuir para a literatura existente sobre incentivos a executivos, adicionando a perspectiva temporal da motivação nos esforços dos agentes a fim de atingir metas de desempenho previamente estabelecidas, consequentemente, reduzindo a assimetria informacional e o conflito de agência. Estudos anteriores que trataram da relação entre incentivos a executivos e desempenho organizacional consideram que o esforço do gestor é uma resposta imediata aos incentivos que tem recebido e não ao que podem receber, dado que suas postulações teóricas consideram a relação motivação - desempenho seja tempestivamente mais próximo tanto por meio da definição temporal das variáveis (FERREIRA, 2012; SANTOS, 2012; KRAUTER, 2013; VENTURA, 2013) quanto na definição de quais variáveis de desempenho organizacional devem ser utilizadas (VASCONCELOS; MONTE, 2013).

Este estudo se justifica pela busca em compreender como a diversificação de incentivos financeiros motiva o agente a tomar decisões que contemplem as expectativas dos principais, dado que esta relação é menos explorada em favorecimento do nível de incentivos (TAYLOR, 1994). Esta pesquisa justifica-se ainda no momento em que busca compreender tais relações em empresas participantes do mercado brasileiro, pelo fato de ser um mercado ainda em desenvolvimento e que ainda não tem 
definições claras acerca das práticas de remuneração de executivos, na forma que se pretende investigar.

Análises que envolvam as eficiências técnicas das organizações e os incentivos dados a executivos das empresas listadas na BM\&FBOVESPA não foram encontradas até a conclusão do presente estudo, o que demonstra que tanto a metodologia quanto a teoria aplicadas nesta pesquisa são inovadoras no que tange aos estudos científicos em contabilidade para o mercado brasileiro.

Os resultados desta tese poderão contribuir para uma melhor compreensão por parte de investidores, conselhos de administração, conselhos e consultores de remuneração das estratégias para elaboração das fórmulas de incentivo com base nos tipos e níveis de incentivos e no uso de uma variável de desempenho organizacional que não incorpore os vieses inerentes às medidas contábeis e financeiras descritas por Aguiar (2009), Santos (2012) e Merchant e Stede (2012). 


\section{REVISÃO DA LITERATURA}

\subsection{Teoria de Contratos}

A teoria de contratos diz que as organizações são formadas por contratos, formais ou não, firmados entre diversas partes no intuito de diminuir conflitos de interesses entre os diversos atores (LAMBERT, 2001). Estes contratos estabelecem os esforços individuais e de cada equipe na consecução dos objetivos organizacionais.

De acordo com Scott (2011) grande parte da teoria de compensação de executivos deriva da teoria da agência ${ }^{2}$ que já é uma derivação da teoria de contratos. Para Lambert (2001), durante as décadas de 80 e 90, a pesquisa contábil demonstrou maior interesse nestas discussões, pois elas permitem incorporar explicitamente conflitos de interesse, problemas de incentivo causados por risco moral e mecanismos para controlar problemas de incentivo nos modelos desenvolvidos pelos pesquisadores. Para o autor, pesquisas contábeis nesta área possuem duas questões básicas: 1) como os recursos da informação, da contabilidade e de sistemas de compensação impactam problemas de incentivo; e 2) como a existência dos problemas de incentivos impactam a estrutura e o desenho da informação, da contabilidade e de sistemas de compensação.

A teoria da agência tem sido discutida em diferentes áreas, mas sempre sob um mesmo aspecto: o conflito de interesses entre duas, ou mais, partes. Essas discussões intensificaram-se com a separação do controle e da propriedade. Os conflitos de agência surgem no momento em que uma parte (principal) que detém a propriedade delega a outro indivíduo (agente) o papel de atuar em busca de seus interesses. Para tanto, o principal delega ao agente autoridade para tomadas de decisão (JENSEN; MECKLING, 1976; ROSS, 1973). Por outro lado, as relações contratuais das organizações geram novos principais, como é o caso de fornecedores de recursos (bancos, fornecedores e funcionários) e do próprio governo. Em todos os casos, o principal espera que o agente maximize sua riqueza e buscará formas de garantir que o agente se comporte de forma a garantir o atingimento deste objetivo.

\footnotetext{
${ }^{2}$ Jensen e Meckling (1976) afirmam que a teoria de agência é oriunda da separação do controle e da gestão empresarial e objetiva compreender as relações entre gestor e acionistas.
} 
Apesar da existência de controles, Jensen e Meckling (1976) afirmam que se tanto o principal quanto o agente buscam maximizar suas riquezas, existem razões para acreditar que o agente não agirá sempre em acordo com os melhores interesses do principal. Eisenhardt (1989) afirma que conflitos de agência surgem em dois momentos: 1) quando não há convergência entre os interesses do principal e do agente; ou 2) quando é muito difícil, ou oneroso, para o principal verificar as ações do agente. A autora utiliza-se ainda de discussões econômicas acerca desta teoria para afirmar que estes conflitos de interesse surgem como decorrência de atitudes diferentes em relação ao risco.

Lambert (2001) afirma que o problema do principal se baseia em maximizar a utilidade esperada por ele, sujeitando à aceitação pelo agente da restrição da utilidade e das compatibilidades de incentivo. Ao reconhecer o problema dos incentivos, o autor descreve a primeira melhor solução da seguinte forma:

$$
\begin{aligned}
& \max _{s(x, y), a} \iint G[x-s(x, y)] f(x, y \mid a) d x d y \\
& +\lambda\left\{\iint U[s(x, y)] f(x, y \mid a) d x d y-V(a)-\underline{H}\right\}
\end{aligned}
$$

Onde, o contrato acordado entre principal e agente é dado por $\mathrm{s}(\mathrm{x}, \mathrm{y})$, as ações selecionadas pelo agente são representadas por $a$, as medidas de avaliação de desempenho são descritas como ( $\mathrm{x}$ e y).Sendo assim, ao agente é pago s (x, y) e o principal mantém $\mathrm{x}-\mathrm{s}(\mathrm{x}, \mathrm{y})$. Desta forma a utilidade do agente é descrita por $\mathrm{G}(\mathrm{x}-\mathrm{s})$ e presume-se que o principal prefere menos a mais dinheiro $\left(G^{\prime}>0\right)$ e é averso ou neutro ao risco $\left(G^{\prime \prime} \leq 0\right)$.

A função de utilidade do agente é definida pela sua compensação monetária, s, e pelas ações que ele escolhe, $a$, sendo descrita como aditivamente separável entre tais componentes, o que resulta em $\mathrm{H}(\mathrm{s}, a)=\mathrm{U}(\mathrm{s})-\mathrm{V}(a)$, sendo $\underline{\mathrm{H}}$ o nível de utilidade aceitável do agente. Na equação 1 , o termo $\lambda$ é o multiplicador de Lagrange para a utilidade aceitável da restrição do agente. 
A dificuldade mencionada por Eisenhardt (1989) foi anteriormente tratada como custos de agência por Jensen e Meckling (1976) que a define como:

$$
\omega=\kappa+\lambda+v
$$

Onde, $\omega=$ Custos de agência; $\kappa=$ Gastos com monitoramento; $\lambda=$ Gastos com seguros; $v=$ Perdas residuais.

Os gastos com monitoramento envolvem diversas formas de controle, dentre elas os contratos de incentivos que incluem uma remuneração variável, de forma a motivar os gestores a buscar atingir os objetivos estratégicos da organização que, espera-se, maximizariam a utilidade dos stakeholders. Merchant e Stede (2012) afirmam que apesar de haver um grande enfoque em pagamentos na forma de dinheiro, estes não são a única forma de recompensar resultados obtidos. Os autores citam ainda outras maneiras como, promoção, reconhecimento e manutenção do emprego.

Para Ross (1973), os problemas de agência seriam teoricamente resolvidos através de uma estrutura de pagamento que resolvesse o problema do principal e levasse para a eficiência de Pareto para todo par de utilidades $(\mathrm{U}, \mathrm{G})$ dos indivíduos envolvidos no conflito. Entretanto, o autor afirma que isto não pode ser atingido porque os participantes deveriam estar em um ambiente de informação perfeita, onde o principal teria conhecimento do preço de cada ação do agente. Jensen e Murphy (1990) concordam que a definição de um contrato ótimo poderia sanar tal conflito, porém outros autores discordam que esta definição seja possível. Merchant e Stede (2012) dizem que sempre haverá variáveis não controláveis (pelo menos em parte) nas fórmulas de incentivo e isto por si só já geraria oportunidade para o surgimento de conflitos de interesse. Bebchuk e Fried (2003) argumentam que muitos gestores têm influência na definição de sua própria remuneração, o que também já é suficiente para acreditar não existir uma situação ótima para todos os participantes. Estes autores criticam ainda o fato do mercado (ou mesmo o Estado) não regular o pagamento de bônus, o que possibilita a oportunidade de ganhos extraordinários por parte dos gestores. 
Os incentivos concedidos aos executivos seriam então resultado de um contrato entre as partes que buscam maximizar suas utilidades. Healy (1985) faz uma descrição da recompensa tentando excluir situações de sorte ou azar, da seguinte forma:

$$
B_{t}^{\prime}=p\left\{\min \left\{U^{\prime}, \max \left\{\left(E_{t}-L\right), 0\right\}\right\}\right\}
$$

Onde, $B_{t}^{\prime}=$ Bônus; $p=$ Percentual de pagamento definido no contrato de bonificação; $L=$ Limite inferior de ganhos; $U^{\prime}=$ Limite para o excesso de ganhos sobre o limite inferior; $E_{t}=$ Resultados divulgados; $L=$ Limite inferior de ganhos.

Desta forma o gerente receberá $p\left(E_{t}-L\right)$ em bônus se os ganhos excederem o limite inferior e forem menores que o limite superior do plano, $U^{\prime}$. Os bônus são fixados em $p U^{\prime}$ quando os ganhos excedem o limite superior. A definição destes limites contribui para a inibição de práticas como o gerenciamento de resultados. Merchant e Stede (2012) apresentaram o modelo de Healy (1985) através da Figura 1.

Figura 1 - Função Típica de Recompensa de Healy (1985)

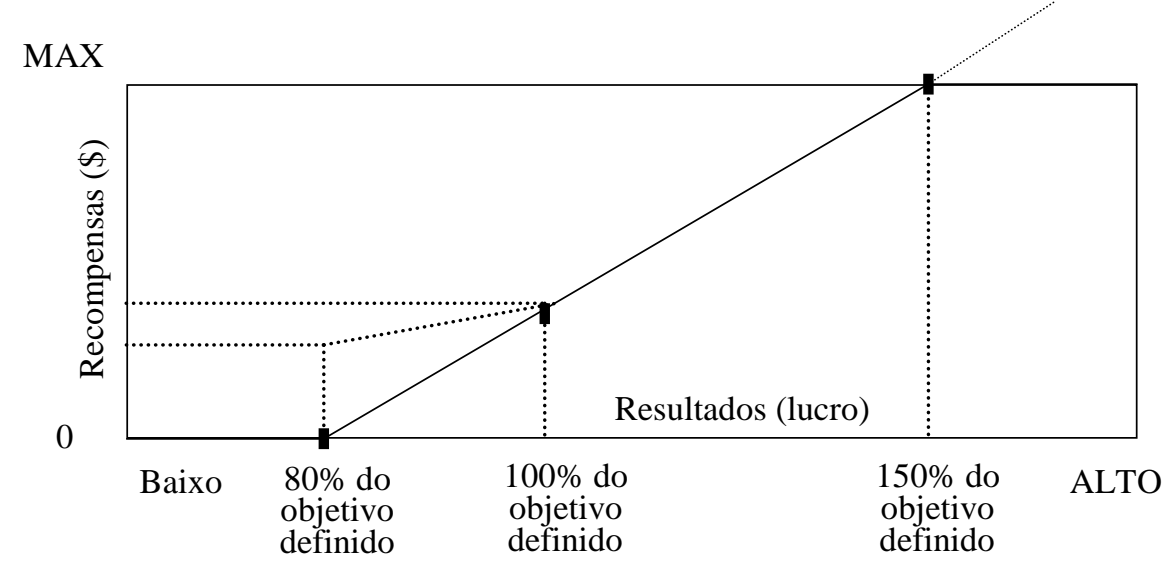

Fonte: Adaptado de Merchant e Stede (2012, p.316).

Apesar das discussões de Healy (1985) e Merchant e Stede (2012) adotarem uma conotação para incentivos como recompensas pecuniárias, não é difícil extrapolar seus argumentos para incluir os incentivos não pecuniários no debate, pois podem representar uma forma complementar, e talvez mais eficaz, de motivar os agentes a tomarem as decisões esperadas pelos principais. Neste sentido, Korman; Glickman e 
Frey JR. (1981) afirmam que não adianta ter alto níveis de incentivo e pouca diversificação de incentivos, pois cada um produz estímulos distintos.

Percebe-se nesta discussão que a contratação de um agente pressupõe que ele buscará maximizar a utilidade do principal. Porém, o principal não consegue monitorar as ações selecionadas pelo agente (HOLMSTRÖM, 1979), mas apenas os resultados obtidos pela organização. Logo, surge a demanda por controles que direcionem o comportamento do agente. Estes controles baseiam-se no que é observável, ou seja, nas medidas de desempenho organizacional.

\subsection{Desempenho Organizacional}

A discussão sobre o que é desempenho organizacional não é algo recente, ou de simples definição (VENKATRAMAN; RAMANUJAM, 1987; MARR; SCHIUMA, 2003; NEELY, 2005). Marr e Schiuma (2003) afirmam que a falta de consenso acerca do que é o desempenho organizacional ocasiona dificuldades na replicação de estudos pela academia e no entendimento, por parte do mercado, de qual foi o real desempenho de determinada organização. Neely (2005) confirma em seu estudo que a discussão acerca do desafio da definição de desempenho, bem como de suas métricas de avaliação, remete à década de 50 e teve poucas alterações até os anos 80 .

Neely (2005) e Merchant e Stede (2012) afirmam que esta realidade pode gerar impactos negativos na obtenção do desempenho desejado ao afirmarem que "você tem o que você mede"3. No ponto de vista destes autores, a definição das métricas que representam o desempenho esperado fará com que os funcionários trabalhem para melhorar a métrica, e não necessariamente o desempenho.

Neely (2005) afirma que a partir da década de 90 os estudos publicados na área começaram a citar mais estudos teóricos do que práticos, invertendo o perfil presente até o final dos anos 80. Segundo o autor, a busca por um consenso na definição de desempenho foi o catalisador desta constatação, evidenciando que algumas questões ainda são bastante recentes e carentes de maior aprofundamento conceitual.

\footnotetext{
3 "What you measure is what you get" (MERCHANT; STEDE, 2012, p. 33).
} 
As pesquisas de Marr e Schiuma (2003) e de Neely (2005) apresentam relações de autores e de pesquisas mais citados na área. A Tabela 1 apresenta os principais resultados evidenciados por estas pesquisas.

Tabela 1 - Autores e obras mais citados acerca de desempenho organizacional

\begin{tabular}{|c|c|c|c|c|}
\hline \multirow[b]{2}{*}{ Ranking } & \multicolumn{2}{|c|}{ Autores mais citados } & \multicolumn{2}{|c|}{ Obras mais citadas } \\
\hline & $\begin{array}{l}\text { Marr e Schiuma } \\
\quad(2003)\end{array}$ & $\begin{array}{l}\text { Neely } \\
(2005)\end{array}$ & Marr e Schiuma (2003) & Neely (2005) \\
\hline $1^{\mathrm{o}}$ & Kaplan & Kaplan & $\begin{array}{l}\text { Kaplan e Norton } \\
\text { (1996a) }\end{array}$ & $\begin{array}{c}\text { Kaplan e Norton } \\
\text { (1992) }\end{array}$ \\
\hline $2^{\circ}$ & Norton & Neely & $\begin{array}{l}\text { Kaplan e Norton } \\
\text { (1992) }\end{array}$ & $\begin{array}{c}\text { Kaplan e Norton } \\
\text { (1996a) }\end{array}$ \\
\hline $3^{\circ}$ & Neely & Banker & $\begin{array}{l}\text { Kaplan e Norton } \\
\text { (2000) }\end{array}$ & $\begin{array}{c}\text { Charnes, Cooper e } \\
\text { Rhodes (1978) }\end{array}$ \\
\hline $4^{\circ}$ & Gregory & Charnes & $\begin{array}{c}\text { Kaplan e Norton } \\
\text { (1996c) }\end{array}$ & $\begin{array}{l}\text { Dixon, Nanni e } \\
\text { Vollmann (1990) }\end{array}$ \\
\hline $5^{\circ}$ & Platts & Cooper & $\begin{array}{c}\text { Neely e Adams }(2001) \text { e } \\
\text { Kaplan e Norton } \\
(1996 b ; 1993)\end{array}$ & $\begin{array}{l}\text { Neely, Gregory e } \\
\text { Platts (1995) }\end{array}$ \\
\hline
\end{tabular}

Fonte: Adaptado de Marr e Schiuma (2003) e de Neely (2005).

Dentre as obras e autores apresentados na Tabela 1, pode-se destacar Neely (2005) que classifica as obras em dois grupos: (1) - Com foco na metodologia, especificamente a análise envoltória de dados (Banker, Charner e Cooper), e; (2) Com foco no alinhamento entre estratégia e mensuração de desempenho (todos os demais apresentados na Tabela 1).

Taticchi, Tonelli e Cagnazzo (2010) desenvolveram um estudo com objetivo de atualizar a pesquisa originariamente desenvolvida por Neely (2005). Porém, os resultados apresentados não apresentaram diferenças significativas. Notadamente quanto às obras mais citadas, os resultados foram idênticos aos de Neely (2005), o que evidencia que aquelas obras ainda possuem forte impacto sobre as pesquisas em mensuração do desempenho.

Especificamente no que concerne à conceituação da mensuração de desempenho, Taticchi, Tonelli e Cagnazzo (2010) a apresentam como um sistema dinâmico e balanceado que oferece suporte à tomada de decisões. Para os autores o "balanceamento" refere-se à necessidade de se utilizar diferentes medidas e perspectivas que forneçam, conjuntamente, uma visão holística da organização. Já o dinamismo diz 
respeito à análise constante do contexto interno e externo à empresa, para ajustar prioridades e objetivos.

Apesar da ideia de que as firmas devem entender e analisar seus desempenhos o discurso acerca do que eles vêm a ser acaba sendo confundido algumas vezes com as próprias métricas de sua mensuração. Diversos estudos que relacionam contratos de incentivos a executivos e desempenho organizacional utilizam como proxy para este último alguma medida de lucro ou retorno da firma (VENKATRAMAN; RAMANUJAM, 1987; SLOAN, 1993; CONYON, 1997; AGGARWALL; SAMWICK, 1999; JOH, 1999; LIU; STARK, 2009).

Por outro lado, a decisão acerca das métricas a serem utilizadas na avaliação de desempenho organizacional não é objetiva e depende de fatores como setor e porte da empresa, tipo de usuário e necessidades de cada usuário. Logo, a decisão de se testar determinado grupo de variáveis para mensurar o desempenho de um grupo diversificado de empresas é discricionário e pode enfraquecer os resultados obtidos.

Buscando-se um arcabouço teórico que possa definir o que efetivamente venha a ser o desempenho organizacional, Venkatraman e Ramanujam (1986) apresentaram um esquema conceitual com base na eficácia organizacional, como pode ser visto na Figura 2.

Inicialmente pode-se perceber que os autores entendem que o desempenho organizacional não se confunde com a eficácia organizacional, mas é parte desta. Além disso, deixam claro que o desempenho financeiro, medido por variáveis contábeis ou de mercado são parte, mas não a completude do desempenho organizacional. Este último é composto ainda por variáveis denominadas organizacionais, que são assim exemplificadas por Venkatraman e Ramanujan (1986): participação de mercado, introdução de novos produtos, e qualidade do produto.

Miranda e Silva (2002) fazem enfoque semelhante em seu estudo ao classificarem as medidas de desempenho como: (i) financeiras tradicionais; (ii) nãofinanceiras tradicionais; e (iii) não tradicionais. A classificação de ser ou não tradicional foi dada pela frequência em que as medidas aparecem na literatura. Por outro lado, os autores apresentam críticas ao uso exclusivo de medidas de desempenho financeiras. Merchant e Stede (2012) também dão ênfase a tais críticas destacando o foco no curto prazo que seu uso leva os gestores a ter. 
Figura 2 - Circunscrevendo o domínio do desempenho organizacional

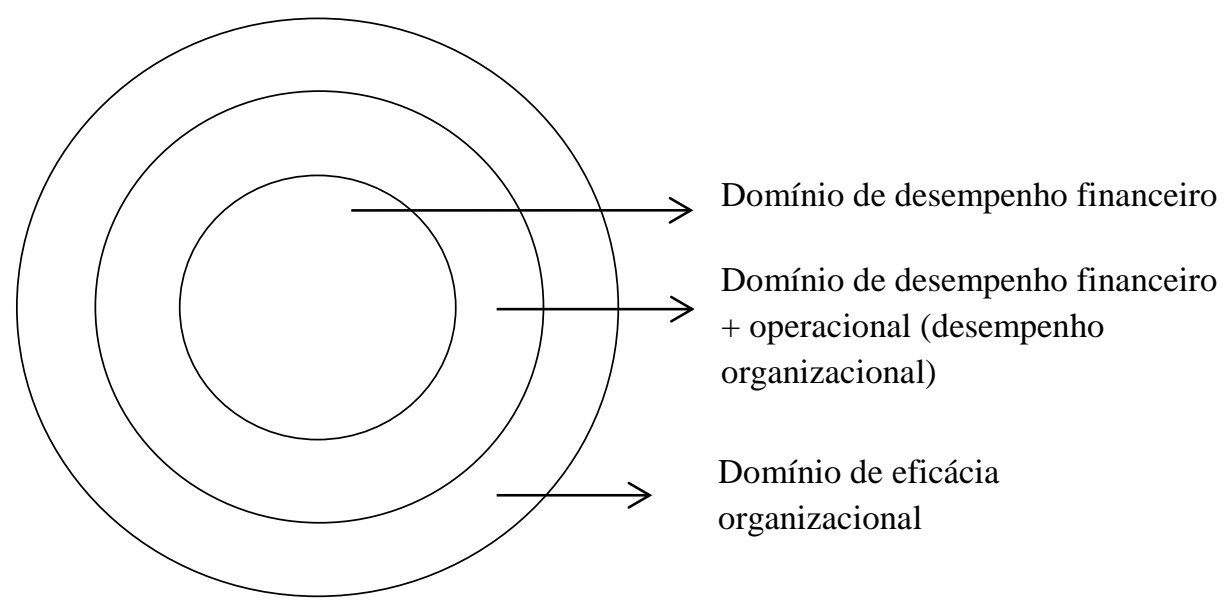

Fonte: Adaptado de Venkatraman, Ramanujam (1986, p. 803, tradução nossa).

Kaplan (2010) afirma que o desempenho organizacional deve ser uma consequência da visão e estratégia da firma refletida em diferentes perspectivas: processos internos, aprendizado e crescimento, clientes e financeira. Para o autor cada perspectiva terá uma, ou mais métricas que, em uma relação de causalidade, criam valor de longo tempo aos acionistas. $\mathrm{O}$ autor se posiciona firmemente afirmando que o modelo proposto (ver Figura 3) não é uma representação de métricas de desempenho organizacional, mas a própria definição do que seria tal desempenho.

A proposição apresentada por Kaplan (2010), também conhecida como Balanced Scorecard, concorda conceitualmente com a definição de desempenho organizacional formulada por Venkatraman e Ramanujan (1986) no momento em que desenvolve um conceito de desempenho organizacional que extrapola questões financeiras e contábeis. Por outro lado, para Kaplan (2010) existe uma relação de causalidade entre as variáveis que explicam cada perspectiva e que findam em um desempenho financeiro. Para ele as demais perspectivas complementam a financeira.

Percebe-se que Kaplan (2010) ainda que entenda que o desempenho organizacional seja maior que apenas o desempenho financeiro, mantém este último como a representação final do desempenho ótimo esperado ${ }^{4}$.

\footnotetext{
4 "The BSC retains financial metrics as the ultimate outcome measures for company succes, but supplements these with metrics from three additional perspectives..." (KAPLAN, 2010, p. 3, tradução nossa).
} 
Figura 3 - Perspectivas da visão e estratégia

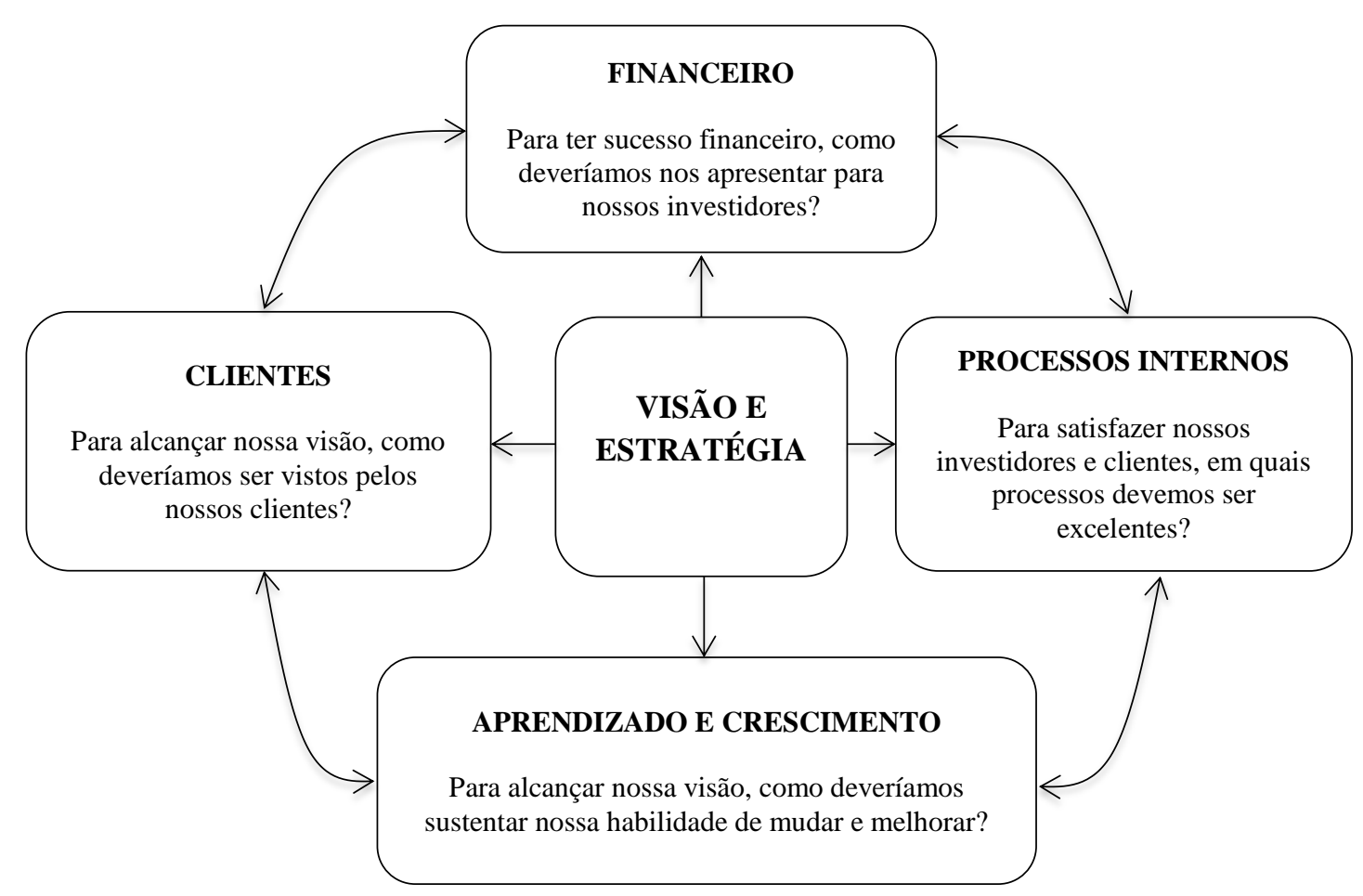

Fonte: Adaptado de Kaplan (2010, p. 3, tradução nossa).

Na mesma linha conceitual apresentada por Venkatraman e Ramanujan (1986), Miranda e Silva (2002) afirmam que deve haver um alinhamento entre os objetivos dos usuários e as medidas de desempenho utilizadas. Como consequência desta afirmação é possível inferir que em todo ambiente onde haja mais que um principal, haverá também mais que uma única necessidade de informação, levando o agente a ter que responder por mais de uma métrica, ou área, de medição de desempenho. Caso o agente considere ser muito difícil escolher as ações que maximizem a utilidade de todos os principais, considerando sua racionalidade, espera-se que ele escolha aquelas que também maximizem a sua utilidade (MERCHANT; STEDE, 2012). Como decorrência desta afirmação, algum usuário pode não ter seus objetivos atendidos.

O objetivo principal das avaliações de desempenho seria então o de garantir o cumprimento das estratégias definidas para a organização (VENKATRAMAN; RAMANUJAM, 1986; MIRANDA; SILVA, 2002 ANTHONY; GOVINDARAJAN, 2008; KAPLAN, 2010). Para que a estratégia seja alcançada, diversos esforços deverão ser implementados, logo seria mais adequado se a avaliação do desempenho 
considerasse um cenário onde os esforços são definidos para se atingir mais do que um objetivo. Anthony e Govindarajan (2008) apresentam uma estrutura para projetar sistemas de mensuração de desempenho (Figura 4). Pode-se verificar que para estes autores a organização define em sua estratégia que medidas de desempenho são relevantes para o negócio, a partir de então inicia-se o ciclo de execução de trabalho do gestor e análise de seu desempenho.

Figura 4 - Estrutura para mensuração de desempenho organizacional

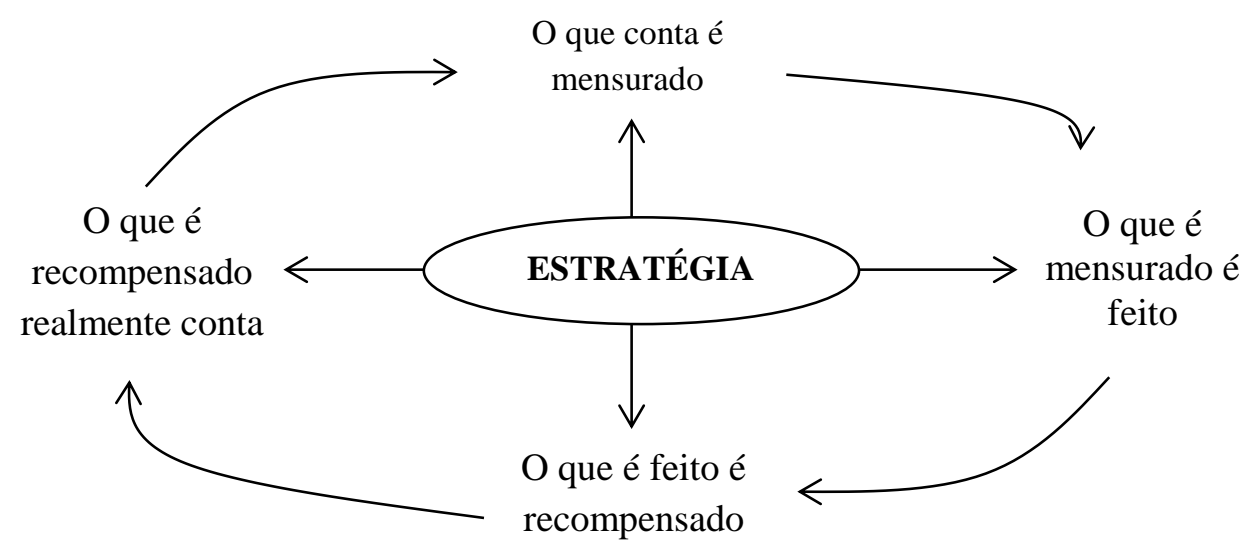

Fonte: Anthony e Govindarajan (2008, p. 461)

Vance (2003) subdivide o desempenho organizacional em: (i) desempenho operacional, e (ii) desempenho financeiro. O primeiro seria uma medida de eficiência da firma na gestão de vendas, custos e estoques, enquanto que o segundo trata da produtividade dos ativos, independente da forma que foram adquiridos. Apesar da proposição de Vance (2003) apresentar uma separação entre os desempenhos operacional e financeiro, percebe-se que o seu entendimento pelo que seria o desempenho operacional parece ainda estar preso às informações internas e contábeis.

Tal abordagem vai de encontro ao proposto por Venkatraman e Ramanujan (1986; 1987) do que seria um esquema classificatório para avaliação do desempenho econômico. Para estes autores, as questões subjacentes que são inerentes à avaliação de desempenho são a fonte de dados (primária ou secundária) e o modo de avaliação (objetivo ou subjetivo). Com base nisso, Venkatraman e Ramanujan (1986) desenvolveram um esquema classificatório em quatro células como pode ser visto na Figura 5. 
Figura 5 - Esquema para classificar enfoques alternativos para medir o desempenho organizacional

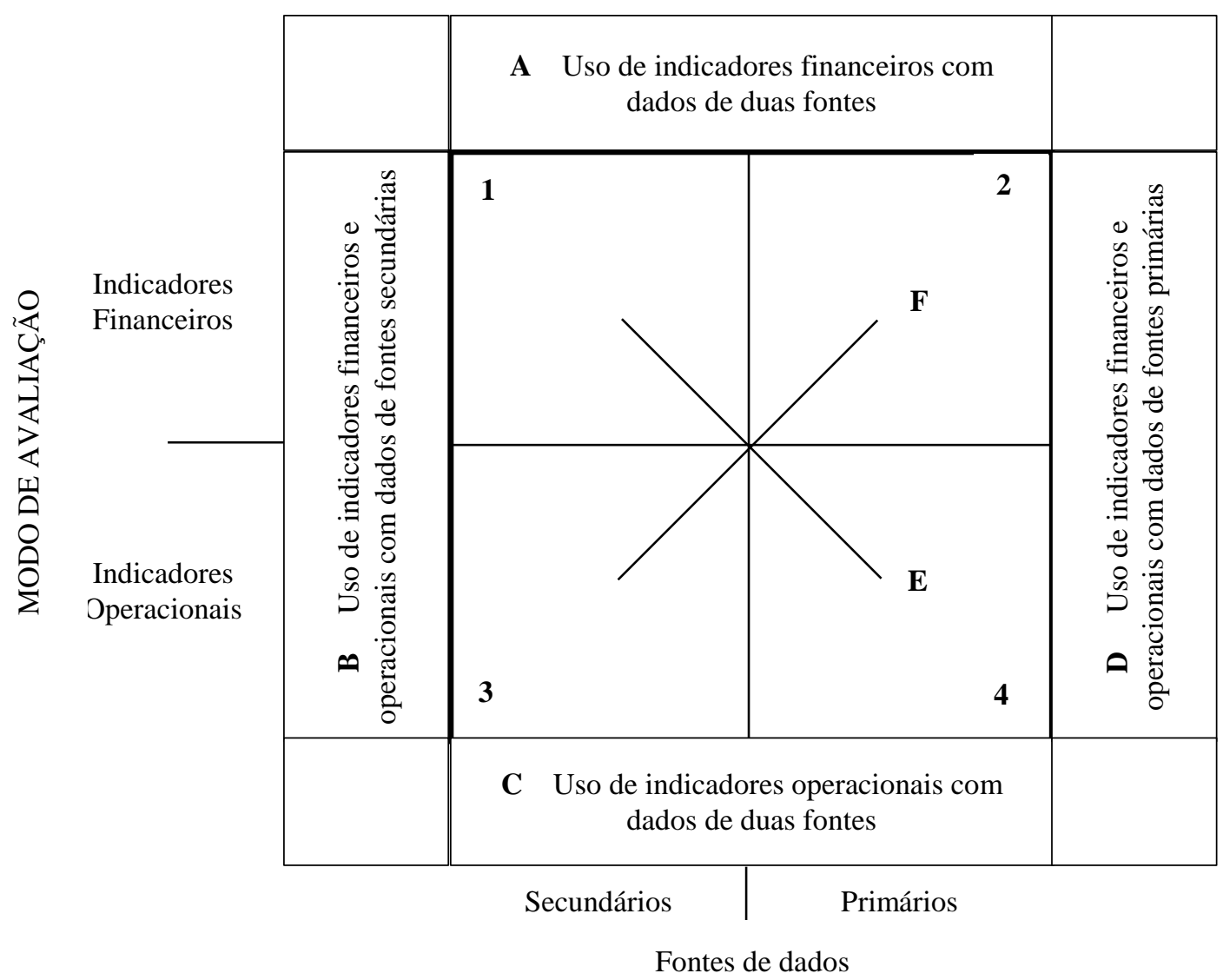

Fonte: Venkatraman e Ramanujam (1986, p. 805, tradução nossa).

Alguns estudos como os de Venkatraman e Ramanujam (1987) e de Bezerra e Corrar (2006) evidenciam a possibilidade de se realizar avaliações de desempenho não com o uso direto de variáveis, mas com o agrupamento das métricas, utilizando metodologias como a análise fatorial ou análise de cluster, a fim de diminuir o peso do uso específico de uma variável e aumentar o peso do grupo teórico no qual a variável está inserida. Isto poderia diminuir o viés da análise do desempenho em ambientes onde existem mais do que um principal.

Percebe-se então que a formulação de uma proposição de mensuração do desempenho organizacional deve zelar pelo próprio conceito de desempenho, para que não incorpore vieses que prejudiquem a percepção do desempenho real. Ambientes com mais que um principal podem não apresentar convergência nas utilidades esperadas por cada um destes principais. Logo, a restrição do desempenho a métricas de uma única categoria (contábeis, financeiras, operacionais, de mercado) pode culminar em uma 
percepção equivocada do desempenho obtido. Outros autores como Aguiar (2009) e Merchant e Stede (2012) criticam o uso exclusivo de variáveis financeiras devido ao viés "míope" (maior foco no curto prazo) que tal comportamento pode causar.

Por outro lado, a decisão de se manter variáveis não financeiras no contrato de incentivo não é tão simples. HassabEnalby, Said e Wier (2005) evidenciaram em seu estudo que as firmas que retêm variáveis não financeiras nos contratos de incentivo se diferenciam das que não retêm nos seguintes aspectos: os pesos atribuídos a medidas de desempenho não financeiras, alterações nos retornos das ações, estratégia organizacional, ruído financeiro e ciclo de vida do produto.

Algumas formas que a literatura apresenta como possíveis soluções nestes casos seriam aumentar os incentivos de longo prazo, e diminuir o foco da avaliação de desempenho nas medidas financeiras (MIRANDA; SILVA, 2002; ANTHONY; GOVINDARAJAN, 2008; MERCHANT; STEDE, 2012).

O uso de medidas subjetivas na avaliação do desempenho pode motivar o agente a escolher as melhores ações, pois algumas medidas podem estar sujeitas a fatores que não são de seu controle e ele poderia ser penalizado por algo que não teve responsabilidade (MERCHANT; STEDE, 2012). Gibbs et al. (2004), fazem uma análise do uso de medidas subjetivas na avaliação do desempenho e evidenciam que quanto maior for a confiança entre superior e subordinado, a subjetividade aumentará a motivação do subordinado. Esta discussão pode ser facilmente extrapolada para a relação principal - agente.

Outra possibilidade foi explorada por Santos (2012) ao testar se o uso do lucro econômico motivaria os agentes a aumentarem seu foco em ações que maximizem o valor da empresa no longo prazo. Considerando que o agente tenha conhecimento sobre como é composto o lucro econômico, o autor confirma sua hipótese de pesquisa e evidencia inadequações dos contratos de incentivo com base em medidas de desempenho que podem distorcer o horizonte temporal dos esforços dos agentes. 


\subsection{Desempenho de Executivos}

Para fins de elaboração desta tese as discussões referentes ao desempenho do agente ou do indivíduo estarão sempre se referindo ao desempenho do executivo, considerando este como o agente definido na seção 2.1 .

A discussão acerca do desempenho de executivos apresenta uma restrição que é a sua mensuração, pois nem as ações escolhidas pelos agentes nem seus resultados consequentes e específicos podem ser nitidamente identificados (LAMBERT, 2001; SCOTT, 2011). Sendo assim, a definição dos contratos de incentivos acabam utilizando como proxy o desempenho organizacional que, por sua vez, pode ser influenciado por decisões do agente que não necessariamente expressem esforços direcionados a maximização do desempenho organizacional (WATTS; ZIMMERMAN, 1978; DECHOW; SLOAN, 1991; SLOAN, 1993).

Com base nestes pressupostos, Sloan (1993) formula definições para o desempenho de executivos separando os tipos de desempenhos organizacionais, se com base no mercado ou no resultado contábil. De forma geral a proposição do autor pode ser interpretada da seguinte forma ${ }^{5}$ :

$D_{t}=x_{t}+\varepsilon_{t}$

Onde, $D_{t}$ representa o desempenho organizacional, $x_{t}$ os esforços do agente, e $\varepsilon_{t}$ um componente de ruído externo.

Logo, percebe-se que o desempenho organizacional é função das ações escolhidas pelo agente e de fatores que estão além do seu controle. Merchant e Stede (2012) abordam o assunto ao discutir a controlabilidade das medidas de desempenho que são utilizadas para aferir a compensação aos executivos e afirmam que fatores incontroláveis podem fomentar comportamentos oportunistas.

\footnotetext{
${ }^{5}$ Sloan (1993) não apresenta formalmente o modelo da Equação 4, na verdade são feitas duas proposições relacionando separadamente o desempenho organizacional com base no mercado e com base no lucro contábil. Em ambos, Sloan (1993) afirma que o desempenho organizacional é função dos esforços do gestor, mais um fator representativo dos ruídos que não são controláveis pelo agente. Logo, a ideia fundamental é a apresentada na Equação 4.
} 
Esta formulação vai de encontro à proposição de Baker, Jensen e Murphy (1988), para quem os modelos econômicos de compensação a executivos possuem como pressuposto que melhores desempenhos exigem maiores esforços. Dechow e Sloan (1991) indicam que vários fatores podem definir o desempenho e consequentemente a remuneração, como por exemplo, o porte da empresa.

Sendo assim, pode-se inferir que a definição de um contrato ótimo será consequência de uma ponderação ótima entre as variáveis baseadas no lucro e as baseadas no mercado que comporão a fórmula de compensação. Banker e Datar (1989) afirmam que ao se incluir linearmente medidas de ambas as bases em uma mesma equação, a ponderação delas deverá ser resultado da sensibilidade da medida em relação às ações do agente e à precisão que tais medidas conseguem expressar os esforços destes agentes.

Se por um lado autores como Healy (1985), Sloan (1993) e Conyon (1997) testaram a sensibilidade das medidas de desempenho, por outro lado, Murphy (2001) e Indjejikian e Nanda (2002) criticam o fato que a escolha do padrão de desempenho, apesar de relevante, ser pouco explorada como uma das dimensões da definição de planos de incentivos.

Para Murphy (2001) e Indjejikian e Nanda (2002) o padrão de desempenho é a base para comparação dos resultados obtidos, por exemplo: lucro por ação vs. lucro por ação do período anterior, retorno sobre o investimento obtido vs. o retorno sobre o investimento projetado e desempenho medido vs. o desempenho do setor. Percebe-se, portanto, que o padrão de desempenho é o desempenho esperado, ou como Murphy (2001) conceitua, "o nível de desempenho exigido para atingir o bônus". 6

Desta forma, Murphy (2001) extrapola a Equação 4 para evidenciar a importância da definição dos padrões de desempenho, da seguinte forma:

\footnotetext{
6 “[...] the levelof performance required to attain the executive's "target bonus"." (MURPHY, 2001, p. 246 , tradução nossa)
} 


$$
E[w]=s+\bar{b} E[\varepsilon]+\bar{b} \bar{e}
$$

Onde, $E[w]$ representa o nível de compensação esperado; $s$ a parcela fixa do salário; $\bar{b}$ a curva de sensibilidade necessária para implementar um esforço do nível $\bar{e}$; e $E[\varepsilon]$ a parcela dos ruídos idiossincráticos que impactam a compensação.

Para Murphy (2001) se $E[\varepsilon]$ for conhecido com certeza, $s$ poderá ser definido de forma a satisfazer a utilidade do agente. Porém, se $E[\varepsilon]$ for superestimado ex-ante podese chegar ao seguinte cenário de conflito de agência: os salários serão baixos e os níveis de pagamentos não atingirão o nível mínimo de utilidade para o agente que o mercado proporcionaria para ele, logo os gestores deverão receber uma remuneração compensatória que reduzirá a distribuição de lucros para os acionistas, consequentemente reduzindo a probabilidade de se atingir a utilidade destes. Consequentemente $E[\varepsilon]$ quem define o padrão de desempenho.

Lambert (2001) concorda com a proposição de Murphy (2001) e ambos autores afirmam que a definição do contrato de compensação deve partir deste nível mínimo de utilidade que o agente obteria no mercado, conforme a Equação 6.

$w(X-\bar{X})=s^{\prime}+b(X-\bar{X})$

Onde, $w(X-\bar{X})$ é a compensação a ser recebida comparando-se os resultados obtidos com os resultados passados, s'é o nível mínimo de utilidade que o mercado oferece ao agente, e $b(X-\bar{X})$ a curva de sensibilidade da medida atual versus seu próprio histórico.

Percebe-se que a proposição de Murphy (2001) exposta na Equação 6 remete a uma avaliação relativa do desempenho, o que de acordo com Holmstrom (1982) proporcionaria uma avaliação mais precisa do desempenho e maximizaria a utilidade do(s) principal(is).

Indjejikian e Nanda (2002) reforçam a discussão sobre os parâmetros de comparação com base em dados históricos (conforme apresentado na Equação 6) ao 
afirmar que a probabilidade de um executivo ter uma compensação maior do que seu bônus alvo é a mesma dele obter um desempenho superior ao seu desempenho padrão. Sendo assim, a probabilidade deste executivo receber bônus maiores que o bônus alvo seria independente do seu desempenho passado.

De modo geral, percebe-se que a definição do desempenho do agente, especificamente o executivo, não coincide com a definição do desempenho organizacional. $\mathrm{O}$ fato das ações e decisões tomadas pelo executivo serem variáveis não observáveis, subordina a discussão do desempenho do agente aos conflitos de agência e teoria de contratos. A literatura indica (AGGARWAL; SAMWICK, 1999; MURPHY; 2001; INDJEJIKIAN; NANDA 2002) que as proxies utilizadas para definição e mensuração do desempenho do executivo são o próprio desempenho organizacional e variáveis específicas do setor e da organização, o que remete à avaliações relativas de desempenho,

As subseções 2.4, 2.5 e 2.6 aprofundarão a discussão acerca dos incentivos aos executivos, avaliação relativa de desempenho e análise de eficiência. 


\subsection{Motivação de Executivos}

Esta subseção objetiva refletir acerca de dois aspectos específicos: 1) discutir uma definição geral de motivação, e 2) analisar trabalhos que abordem a motivação dentro do contexto de incentivos a executivos.

\subsubsection{Definição de Motivação}

A motivação é um conceito utilizado na área de psicologia em diferentes contextos e com significados distintos (KLEINGINNA; KLEINGINNA, 1981; TODOROV; MOREIRA, 2005). Desta forma, esta seção buscará delinear a definição para motivação aplicável a este estudo e apresentar estudos que tratem especificamente da motivação de executivos.

Todorov e Moreira (2005) apresentam três correntes que sustentam a discussão acerca de como a motivação deve ser compreendida: 1) Psicoterapia: nesta área o objetivo principal é aliviar desconfortos, que os pacientes sentem, decorrentes de conflitos motivacionais; 2) Psicometria: seu foco consiste na aplicação e mensuração de testes de aptidões e de desempenho, onde o pressuposto básico é o interesse no desenvolvimento da tarefa; e 3) Teoria de Aprendizagem: esta última área tem como origem a educação, buscando entender variáveis motivacionais e de aprendizagem que influenciam interesses na área educacional.

Existe ainda outra dicotomia epistemológica de onde se precisa definir o ser humano como um ser essencialmente racional, apto para fazer suas decisões e consciente das consequências destas escolhas (ROOJEN; 1995), ou que o homem por vezes é irracional e age de forma passional, devendo ter suas ações controlados pela sociedade. (TODOROV; MOREIRA, 2005).

Já no século XIX, pesquisadores da área convergiram no sentido de que o comportamento humano pode ser explicado na consciência de quem age e por herança genética, não sofrendo grandes influências do ambiente em que vive na fase adulta (ALLPORT, 1953). Este consenso denota que à época a percepção era que o ser humano seria essencialmente irracional. Tal compreensão do ser humano permanece 
ainda no século XX, conforme argumenta Cofer (1981) ao criticar a corrente racionalista defendida por pesquisadores cognitivistas.

Porém, Todorov e Moreira (2005) e Pakdel (2013) afirmam que a corrente racionalista é anterior à irracionalista e tem origem em filósofos como Platão e Aristóteles, com uma linha de pensamento que afirma que se o homem como um ser racional consegue escolher seus objetivos, então esta escolha é o que determinará seu comportamento futuro, logo, não estaria dependente de restrições. Para os psicólogos desta linha de pensamento, comportamentos que fogem dessa descrição são aleatórios e não naturais do homem.

Essa dicotomia persiste até os dias de hoje e Todorov e Moreira (2005) afirmam que conceitos de motivação surgem como determinantes do comportamento, e que a partir deste raciocínio, e objetivando a viabilização de testes empíricos acerca do tema, o conceito de motivação não deve estar focado no "porquê" o indivíduo se comporta de determinada maneira, mas "como" ele se comporta sob alguma condição pré-definida. Desta forma, pode-se concluir que:

[...] (1) os estímulos evocam respostas; (2) um determinado estímulo evoca uma certa resposta em vez de quaisquer outras concebíveis; (3) certos estímulos têm um valor de recompensa e outros não; (4) certas respostas parecem surgir por si mesmas, sem nenhum desencadeante exterior aparente. (TODOROV; MOREIRA, 2005)

Percebe-se que, para os autores, o comportamento é decorrente de escolhas do indivíduo a partir dos estímulos que lhes são fornecidos. Além disso, estímulos diferentes causam comportamentos diferentes, o que é coerente com a criação de conjuntos de incentivos que estimulem o indivíduo a desempenhar determinados papéis, como é objetivado ao se elaborar fórmulas de incentivos a executivos.

Miguel (2000) afirma que problemas de motivação vêm sendo analisados a partir do conceito de reforço, ou "reforçamento". Sob esta perspectiva, o querer (ou deixar de querer) executar determinada tarefa é decorrente da falta de reforço aplicado para que o comportamento desejado ocorra. Este reforço pode ser positivo ou negativo, porém a falta de eficácia das consequências de não se desempenhar determinada tarefa pode prejudicar o impacto destes reforços no comportamento do indivíduo.

Michael (1982) e Miguel (2000) afirmam que o conceito de motivação inclui variáveis de privação e de saciação, logo, tem-se como pressuposto que o indivíduo 
possui necessidades que orientam seu comportamento. Desta forma, um único reforço pode não ser suficiente para motivar o indivíduo a cumprir uma tarefa esperada, na verdade, seria impositivo que se entendessem as demandas que este indivíduo tem e quais estímulos poderiam saciar tais necessidades.

Neste mesmo sentido, Pakdel (2013) afirma que a motivação é afetada por quatro fatores: estímulos internos e externos, temperamento (no momento e em geral), propósito do comportamento e atitude, e ferramentas para alcançar o objetivo. Apesar de ser uma tentativa de definição geral, pode-se observar que para Pakdel (2013) a motivação é um processo intrínseco ao indivíduo.

Por outro lado, a motivação é descrita na psicologia sob dois enfoques: intrínseca e extrínseca. A motivação intrínseca é decorrente da satisfação inerente de fazer algo, independentemente de suas consequências, enquanto que a extrínseca se refere a fazer algo porque este ato fornecerá um resultado específico. (RYAN; DECI, 2000). O Quadro 1 ilustra essa distinção:

\begin{tabular}{|c|c|c|c|c|c|c|}
\hline \multirow{2}{*}{$\begin{array}{c}\text { Estilos } \\
\text { Regulatórios }\end{array}$} & \multirow[b]{2}{*}{ Sem motivação } & \multicolumn{4}{|c|}{ Motivação Extrínseca } & \multirow[b]{2}{*}{$\begin{array}{l}\text { Motivação } \\
\text { Intrínseca }\end{array}$} \\
\hline & & $\begin{array}{c}\text { Regulação } \\
\text { Externa }\end{array}$ & Introjeção & Identificação & Integração & \\
\hline $\begin{array}{l}\text { Processos } \\
\text { associados }\end{array}$ & $\begin{array}{l}\text { Sem } \\
\text { circunstância } \\
\text { percebida; } \\
\text { Baixa } \\
\text { competência } \\
\text { percebida; } \\
\text { Sem relevância; } \\
\text { Sem } \\
\text { intencionalidade }\end{array}$ & $\begin{array}{l}\text { Projeção de } \\
\text { recompensas } \\
\text { ou punições } \\
\text { extrínsecas; } \\
\text { Conformidade }\end{array}$ & $\begin{array}{l}\text { Envolvimento } \\
\text { do ego; } \\
\text { Foco na auto } \\
\text { aprovação e } \\
\text { de outros }\end{array}$ & $\begin{array}{l}\text { Consciência } \\
\text { de valor da } \\
\text { atividade; } \\
\text { Auto aval dos } \\
\text { objetivos }\end{array}$ & $\begin{array}{l}\text { Síntese } \\
\text { hierárquica } \\
\text { dos objetivos; } \\
\text { Congruência. }\end{array}$ & $\begin{array}{l}\text { Interesse; } \\
\text { Prazer; } \\
\text { Satisfação } \\
\text { inerente. }\end{array}$ \\
\hline $\begin{array}{l}\text { Lócus de } \\
\text { causalidade } \\
\text { percebido }\end{array}$ & Impessoal & Externo & Mais externo & Mais interno & Interno & Interno \\
\hline
\end{tabular}

Quadro 1 - Taxonomia da motivação humana

Fonte: adaptado de Ryan e Deci (2000, p. 61)

A coluna "Sem motivação" representa o estado de falta de intenção de agir e tem relação com os processos associados descritos abaixo de seu título. A coluna central inclui quatro categorias. "Regulação externa" trata de comportamentos realizados para atender a uma demanda externa vinculada a determinada recompensa ou punição e é o único tipo de motivação reconhecido por teóricos operacionais. A "Introjeção" está relacionada em como o indivíduo deseja ser visto / avaliado por si mesmo e por outras pessoas. Na "Identificação" o indivíduo possui uma crença nos valores que serão 
gerados pela ação. A "Integração" quando as orientações externas foram complemente absorvidas e adotadas pelo indivíduo. Por fim, a "Motivação Intrínseca" advém do interesse próprio em desempenhar determinada ação, independentemente das consequências e percepções decorrentes dela. (RYAN; DECI, 2000).

Sendo assim, entende-se neste trabalho que motivação é o conjunto de estímulos que fazem com que o indivíduo empreenda esforços a fim de atingir determinado comportamento.

\subsubsection{Estudos anteriores}

O conceito de motivação discutido na subseção anterior deve ser refletido ao se elaborar fórmulas de incentivo a executivos, haja vista que o objetivo de se estabelecer critérios para concessão de benefícios e remunerações é gerar motivação para que os executivos direcionem a organização no sentido de cumprir as metas previamente estabelecidas.

Nesta perspectiva, Ericson (1962) afirma que os objetivos pessoais dos indivíduos desempenham papel importante no processo de tomada de decisão da companhia, logo, a definição de um sistema de compensação aos executivos precisa antever como estes agentes internalizariam os objetivos da firma com os seus próprios, tornando-os convergentes. Lawler (1983) concorda com este posicionamento ao afirmar que os executivos tendem a se comportar da forma que eles percebam que gere as recompensas que ele valoriza. Logo, problemas de incentivos representam a tentação para os executivos gastarem recursos em atividades que lhe proporcionam maiores benefícios, mas que não aumentam a riqueza dos acionistas (TAYLOR, 1994).

Este processo consideraria como tirar o indivíduo de um estado sem motivação abordando aspectos de motivação intrínseca e extrínseca, conforme exposto por Ryan e Deci (2000) e apresentado no Quadro 1. A internalização dos objetivos da firma pelo executivo teria relação com um lócus de causalidade percebido mais propenso ao interno. Ao passo que a regulação externa despertaria interesses específicos atrelados à percepção que o indivíduo possui acerca do estilo de vida inerente à função desempenhada. 
Ericson (1962) converge com este pensamento ao afirmar que fatores externos e internos influenciam o sucesso do executivo, e aponta uma relação entre categorias de necessidades humanas que geram a dicotomia entre sucesso profissional e bem-estar social.

A proposição apresentada na Figura 6 evidencia que, de diferentes modos, enquanto os propósitos desenvolvidos nas organizações forçam o executivo em direção ao sucesso, ele também é pressionado a buscar um equilíbrio afetivo. Consequentemente, as pressões exógenas competem com / complementam a necessidade endógena destes indivíduos. Competem, pois - nas suas relações com pares - vetores como o 'Domínio' representam que o executivo buscará controlar as ações dos seus colegas de trabalho e isso pode gerar conflito na relação pessoal representada pelo 'Amor e afeto'. Por outro lado, complementam, pois ao serem reconhecidos pelos seus superiores, esperam obter proteção acerca de sua independência. Sendo assim, a busca pela motivação do gestor deveria contemplar tanto fatores extrínsecos, como intrínsecos.

Figura 6 - Vetores na motivação de executivos

\begin{tabular}{|l|l|l|}
\hline $\begin{array}{l}\text { Direção da força } \\
\text { Origem da força }\end{array}$ & $\begin{array}{l}\text { Desejo de ter sucesso } \\
\text { Vetores verticais }\end{array}$ & $\begin{array}{l}\text { Desejo de viver bem } \\
\text { Vetores horizontais }\end{array}$ \\
\hline $\begin{array}{l}\text { 1. Relações de trabalho } \\
\text { a. Pares }\end{array}$ & $\begin{array}{l}\text { Reconhecimento } \\
\text { Domínio } \\
\text { Independência } \\
\text { b. Superiores }\end{array}$ & $\begin{array}{l}\text { Conforto físico } \\
\text { Amor e afeto }\end{array}$ \\
\hline 2. Esposa e filhos & $\begin{array}{l}\text { Reconhecimento } \\
\text { Amor e afeto }\end{array}$ & $\begin{array}{l}\text { Amor e afeto } \\
\text { Proteção / dependência }\end{array}$ \\
\hline 3. Pais e parentes próximos & Amor e afeto & Conforto físico \\
\hline 4. Amigos & Amor e afeto \\
\hline
\end{tabular}

Fonte: Adaptado de Ericson (1962).

Para Masson (1971) a satisfação de um indivíduo trabalhar em determinado lugar depende das características da função e das formas de incentivo que são concedidas. Logo, a fórmula de compensação dos executivos deveria ser composta por elementos pecuniários e não-pecuniários de forma que a firma consiga minimizar tanto 
custos diretos, como os custos de oportunidade presentes em uma curva de indiferença do executivo.

Outro problema exposto em estudos como o de Masson (1971), Lewellen, Loderer e Martin (1987) e Aguiar (2009) é a preocupação que a motivação deve contemplar o horizonte temporal dos objetivos estabelecidos.

Masson (1971) afirma que estudos que tratem de motivação e compensação a executivos devem considerar três aspectos:

1. Dados transversais não são relevantes para um estudo motivacional de um executivo em sua firma, pois o efeito da motivação deve ser analisado após a concessão dos elementos que deveriam gerá-la. Pennings (1993) afirma que a remuneração possui efeito motivacional no executivo, e que este efeito gerará impacto no desempenho auferido no exercício subsequente ao que o gestor recebeu sua compensação.

2. A inclusão de variáveis de lucro de apenas um ano enviesa o modelo fazendo com que ele analise uma maximização de lucros de curto prazo.

3. A análise da compensação medida apenas pela soma do salário mais benefícios omite a maior parte da remuneração de executivos de grandes corporações.

Esta visão de Masson (1971) foi expressa também por Lawler (1983) quando assegura que a definição dos sistemas de compensação resulta em impactos comportamentais que influenciam o desempenho das organizações. 


\subsection{Sistemas de Incentivo e Remuneração de Executivos}

De acordo com Merchant e Stede (2012, p. 367) "sistemas de incentivo amarram recompensas (e/ou punições) às avaliações de desempenho"7 . O fato do principal não conseguir observar as ações selecionadas pelo agente faz com que ele tente incluir incentivos no contrato para que as saídas (observáveis) sejam influenciadas pelos inputs do contrato, logo os incentivos contratados representam uma forma do principal influenciar o agente na seleção de ações. (LAMBERT, 2001)

Sendo assim, os sistemas de incentivos representariam uma relação em equilíbrio entre a firma, como consumidora de experiência / conhecimento de gestão, e o executivo como fornecedor dessa expertise gerencial (DEEGAN, 1997).

Partindo deste enfoque maior na gestão, Lawler (1983) afirma que os sistemas de incentivo influenciam cinco fatores da eficácia organizacional: 1) Atração e retenção de executivos de alto desempenho; 2) Motivação; 3) Cultura e clima organizacional; 4) Reforçar e definir a estrutura organizacional; e 5) Custo. Bonner e Sprinkle (2002) e Merchant e Stede (2012) concordam com este posicionamento ao reiterar que os incentivos possuem propósitos motivacionais (influenciar os indivíduos a desenvolver determinada carga de esforço), informacionais (evidenciar onde os esforços devem ser focados) e de atração e retenção de pessoal (captar e manter na organização indivíduos reconhecidamente de alto desempenho).

Em uma visão mais contábil, os estudos seminais de Watts e Zimmerman (1978), Zmijewski e Hagerman e Zmijewski (1979), Hagerman (1981), e de Healy (1985), testam relações entre decisões acerca de procedimentos contábeis e dos incentivos de divulgação de receita com base nas estruturas dos sistemas de incentivo. Estes estudos não convergem para um mesmo resultado e a causa disto é apresentada por dois autores: Masson (1971) afirma que a definição de remuneração a executivo tem excluído aspectos de valor presente das opções de ações e de benefícios pós-emprego, além da propriedade de ações da empresa pelo próprio executivo; já segundo Healy (1985) o problema é que a definição de ganhos, dentro dos contratos, é ignorada o que gera conclusões conflitantes.

\footnotetext{
7 "Incenive systems [...] tie rewards (and/or punishments) to the performance evaluations."
} 
Deve-se notar que a discussão sobre incentivos vai além da remuneração pecuniária, porém esta acaba sendo a proxy mais utilizada nas pesquisas analisadas neste estudo. De acordo com Healy (1985), planos baseados em metas de desempenho utilizam informações contábeis como saídas observáveis, por manterem maior foco no retorno e no valor da ação.

De qualquer forma, deve-se deixar claro que semelhantemente ao estudo de Watts e Zimmerman (1978), esta tese parte do pressuposto que os executivos são racionais e, portanto, pretendem maximizar sua utilidade. A implicação mais direta disto é que eles utilizarão a elaboração e a divulgação da informação contábil para alcançar seus próprios interesses. Consequentemente, a utilidade do agente é uma função positiva das compensações esperadas. Por outro lado, presume-se que a utilidade do principal é, exclusivamente, uma função positiva do resultado contábil. ${ }^{8}$

Assim como no estudo de Masson (1971), as discussões acerca das compensações esperadas envolvem não apenas definição do valor do salário, ou da remuneração, mas tudo aquilo que motiva o agente a desenvolver as funções e escolher as ações conforme as expectativas dos principais. Seja por medidas de entrada no sistema de incentivos (remuneração fixa), ou de saídas (baseadas no resultado organizacional) (DEEGAN, 1997).

\subsubsection{Incentivos Não Pecuniários}

As discussões apresentadas nesta seção têm como pressuposto os achados do estudo de Korman, Glickman e Frey Jr. (1981) que evidenciam que incentivos de maior magnitude, ou maior quantidade do mesmo incentivo, podem não ter o impacto esperado na probabilidade de mudança de comportamento. Na verdade, os autores indicam uma probabilidade que 'mais pode não ser melhor', logo a motivação pela escolha de determinadas ações poderia ser gerada não apenas por um (ou poucos) incentivo de grande magnitude, mas por uma variedade de incentivos que afetem o comportamento do agente de maneiras distintas.

\footnotetext{
${ }^{8}$ Estudos como o de Hagerman e Zmijewski (1979), Healy (1985) apontam que os gestores podem influenciar a elaboração da informação contábil tanto na escolha de políticas contábeis, como alterando os esforços para o cumprimento das metas de forma a alterar o resultado das variáveis que mensuram o seu próprio desempenho. Desta forma podem antecipar, ou postergar, o recebimento de bônus.
} 
Baker, Jensen e Murphy (1988) trazem esta discussão à tona ao debaterem motivos que levariam as empresas a optarem por utilizar incentivos não pecuniários (promoção neste caso), apresentando prós e contras de se optar por tal metodologia. Campbell (2008) continua este debate vinculando este incentivo a outras medidas de desempenho que não apenas as contábeis e financeiras. O autor diz que recompensas como estas podem ser concedidas pelas organizações através da utilização de outras métricas mais subjetivas.

Peterson e Luthans (2006), utilizando um quase-experimento com gestores de unidades de negócio de uma rede de fast-food, analisaram o impacto do uso de incentivos pecuniários, ou não pecuniários, nos desempenhos (lucratividade, tempo de atendimento e turnover) de cada uma das unidades. Os autores evidenciaram que tanto os incentivos pecuniários, como os incentivos não pecuniários, impactam os resultados das organizações. Porém, os pecuniários apresentam resultados iniciais maiores. Por outro lado, no longo prazo, os incentivos não pecuniários apresentaram impacto estatisticamente significativo nos resultados das unidades, com exceção do turnover.

Sob outra ótica Koetz, Koetz e Marcon (2009) analisaram, através de um quaseexperimento, a influência do tipo de incentivo (pecuniário, não pecuniário ou misto) sobre o comportamento oportunístico do gestor. Os autores evidenciaram que não há diferença entre os tipos de incentivos quando o principal consegue monitorar as ações do agente. Porém, quando este cenário não acontece os incentivos pecuniários aumentam a intenção de risco moral.

Morrel (2011) reconhecendo a falta de recursos nas organizações para manter programas de incentivos financeiros tradicionais, e que incentivos não financeiros aumentam a motivação intrínseca do gestor, desenvolveu um estudo onde destacou vantagens de se utilizar incentivos não financeiros. Uma pesquisa da McKinsey \& Company conduzida por Dewhurst, Guthridge e Mor (2009), com 1.047 executivos e gestores, evidencia a prevalência de incentivos não financeiros sobre os financeiros na opinião dos respondentes, o que vai ao encontro do pressuposto deste estudo, com base em Korman, Glickman e Frey Jr. (1981). O Quadro 1 mostra uma inversão entre efetividade motivacional - de acordo com a percepção dos próprios gestores - e uso de cada tipo de incentivo: 


\begin{tabular}{|c|c|c|}
\hline Incentivos & Efetividade (\%) & Uso $(\%)$ \\
\hline \multicolumn{3}{|c|}{ Incentivos Financeiros } \\
\hline Bônus em dinheiro baseado em metas de desempenho & 60 & 68 \\
\hline Aumento salarial & 52 & 71 \\
\hline Ações ou opções de ações & 35 & 24 \\
\hline \multicolumn{3}{|c|}{ Incentivos Não Financeiros } \\
\hline Agradecimento ou reconhecimento do superior imediato & 67 & 63 \\
\hline Atenção dos líderes & 63 & 41 \\
\hline Oportunidade para liderar projetos ou equipes & 62 & 54 \\
\hline
\end{tabular}

Quadro 2- Efetividade motivacional e uso de incentivos Fonte: Adaptado de Dewhurst, Guthridge e Mohr (2009)

Uma explicação para isso é dada pelo próprio Morrel (2011) para quem a motivação para que indivíduos desempenhem determinada tarefa advém de recompensas internas e externas. Recompensas internas - intrínsecas - se referem a satisfação obtida por simplesmente desempenhar a atividade, já as externas extrínsecas - remetem a outras formas de recompensa além do que o indivíduo já receberia por desempenhar a tarefa. $\mathrm{O}$ autor complementa ainda que a motivação intrínseca é mais difícil de aumentar através das práticas tradicionais de compensação, e que recompensas monetárias ao mesmo tempo em que aumentam a motivação extrínseca, reduzem a intrínseca (DECI; KOESTNER; RYAN, 1999), deixando evidente a necessidade de que os contratos entre principal e agente estabeleçam ambas as formas de incentivos.

De acordo com Ryan e Deci (2000), existem três necessidades principais que servem como base para automotivação: competência, relacionamento e autonomia. Estes mecanismos possibilitariam um ambiente propício para crescimento, integração e sensação de bem-estar, que no final resultariam em motivação como definida por estes autores como sendo "motivação diz respeito à energia, direção, persistência e finais iguais" ". Desta forma, fica perceptível o desafio que é estabelecer contratualmente incentivos que gerem tais resultados.

Holtmann (2002) contribui com esta discussão ao afirmar que incentivos pecuniários não são suficientes para motivar os indivíduos, mas o status social aplica forte impacto na motivação, devendo-se observar dois fundamentos: transparência e justiça. A transparência permite que o indivíduo entenda como será recompensado pelas suas escolhas e garante que a regra do jogo não será alterada arbitrariamente. Por outro

\footnotetext{
9 “Motivation concerns energy, direction, persistence and equifinality” (RYAN; DECI, 2000, p. 69).
} 
lado, a justiça assegura que os objetivos são atingíveis, e que aqueles com melhor desempenho receberão maiores compensações.

Groen, Wouters e Wilderom (2012) concordam com este posicionamento ao evidenciarem que participação do funcionário na elaboração do modelo de avaliação de desempenho aumenta suas atitudes, a pressão social percebida, a capacidade de tomar iniciativas, além do próprio desempenho departamental.

Até o momento atual desta tese, foi identificado apenas um estudo no Brasil que relaciona, empiricamente, incentivos não financeiros a executivos com o desempenho financeiro. Esta carência é influenciada pela dificuldade de se obter dados para desenvolver mais pesquisas. Krauter (2013) utilizou dados do Programa de Estudos e Gestão de Pessoas (PROGEP) e da Fundação Instituto de Pesquisas Contábeis, Atuariais e Financeiras (FIPECAFI) para criar três índices acerca do fornecimento de benefícios, suporte à carreira e desenvolvimento profissional, sendo o primeiro tipificado como incentivo financeiro, e os demais como não financeiros.

Krauter (2009) parte da estrutura conceitual apresentada na Figura 6 e verifica relação significativa entre remuneração financeira e desempenho financeiro. Percebe-se que o conceito de remuneração total perpassa a remuneração financeira e abarca a utilização de incentivos não financeiros como componentes da compensação total dos executivos.

Figura 7 - Conceito de Remuneração dos Executivos

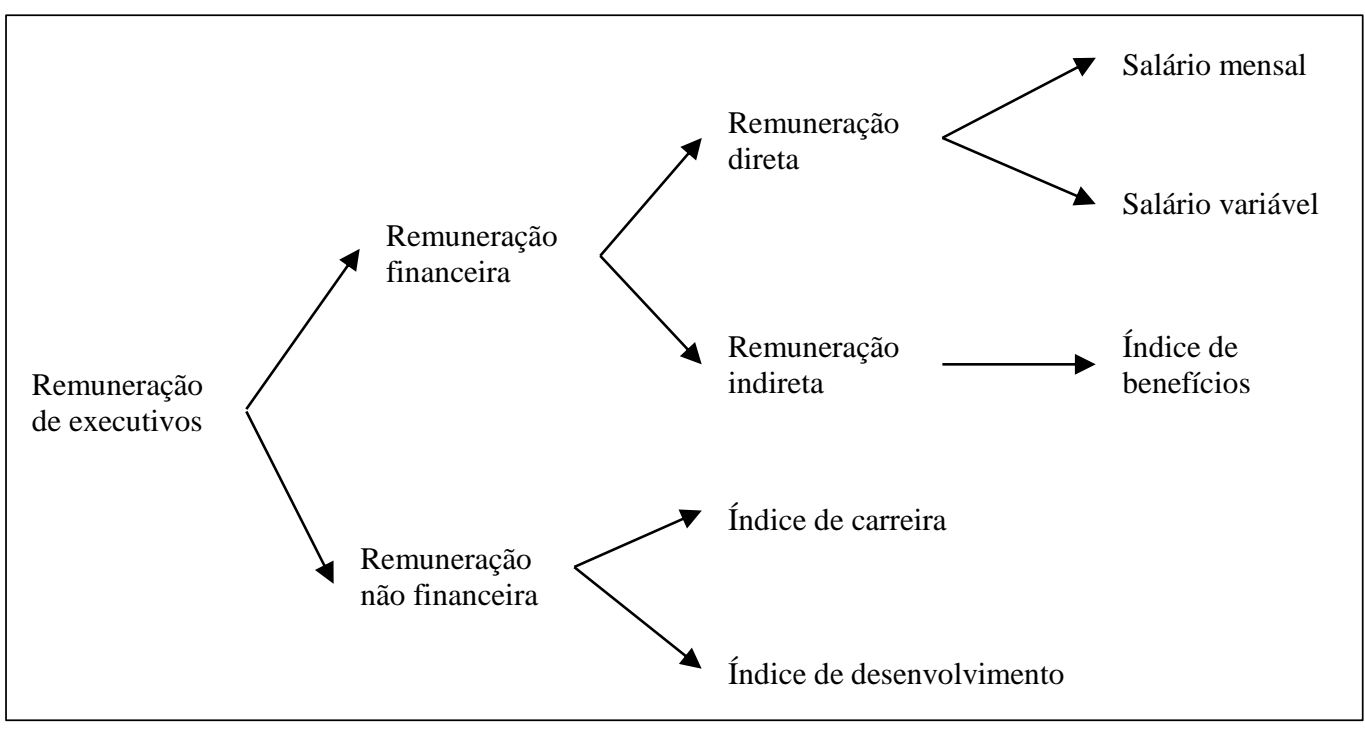

Fonte: Krauter (2009, p. 22) 
Entretanto, a não obrigatoriedade de divulgação de informações acerca de incentivos não pecuniários restringe a viabilidade do desenvolvimento de pesquisas nesta área. O conhecimento dos efeitos motivacionais destes incentivos, por outro lado, permite aprofundar a reflexão acerca dos incentivos divulgados pelas organizações listadas na BM\&FBovespa em seus Formulários de Referência.

\subsubsection{Incentivos Pecuniários}

Corroborando com os debates acerca de motivações extrínsecas já apresentadas nesta tese, Jensen e Meckling (1976) e Watts e Zimmerman (1978) afirmam que a utilidade total do agente é uma ponderação entre compensação pecuniária e não pecuniária. Watts e Zimmerman (1978) afirmam que ao aplicar maior foco na compensação pecuniária, a utilidade do agente seria afetada:

- Indiretamente por: tributos (apesar destes autores enfatizarem a organização, Merchant e Stede (2012) e Aguiar e Souza (2012) evidenciam que isto também é válido no nível individual), regulação, custos políticos, e custos de produção da informação. Estes fatores aumentariam a utilidade do agente ao aumentar o fluxo de caixa e, por conseguinte, seus esforços para aumentar o valor da ação;

- Diretamente por: planos de compensação. Assumindo que os gestores não fazem parte do grupo de acionistas, à medida que o resultado divulgado aumentar, ceteris paribus, sua compensação também aumentará.

Bonner e Sprinkle (2002) apresentam uma estrutura conceitual dos efeitos que os incentivos monetários baseados em metas de desempenho exercem sobre esforço e desempenho (Figura 8). Percebe-se que o esquema elaborado pelos autores está coerente com as discussões de Jensen e Meckling (1976), Watts e Zimmerman (1978) e de Merchant e Stede (2012), haja vista que evidencia a racionalidade do agente e a tentativa de controlar as ações selecionadas (não observáveis) por este através de contratos. 
Figura 8 - Estrutura conceitual para efeitos de incentivos monetários sobre esforço e desempenho

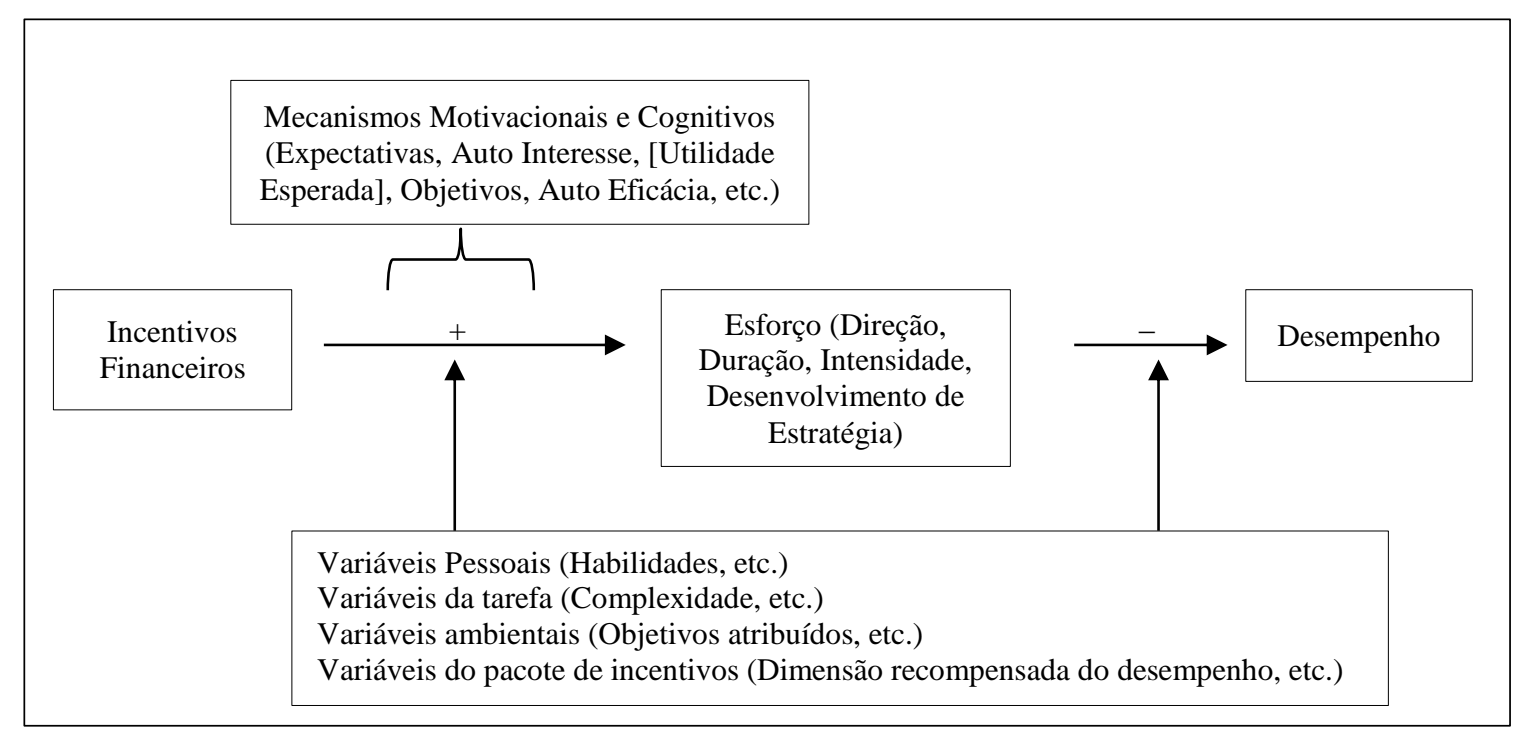

Fonte: Adaptado de Bonner e Sprinkle (2002, p. 304, tradução nossa)

Discussões envolvendo sistemas de incentivo, ou remuneração de executivos, com informações contábeis têm aumentado à medida que os mercados financeiros se fortalecem. Isto pode ser explicado pelo crescimento da demanda por informação contábil decorrente da maior quantidade de investidores e de investidores mais qualificados. Sendo assim, o uso da informação contábil reduziria o risco do investimento.

Prova disso é que considerando a falta de regulação para divulgação de informações acerca de remuneração e a possibilidade de interferência do próprio gestor na definição da fórmula de sua remuneração, da mesma forma que apresentado por Bebchuk e Fried (2003) para o mercado norte-americano, tem levado órgãos reguladores e de pesquisa a reconhecer a demanda por uma melhor evidenciação das características e montantes pagos a título de remuneração para executivos e conselhos gestores. O cenário de crise econômica internacional, juntamente com o surgimento de normas contábeis referentes ao reconhecimento, mensuração e evidenciação de aspectos inerentes a pagamentos de benefícios a empregados, motivou estes órgãos a regular esta evidenciação. 
A CVM promulgou as Deliberações n 562/2008 (pagamento baseado em ações) e 600/2009 (benefícios a empregados) e a Instrução n 480/2009 que obriga as empresas de capital aberto no Brasil a divulgarem informações específicas acerca da remuneração dos conselhos administrativo e fiscal e da diretoria estatutária. O IBGC também tem coletado informações semelhantes e divulga através de pesquisa intitulada Remuneração dos Administradores, que também é publicada anualmente. Esta pesquisa até 2012 só considerava empresas listadas nos segmentos de governança corporativa da BM\&FBOVESPA, e a partir de 2013 analisou também as não listadas. Além destes órgãos, o próprio Banco Central do Brasil (BACEN) emitiu a 3.921/2010 que obriga as instituições financeiras a estabelecerem um comitê de remuneração.

O Anexo 24 da Instrução CVM 480/2009 define os elementos da remuneração que devem ser divulgados. O texto do Anexo 24 informa que a divulgação do Formulário de Referência (FR) deve conter informações referentes aos três últimos exercícios acerca de diversas informações, entre elas alguns elementos de remuneração como descrito no Quadro 3:

\begin{tabular}{|l|l|}
\hline \multicolumn{1}{|c|}{ Informação } & \multicolumn{1}{c|}{ Detalhamento } \\
\hline Órgão $^{1}$ & Conselho de administração \\
& Diretoria Estatutária \\
& Conselho fiscal \\
\hline Número de membros do órgão & \\
\hline \multirow{3}{*}{ Remuneração Fixa Anual } & Salário ou pró-labore \\
& Benefícios diretos e indiretos \\
& Remuneração por participação em comitês \\
& Outros \\
\hline \multirow{2}{*}{ Remuneração Variável Anual } & Bônus \\
& Participação nos resultados \\
& Remuneração por participação em reuniões \\
& Comissões \\
\hline \multirow{2}{*}{ Outros Benefícios / Remunerações } & Outros \\
\hline & Benefícios pós-emprego \\
& Cessação do Cargo \\
& Remuneração baseada em ações ${ }^{2}$ \\
\hline
\end{tabular}

Quadro 3 - Informações Sobre Remuneração Exigidas no FR

Fonte: adaptado de CVM (2009).

${ }^{1}$ Para evitar a duplicidade, os valores computados como remuneração dos membros do conselho de administração devem ser descontados da remuneração dos diretores que também façam parte daquele órgão.

2 Este campo é preenchido de acordo com a definição de remuneração baseada em ações, paga em ações ou dinheiro, conforme normas contábeis que tratam do assunto. 
A remuneração fixa é descrita como uma forma de compartilhar os riscos acerca das atividades específicas da firma e dos resultados organizacionais esperados, entre principal e agentes. Porém, ela possui baixo efeito motivador para aumentar o valor da firma, quando comparada a outras remunerações atreladas ao desempenho organizacional (DEEGAN, 1997). Logo, se o gestor possui alta remuneração fixa, ele preferirá adotar estratégias que minimizem o risco da firma, protegendo, desta forma, seu fluxo de caixa constante, como: rejeitar o nível ótimo de dívida e minimizar a variância do fluxo de caixa da empresa.

Taylor (1994) afirma que as variações dos montantes fixos de um período para outro também se caracterizam como remuneração fixa, e possuem efeitos motivacionais de curto prazo distintos dos indivíduos que são remunerados com base no desempenho organizacional (BONNER; SPRINKLE, 2002).

Os incentivos baseados no desempenho organizacional tendem a ser mais eficientes no encorajamento dos gestores a maximizar o valor da firma (DEEGAN, 1997), mas os expõem a maiores riscos decorrentes de fatores incontroláveis. Consequentemente, os executivos empreenderiam esforços para maximizar a utilidade dos principais, se tais ações o rendessem remunerações variáveis totais superiores à fixa.

A forma para reduzir o risco descrito no parágrafo anterior, seria implementar remunerações para cessação do cargo, ou pós-emprego, pois funcionariam como uma garantia para o agente de que sua utilidade estaria assegurada caso fatores de mercado impactassem o desempenho organizacional reduzindo, ou encerrando, o fluxo de benefícios esperado. O diferimento dos fluxos de caixa do agente controlaria seus comportamentos oportunísticos que não seriam percebidos por outros interessados do desempenho da firma (TAYLOR, 1994; DEEGAN, 1997).

Além dessas, as remunerações baseadas em opções de ações possuem efeitos de longo-prazo na motivação e remuneração dos executivos (TAYLOR, 1994) e costumam gerar impactos significativos no nível de incentivos. Estes incentivos têm como pano de 
fundo o objetivo de alinhar a expectativa de longo prazo do agente com a dos principais, no momento em que as opções de ações protegem os executivos de perdas (pois não são forçados a exercer a ação quando estão out-of-the-money) e se tornam mais valiosas a medida que a volatilidade do fluxo de caixa da firma, e - consequentemente - o preço da ação, aumentam. Taylor (1994) afirma ainda que o uso destes mecanismos protege a firma contra o mercado de trabalho, haja vista que à medida que a data para exercer a opção se aproxima o interesse do executivo em deixar a firma tende a diminuir.

No Brasil, a promulgação das resoluções da CVM e do BACEN, bem como a divulgação da pesquisa do IBGC, proporcionou a possibilidade de desenvolvimento de diversos estudos empíricos acerca da remuneração de executivos no mercado brasileiro como os de Vasconcelos e Monte (2013), Silva, Ribeiro e Matias (2013) e Ventura (2013), Chien (2012), Ferreira (2012). Porém, duas críticas de Healy (1985) às pesquisas no mercado norte-americano parecem também serem aplicáveis a estas desenvolvidas no mercado brasileiro: não há uma análise acerca de como os planos de incentivos (ou de bonificação) definem as metas de desempenho, e assumem que os esquemas de bonificação sempre induzem os gerentes a escolherem ações que aumentem o resultado contábil.

Dos estudos mencionados no último parágrafo, a única exceção às críticas de Healy (1985) é o de Silva, Ribeiro e Matias (2013), pois seu objetivo foi examinar o modelo de remuneração de instituições financeiras brasileiras, conforme descrito no Formulário de Referência. As autoras verificaram que o lucro líquido é a medida de desempenho mais utilizada nas instituições que compuseram sua amostra, seguido pelo retorno sobre o patrimônio líquido (ROE) e por medidas qualitativas. Além disso, apenas 5 indivíduos da amostra remuneram seus executivos através de programas de opções de ações. Pode-se perceber então que de acordo com a pesquisa de Silva, Ribeiro e Matias (2013) o lucro líquido e o ROE são metas comumente utilizadas em planos de incentivo a executivos.

Na pesquisa de Chien (2012) o retorno sobre o ativo (ROA) e a variação de vendas não apresentaram relações estatisticamente significativas com a remuneração, ao 
contrário do valor de mercado da firma. Ferreira (2012) realizou diversos testes para analisar relações entre o tamanho da firma e a remuneração, e não encontrou relações significativas. Ventura (2013) encontrou relação significativa entre remuneração e tamanho da firma, valor de mercado e ROE, porém não encontrou evidências de relações significativas da remuneração com os níveis de governança corporativa da BM\&FBOVESPA. Vasconcelos e Monte (2013) fazem uma abordagem distinta das demais pesquisas ao defasar as medidas de desempenho em relação à remuneração e identificaram que o ROA, o ROE e dividendos por ação apresentaram relações significativas, enquanto que o valor contábil, o lucro por ação, a margem líquida sobre vendas e a margem EBITDA não apresentam significância estatística.

O Quadro 4 apresenta um resumo das variáveis utilizadas nas pesquisas que compõem o suporte teórico desta tese.

A defasagem utilizada por Vasconcelos e Monte (2013), que não foi identificada em nenhum dos outros estudos utilizados na presente tese, é respaldada no estudo de Jensen e Murphy (1990) que argumenta que o desempenho deve ser avaliado antes da despesa com compensação. Apesar de parecer uma simples discussão de tempestividade, levanta-se um debate acerca da causalidade teórica das variáveis. O modelo proposto por Healy (1985) (ver eq. 3), bem como os de Jensen e Murphy (1990), Conyon (1997), Carter, Lynch e Tuna (2007) e Bruce et al. (2007) assumem uma relação temporal onde a avaliação de desempenho e a despesa com compensação ocorrem no mesmo período, da mesma forma que os estudos empíricos no mercado brasileiro citados anteriormente. 


\begin{tabular}{|c|c|c|}
\hline Autores & Variável Dependente & Variáveis Independentes \\
\hline \multicolumn{3}{|l|}{ Artigos Internacionais } \\
\hline Aggarwall e Samwick (1999) & $\begin{array}{c}\text { Remuneração de curto prazo } \\
\text { (salário, bônus e outros) } \\
\text { Remuneração de longo prazo (ações, } \\
\text { opções de ações, planos de } \\
\text { benefício, indenizações e outros) } \\
\end{array}$ & $\begin{array}{l}\text { Valor da firma (fluxo de caixa futuro } \\
\text { descontado) e média ponderada do } \\
\text { retorno aos acionistas que as demais } \\
\text { firmas do setor forneceram. }\end{array}$ \\
\hline Joh (1999) & $\begin{array}{c}\text { Variação da remuneração pecuniária } \\
\text { total da diretoria executiva de } t-1 \\
\text { para } t\end{array}$ & $\begin{array}{l}\text { ROA, ROA ponderado, retorno de } \\
\text { mercado, retorno de mercado } \\
\text { ponderado, dummy temporal. }\end{array}$ \\
\hline Liu e Stark (2009) & $\begin{array}{l}\text { Variação da compensação total de } \mathrm{t}- \\
1 \text { para } \mathrm{t} \text {. }\end{array}$ & $\begin{array}{l}\text { Dummies temporais, retorno de } \\
\text { mercado da firma, retorno médio } \\
\text { ponderado fornecido pelas demais } \\
\text { firmas do setor, lucro antes do } \\
\text { imposto de renda, lucro antes do } \\
\text { imposto de renda médio ponderado } \\
\text { das demais firmas do setor, tamanho } \\
\text { (faturamento). }\end{array}$ \\
\hline Angelis e Gristein (2011) & Remuneração total & $\begin{array}{l}\text { Dummies setoriais, retorno diário da } \\
\text { firma, retorno diário do setor, } \\
\text { tamanho da firma (ativo total), Q de } \\
\text { Tobin, proporção de novos } \\
\text { executivos na firma vs. setor e } \\
\text { proporção de diretores internos no } \\
\text { Conselho de Administração. }\end{array}$ \\
\hline Gong, Li e Shin (2011) & $\begin{array}{l}\text { Ocorrência de remuneração relativa } \\
\text { de desempenho }\end{array}$ & $\begin{array}{l}\text { Risco idiossincrático, tamanho, } \\
\text { retorno da ação, ROA, concentração } \\
\text { da indústria, remuneração do CEO, } \\
\text { idade do CEO, total de concentração } \\
\text { acionária dos } 5 \text { maiores acionistas, } \\
\text { independência do conselho de } \\
\text { administração, uso de consultores } \\
\text { externos para elaborar a fórmula de } \\
\text { compensação dos executivos }\end{array}$ \\
\hline \multicolumn{3}{|l|}{ Artigos Nacionais } \\
\hline Chien (2012) & $\begin{array}{c}\text { Price-to-Book } \\
\text { ROA } \\
\text { Média anual de crescimento das } \\
\text { vendas }\end{array}$ & $\begin{array}{l}\text { Remuneração total e média, nível de } \\
\text { governança, percentual de capital } \\
\text { votante do acionista controlador, } \\
\text { percentual do capital total do } \\
\text { acionista controlador, alavancagem, } \\
\text { tamanho (ativo total), tangibilidade } \\
\text { dos ativos. } \\
\end{array}$ \\
\hline Ferreira (2012) & $\begin{array}{l}\text { Percentual de variação da } \\
\text { remuneração total }\end{array}$ & Tamanho (ativo total) \\
\hline Ventura (2013) & Remuneração média total & $\begin{array}{c}\text { Tamanho (ativo total), dummy para } \\
\text { pagamento em ações, dummy para } \\
\text { pagamento de bônus, quantidade de } \\
\text { membro da diretoria estatutária, } \\
\text { valor da ação, lucro por ação, ROE e } \\
\text { ROA. }\end{array}$ \\
\hline Vasconcelos e Monte (2013) & Remuneração total & $\begin{array}{c}\text { ROA, ROE, margem líquida, } \\
\text { margem EBITDA, lucro por ação, } \\
\text { valor da ação e dividendos por ação. }\end{array}$ \\
\hline Krauter (2013) & $\begin{array}{c}\text { Crescimento das vendas, ROE, } \\
\text { ROA. }\end{array}$ & $\begin{array}{l}\text { Salário mensal médio, salário } \\
\text { variável médio, índice de acesso a } \\
\text { benefícios, índice de suporte a } \\
\text { carreira, índice de estímulo a } \\
\text { educação. }\end{array}$ \\
\hline
\end{tabular}

Quadro 4 - Variáveis utilizadas em estudos já desenvolvidos.

Fonte: Elaboração própria com base em Aggarwall e Samwick (1999), Joh (1999), Liu e Stark (2009), Angelis e Gristein (2011), Gong, Li e Shin (2011), Chien (2012), Ferreira (2012), Ventura (2013), Vasconcelos e Monte (2013), Krauter (2013). 
Aguiar (2009) também traz essa discussão em seu estudo expondo um posicionamento que a relação de causalidade, em modelos que consideram defasagem entre a avaliação de desempenho e a remuneração, seria que a remuneração no ano $t$ motivaria o agente a melhores desempenhos no ano $t+1$, pois racionalmente ele deseja aumentar sua utilidade e tem conhecimento de que ações deve escolher para tal. Logo, o desempenho em $\mathrm{t}$ influencia a remuneração em $\mathrm{t}$, que por sua vez influencia o desempenho em $\mathrm{t}+1 \mathrm{e}$ assim sucessivamente. No que tange à relação de causalidade entre remuneração e desempenho, esta tese se propõe a seguir a relação descrita por Aguiar (2009):

Remuneração $_{i, t}=f\left(\right.$ Desempenho $\left._{i, t}\right)$

$\mathrm{e}$

Desempenho $_{i, t}=f\left(\right.$ Remuneração $\left.o_{i, t-1}\right)$

Por fim, a avaliação do desempenho também levanta outras discussões, como: por que as pesquisas têm encontrado resultados divergentes para as mesmas medidas? Em situações "multi-principais" (onde há mais de um principal) apenas as métricas de lucro são suficientes? Variáveis que envolvem preço seriam mais importantes por incorporarem mais conteúdo (hipótese do mercado eficiente)? As pesquisas atuais ainda não nos permitem responder a todos estes questionamentos, evidenciando a oportunidade de novas pesquisas na área. 


\subsection{Avaliação de Desempenho}

De acordo com Anthony e Govindarajan (2008) a avaliação de desempenho é um sistema desenvolvido para auxiliar na implementação da estratégia de uma organização. Porém, o uso exclusivo de indicadores financeiros de desempenho e a ocorrência de fatores não controláveis enviesam este sistema, tornando-o míope e separador dos interesses dos agentes e do principal (MERCHANT; STEDE, 2012).

Por outro lado, como pode ser observado no Quadro 3, as pesquisas que envolvem remuneração a executivos e avaliação de desempenho tendem a priorizar o uso de métricas contábeis e financeiras na avaliação de desempenho das organizações. Para Anthony e Govindarajan (2008) a ênfase nestas medidas levaria os gestores a agirem na maximização dos resultados de curto prazo, afim de garantir o lucro do exercício e sua continuidade na função. O foco nos resultados de curto prazo pode não representar a estratégia de longo prazo da firma, comprometendo a utilidade dos investidores.

Merchant e der Stede (2012) afirmam que existe um trade-off entre métrica de curto e de longo prazos e que o que promove uma oculta a outra. Estes autores afirmam que o gestor tem que estar atento a estes fatos e que uma solução plausível seria a utilização de um conjunto de indicadores de desempenho, conforme exemplificado nas Figuras 3 e 5 .

Catelli e Guerreiro (2010), por outro lado, acreditam que a mensuração do desempenho através do lucro econômico poderia auxiliar a resolver a dicotomia da escolha de indicadores de desempenho, devido ao fato desta medida ser uma expectativa do futuro da organização, tendo como premissa o incremento do valor presente da entidade. Catelli e Guerreiro (2010) apontam algumas das características do lucro econômico, dentre as quais destaca-se: avaliação dos ativos pela possibilidade de geração de benefícios econômicos futuros, ajustes devido a mudanças nos níveis de preços dos bens na economia, o lucro é independente da distribuição de dividendos, e utilização de regras e critérios econômicos.

Percebe-se que estas características poderiam ser resumidas em dois aspectos principais: (i) é uma medida econômica que baseia-se no uso dos ativos, logo sofre 
bastante influência da gestão, e (ii) é impactado por fatores externos à organização. Logo, contempla tanto fatores incontroláveis como ineficiências da gestão.

Essa percepção acerca de uma variável econômica que permita o desenvolvimento de uma avaliação do desempenho de curto e longo prazos é consistente com as discussões acerca de fronteira estocástica de eficiência. $\mathrm{O}$ estudo desenvolvido por Aigner, Lovell e Schmidt (1977) acerca da formulação e estimação de modelos de funções de produção estocástica se caracteriza pela especificação do termo de erro em dois componentes, sendo um normalmente distribuído e o outro unicaudal.

Este componente unicaudal do termo de erro representa a ineficiência técnica de produção de uma firma, enquanto que o outro componente expressa fatores aleatórios externos à empresa que impactaram seu desempenho na produção de uma saída qualquer (BATTESE; COELLI, 1995), o que traduz a mesma percepção dos fatores do lucro econômico proposto por Catelli e Guerreiro (2010).

A partir do termo de ineficiência técnica, pode-se estimar o termo de eficiência técnica (ver Equação 19), que representaria os sucessos dos esforços do gestor no atingimento das metas definidas previamente, gerando valor para a firma no curto e longo prazos.

Outros estudos, envolvendo remuneração a executivos e avaliação de desempenho, trilham o mesmo cenário de fatores incontroláveis, porém a partir de um enfoque distinto. Ao aceitar que a avaliação de desempenho serve como um mecanismo para recompensar o agente por suas decisões e que o contrato que define os incentivos pagos é um instrumento de compartilhamento de risco (MURPHY, 1985). É possível inferir que o agente buscará opções para não incorrer em riscos sobre fatores que não possa controlar (LAMBERT, 2001; MERCHANT; STEDE, 2012; FARMER; ARCHBOLD; ALEXANDROU, 2013). Consequentemente, na definição do contrato de compensação o agente buscará expurgar o risco sistêmico de sua fórmula de remuneração.

Este raciocínio foi explicado inicialmente por Holmstrom (1982) que, ao discutir o problema de risco moral em equipes, desenvolveu o conceito de avaliação relativa de desempenho (relative performance evaluation - RPE), no qual o desempenho do indivíduo é analisado com base no desempenho do grupo. Extrapolando isto para os executivos, a ideia seria que o desempenho organizacional fosse analisado 
conjuntamente com o desempenho do setor econômico específico ao qual a empresa faz parte. Logo, fatos econômicos que impactam - positivamente ou negativamente - o desempenho de determinada firma seria expurgado da análise, pois não são consequência das decisões do agente.

A U.K. Secretary of State (2002) e a Securities Exchange Comission - SEC (2006) indicam que a avaliação relativa de desempenho é uma prática importante na definição das relações entre o desempenho da firma e os incentivos concedidos aos executivos. Porém, no Brasil, até o momento de conclusão desta tese, não se identificou algum tipo de movimento no mercado a fim de elaborar recomendação semelhante.

Aggarwal e Samwick (1999) estão entre os estudos pioneiros que testaram a teoria da RPE. Estes autores, semelhantemente a Jensen e Murphy (1990), Joh (1999) e Liu e Stark (2009), constataram relações estatisticamente significativas entre o desempenho de firmas rivais e a remuneração paga a executivos. Aggarwal e Samwick (1999) desenvolveram esta discussão explicitando um cenário entre empresas que partilham um ambiente de competição estratégica, que para os autores não é capturado no modelo de agência comum. Todo o trabalho deles é desenvolvido com base na competição de mercado e suas implicações para a definição de planos de incentivos. Para tanto, a competição de mercado foi modelada de duas formas: (i) como complementos estratégicos, ou (ii) como substitutos estratégicos. A discussão parte do seguinte modelo de contrato linear:

$\omega_{\mathrm{i}}=\kappa_{\mathrm{i}}+\alpha_{\mathrm{i}} \pi_{\mathrm{i}}+\beta_{\mathrm{i}} \pi_{\mathrm{j}}$

Onde, $\omega_{\mathrm{i}}$ é o contrato de incentivos acordado na firma $i, \kappa_{\mathrm{i}}$ são fatores não relacionados ao desempenho que impactam os incentivos (exemplo, tamanho e setor), $\pi_{\mathrm{i}}$ são os lucros da firma $i, \pi_{\mathrm{j}}$ os lucros do setor, $\alpha_{\mathrm{i}}$ o contrato ótimo da firma i revelado publicamente e $\beta_{\mathrm{i}}$ o contrato ótimo do setor conhecido pela firma i. Presume-se ainda que os $\kappa_{\mathrm{i}}{ }^{\prime}$ s são escolhidos pelo gestor, logo eles estariam sempre atrelados a um salário de reserva $\omega_{\mathrm{i}}^{\prime}$.

Joh (1999) testou como o desempenho do setor afeta os contratos de incentivos aos gestores em 796 firmas durante os anos de 1968 - 1992. Seus resultados mostram 
que a compensação estaria positivamente relacionada ao lucro do setor, e que este efeito é maior em setores mais competitivos, em firmas com crescimento mais lento.

Liu e Stark (2009) investigaram a evidência da avaliação relativa de desempenho no Reino Unido. Os autores analisaram 169 empresas 'não-financeiras' no período de 1971 - 1998. As medidas utilizadas para desempenho foram o lucro antes de tributos e o retorno de mercado, enquanto que a proxy para incentivos foi a remuneração em caixa e assumiram a linearidade entre as variáveis do modelo. Os autores encontraram evidências de relações positivas com o lucro individual e negativas com o setorial.

Angelis e Grinstein (2011) desenvolveram um estudo transversal com as empresas listadas no S\&P500, no ano de 2007. Os autores identificaram o uso de RPE em mais que um terço de sua amostra, onde na média $49 \%$ da remuneração estava atrelada ao RPE. Entretanto, nem todas as empresas utilizavam índices de mercado, ou do RPE é decorrente da incerteza sobre a medida setorial apropriada. Logo, o agente seria exposto a riscos incontroláveis e isso reduziria a efetividade da medida.

Gong, Li e Shin (2011) investigaram o uso explícito de RPE em 1.419 firmas listadas no mercado norte-americano, no ano de 2006. Vinte e cinco por cento das empresas da amostra fizeram tal uso e os autores identificaram uma relação forte e negativa entre a remuneração do CEO e o desempenho de mercado para o setor. $\mathrm{O}$ estudo mostra ainda que a principal variável utilizada como métrica no RPE é o retorno de mercado $(73,68 \%$ das firmas da amostra) e retorno sobre o PL $(13,85 \%)$.

Farmer, Archbold e Alexandrou (2013) testaram a hipótese da avaliação relativa de desempenho no mercado do Reino Unido analisando a possibilidade da ocorrência da RPE nos diferentes tipos de remuneração pecuniária concedida aos executivos. A premissa geral que subsidiou estes autores, é que cada elemento da remuneração dos executivos deve ser impactado por diferentes métricas do desempenho organizacional, e a não observância disto pode ser uma explicação para que a literatura acerca da RPE ainda ser inconclusiva.

Farmer, Archbold e Alexandrou (2013) testam separadamente a remuneração básica (ou fixa), remuneração em bônus, remuneração de longo prazo e remuneração total. Apesar dos modelos utilizados serem analiticamente idênticos aos dos demais estudos apresentados até este momento nesta tese, empiricamente foi feita a opção de não utilizar medidas contábeis de desempenho, pela possibilidade de discricionariedade 
da gestão por meio de escolhas contábeis ou operacionais. Desta forma, seu modelo pode ser assim descrito:

Remuneração $_{i}=\gamma_{i}+\alpha+\beta_{1}$ firma $_{i}+\beta_{2}$ setor $_{i}+\beta_{3}$ control $_{i}+\mu_{i}$

Onde, Remuneração $o_{i}$ é o elemento da remuneração a ser testado; $\gamma_{i}$ é o efeito específico da firma/executivo invariante no tempo e diferente entre firmas; firma é o vetor de variáveis de desempenho organizacionais de curto e longo prazo; setor $r_{i}$ é vetor de variáveis de desempenho de curto e longo prazos do setor; control ${ }_{i}$ são variáveis de controle que podem variar em no tempo; e $\mu_{i}$ o termo de erro.

Os resultados de Farmer, Archbold e Alexandrou (2013) fornecem evidência da avaliação relativa de desempenho da seguinte forma:

- Remuneração fixa: relação significativa e negativa com retorno do mercado de curto prazo defasado em um período;

- Remuneração em bônus: significativa e positiva com retorno da ação, e significativa e negativa com o retorno do mercado;

- Remuneração de longo prazo: significativa e positiva com o retorno de longo prazo da ação defasado em um período, e significativa e negativo com o retorno de longo prazo do setor defasado em um período;

- Remuneração total: significativa e negativo com retorno de curto prazo do setor e com retorno do mercado.

Os resultados de Farmer, Archbold e Alexandrou (2013) evidenciam que cada elemento da remuneração possui relações com diferentes medidas de desempenho, sendo assim, as especificações de modelos que consideram apenas a remuneração total, ou a remuneração em caixa, estariam enfraquecidas por má especificação dos modelos. Este fator pode ser ainda mais acentuado no caso de empresas listadas na BM\&FBOVESPA. O estudo de Dalmacio, Rezende e Slomski (2009) analisou os contratos de remuneração firmados entre as empresas participantes do mercado brasileiro e seus executivos entre os anos de 1998 e 2005. Os autores identificaram que apenas em alguns setores foi possível identificar relação entre o desempenho da organização e a remuneração do gestor, especificamente em: Alimentos e Bebidas, Construção, Telecomunicações e Veículos. Nos demais setores, o desempenho organizacional foi decorrente do resultado do setor em que a firma estava inserida. 
Logo, os contratos de remuneração não possuem como parâmetro das fórmulas de compensação o desempenho da firma.

\subsection{Análise de Eficiência e Desempenho Organizacional}

A análise de eficiência é discutida sob diversos enfoques (desempenho educacional de instituições ou estudantes, desempenho da força de trabalho, de produção agrícola, de organizações) conforme seja o cerne da pesquisa. $\mathrm{Na}$ contabilidade, a estimação de fronteiras de eficiência remonta a períodos mais recentes.

No Brasil a pesquisa de Kassai (2002) representa um marco no desenvolvimento de pesquisas com tal intuito. Kassai (2002) utiliza uma técnica não-paramétrica conhecida como análise por envoltória de dados (DEA) ${ }^{10}$. Esta é uma técnica de programação linear que de acordo com Seiford e Thrall (1990), Franco e Fortuna (2003), Medrano (2008) e Pereira (2011) é adequada quando os motivos que ocasionam desvios a uma produção eficiente são exclusivamente relativos à ineficiência técnica. Por outro lado, pesquisas em contabilidade estimando fronteiras estocásticas não foram identificadas no Brasil, apesar de já haver discussões neste sentido em outros países. De um modo geral, as pesquisas internacionais identificadas no levantamento feito até o presente momento evidenciam tanto o uso de DEA como o de fronteiras estocásticas aleatórias. (SMITH, 1990; THORE; KOZMETSKY; PHILLIPS, 1994; LAUTERBACH; VANINSKY, 1999; BAEK; PAGÁN, 2002; HABIB; LJUNGQVIST, 2005; CORDEIRO; MUKHERJEE; KENT, 2006)

A técnica para estimação de fronteira estocástica decompõe o termo de erro aleatório em dois termos de erros, onde um indica a ineficiência técnica e o outro evidencia choques aleatórios que tenham influenciado a eficiência de cada indivíduo e que estão fora de seu controle. Este método foi desenvolvido por Aigner, Lovell e Schmidt (1977) e Meeusen e van den Broeck (1977) e teve algumas adaptações como as de Battese e Coelli (1995) que aplicaram a técnica para dados em painel.

De acordo com Kumbhakar e Lovell (2000) a eficiência técnica pode ser entendida com a capacidade da firma minimizar o uso de inputs na produção de um

\footnotetext{
${ }^{10}$ Data Envelopment Analysis.
} 
dado vetor de outputs, ou a maximização de outputs mantendo o mesmo consumo de inputs. Desta forma a eficiência técnica de uma fronteira estocástica representa tudo o que os insumos (variáveis explicativas) conseguem explicar acerca dos produtos gerados (varável explicada), considerando a ineficiência técnica produzida pelos insumos escolhidos e variáveis aleatórias que possam ter impactado o nível de produtos gerados.

Baek e Pagán (2002) desenvolveram um estudo com o objetivo de analisar o impacto da estrutura e do nível de compensação a executivos na eficiência técnica de empresas componentes do S\&P 1500 entre os anos de 1992 - 1998. De acordo com estes autores, a eficiência técnica de uma firma está relacionada com boas práticas produtivas e uso eficiente de recursos, o que estaria associado com a lucratividade de longo prazo e, consequentemente, garantindo uma maior persistência dos resultados, sendo, portanto, uma forma de maximizar a utilidade dos principais. Utilizando o modelo desenvolvido por Battesi e Coelli (1995), Baek e Pagan (2002) identificaram que o nível de compensação aumenta a eficiência técnica das firmas, porém opções de ações e ações com restrição concedidas aos executivos, salário fixo e tempo na função são negativamente relacionadas com a eficiência técnica ${ }^{11}$.

Habib e Ljungqvist (2005) investigaram a eficácia de contratos de incentivo, além de outros esquemas de incentivo para reduzir problemas de agência e maximizar o valor das firmas que negociaram títulos no mercado dos Estados Unidos durante os anos de 1992 - 1997. O Q de Tobin foi a proxy para o valor da firma (a razão entre o valor de mercado da dívida e patrimônio e o custo de reposição dos ativos de determinada firma), enquanto que as proxy para incentivo foram o percentual de ações possuídas pelo executivo, percentual de opções possuídas pelo executivo, pressões de mercado decorrentes de probabilidades de fusões e falências não atendimento da legislação societária. Como resultado principal, os autores afirmam que os executivos falham em maximizar o valor da firma, que a efetividade dos incentivos dependem do tamanho da firma e do setor e que as opções concedidas aos gestores não estão suficientemente expostas ao risco, não gerando o incentivo necessário. Esta reflexão pode explicar também os resultados semelhantes achados anteriormente por Baek e Pagán (2002).

Chen (2010) decompôs a remuneração de gestores para verificar o impacto na eficiência produtiva de firmas taiwanesas durante o período de 1996 - 2004. A

\footnotetext{
${ }^{11}$ A descrição da estimação do termo de eficiência técnica foi feita na seção 3.1.3.
} 
remuneração foi decomposta em três componentes: um esquema de comparações com o mercado de trabalho externo, outro baseado nas alterações de características da firma e do executivo (vendas líquidas, número de empregados, idade da firma, retorno sobre os ativos, retorno de mercado, investimento em $\mathrm{P} \& \mathrm{D}$, idade do gestor, tempo na função, educação), e um terceiro baseado em pagamentos esporádicos. Os resultados da pesquisa sugerem que os ajustes feitos às remunerações com base nos valores pagos no mercado taiwanês são positivamente relacionados com a eficiência técnica. Isto pode ser entendido como uma variação dos resultados de Baek e Pagán (2002) no sentido em que o nível de compensação é importante, porém há um ajuste ótimo confirmando que pagar mais não representa melhores resultados (KORMAN; GLICKMAN; FREY JR., 1981).

Amornkitvikai e Harvie (2011) investigaram os fatores que contribuem para a eficiência técnica de empresas tailandesas durante os anos de 2000 - 2008. Utilizando um painel desbalanceado, os autores concluíram que firmas com problemas financeiros aumentam sua eficiência técnica através da redução de custos de insumos e controles financeiros mais rígidos. Por outro lado, as financeiramente saudáveis negligenciam a eficiência em favor de uma maior liquidez. O financiamento por terceiros também foi negativamente relacionado com a eficiência técnica. A estrutura de controle e controle gerencial foram positivamente relacionados com a eficiência técnica, corroborando com Baek e Pagán (2002) no sentido que o nível de compensação é positivamente relacionado com a eficiência técnica.

Yang e Regis (2011) estudaram a relação entre a compensação a executivos e a eficiência técnica em empresas chinesas durante o período de 1999 - 2010. A remuneração foi dividida em remuneração em caixa e remuneração com base no patrimônio. Os autores utilizaram uma estimação em dois estágios, onde inicialmente estima-se a fronteira de eficiência para em seguida regredir a eficiência técnica em função dos incentivos e controlando pelo tamanho da firma, idade da firma e estrutura de propriedade. Os resultados obtidos na pesquisa evidenciam que houve um crescimento muito maior da remuneração baseada no patrimônio em relação à baseada em caixa, porém ambas são positivamente relacionadas com a eficiência técnica, corroborando com os estudos anteriores. No que tange a estrutura de controle, maior controle gerencial está positivamente relacionado com a eficiência técnica, enquanto que maior controle estatal está negativamente relacionado. 
Conclui-se, portanto, que estes estudos encontraram resultados robustos para suas análises e que a estimação de fronteiras estocásticas e da eficiência técnica das firmas é viável a partir dos dados das empresas listadas na BM\&FBOVESPA.

\subsection{Hipóteses de Pesquisa}

Com base na revisão da literatura realizada foram elaboradas algumas hipóteses acerca dos resultados a serem obtidos a partir dos testes aplicados aos dados coletados.

A primeira hipótese tem como premissa a própria definição de fronteira estocástica citada por Farrel (1957), Aigner, Lovell e Schmidt (1977) e Buck, Liu e Skovoroda (2008) que afirmam existir ineficiências técnicas de produção das firmas envolvendo uma saída decorrente de sua função de produção. Aplicando esta hipótese aos objetivos desta tese, e tendo como pilar de sustentação a aplicação da teoria de contratos à contabilidade proposta por Lambert (2001), pode-se pressupor que caso os incentivos dados aos executivos não o motivem no sentido a atingir as metas de desempenho pré-estabelecidas, estes agentes não exerceriam o esforço esperado deles. Considerando ainda que o desempenho do agente é avaliado a partir de sua capacidade de atingir as metas definidas (SCOTT, 2011), a fórmula de incentivos aos executivos seria ajustada periodicamente a fim de diminuir a distância dos interesses do principal e agente, o que motivaria o gestor a alcançar as metas de desempenho organizacional préestabelecidas. Sendo assim, assume-se que:

H1: As firmas aumentam seu nível suas eficiências técnicas ao passar do tempo, por ajustarem as fórmulas de incentivos aos executivos motivando-os a agir de forma a cumprir as metas de desempenho pré-definidas.

A segunda hipótese baseia-se nas proposições de Korman, Glickman e Frey Jr. (1981), Baker, Jensen e Murphy (1988) e Morrel (2011) de que não há uma proporcionalidade relacionando a quantidade de determinado incentivo com o desempenho do agente. Logo, altos investimentos em incentivos pecuniários não seriam tão eficazes quanto diversificar os tipos de incentivos incluindo os não-pecuniários. A 
literatura prevê que no longo prazo ambos os incentivos possuem efeitos semelhantes no desempenho, porém motivando o gestor de forma distinta, o que maximizaria a riqueza de stakeholders e do próprio gestor. Desta forma, assume-se que:

H2: A diversificação dos incentivos pecuniários possui relação positiva e significativa com o desempenho organizacional.

O conceito de desempenho organizacional é sustentado pela visão estratégica da empresa, que - por definição - pressupõe a maximização da utilidade dos stakeholders durante todo o tempo, e não apenas no curto prazo (VENKATRAMAN; RAMANUJAM, 1986; NEELY, 2005; KAPLAN, 2010). Portanto, para que as firmas sobrevivam ao mercado competitivo é necessário ter os contratos (formais ou não) em um nível de equilíbrio ótimo (WATTS; ZIMMERMAN, 1986). Por outro lado, os próprios contratos constituem sistemas que são impactados tanto pelo ambiente externo, como pelo interno, e que podem ter seus níveis de otimização reduzidos. Pode ainda haver ineficiência na definição / renovação de determinado contrato ao longo do tempo o que reduziria a eficácia da firma. Baek e Pagan (2002) afirmam que uma firma pode ser caracterizada tecnicamente ineficiente se não obtiver resultados ótimos com base nos recursos disponíveis. Desta forma, sabendo-se que medidas de eficiência técnica seriam indicadores razoáveis para mensurar o desempenho organizacional no longo prazo (VENKATRAMAN; RAMANUJAM, 1986; BAEK; PAGAN, 2002), acredita-se que o uso de incentivos contribuiria para o aumento da eficiência técnica das organizações. Sendo assim, a terceira hipótese de pesquisa foi formulada da seguinte maneira:

H3: Os incentivos pecuniários pagos a executivos possuem relação significativa e positiva com a eficiência técnica da firma. 


\section{METODOLOGIA}

Para o desenvolvimento do estudo e consecução do objetivo geral foram utilizados bancos de dados distintos, bem como análises segregadas para que ao fim possa se chegar a um resultado geral para o tema.

\subsection{Modelo Teórico}

As definições conceituais dos constructos primários das relações de causalidade verificadas na literatura e as hipóteses de pesquisa elaboradas dão sustentação para o modelo conceitual elaborado apresentado na Figura 9.

Nesta figura pode-se perceber que os incentivos concedidos no período $t$ influenciam o desempenho organizacional em $t+1$ e geram diferentes tipos de motivação. Por outro lado, o desempenho organizacional é decorrente de fatores exógenos (fatores econômicos contingenciais e outros fatores aleatórios) e endógenos (desempenho individual). A escolha das ações por parte do agente será uma decorrência de sua motivação, considerando que o mesmo agirá racionalmente de forma a maximizar sua utilidade. Logo, a política de incentivos deve direcionar a motivação do executivo de forma que ele atinja os objetivos esperados pelos principais e não seja penalizado por fatores que estão além de seu controle.

Dentre tais fatores, o modelo conceitual separa fatores econômicos que impactam exclusivamente determinado setor ou firma, e fatores aleatórios que influenciem a eficiência de um indivíduo especificamente (greves, dificuldades para manutenção / aquisição de novos equipamentos, desastres naturais), que serão capturados na estimação da ineficiência técnica da firma. Ao final, o desempenho organizacional auferido servirá como base para compensação pelos seus esforços, em um ciclo onde a motivação gera esforços, que resultam em desempenho, que levam ao estabelecimento de novos incentivos, iniciando, assim, um novo ciclo. 
Figura 9 - Modelo Conceitual da Relação Entre Tipos de Incentivos e Compensação Baseada em Metas de Desempenho

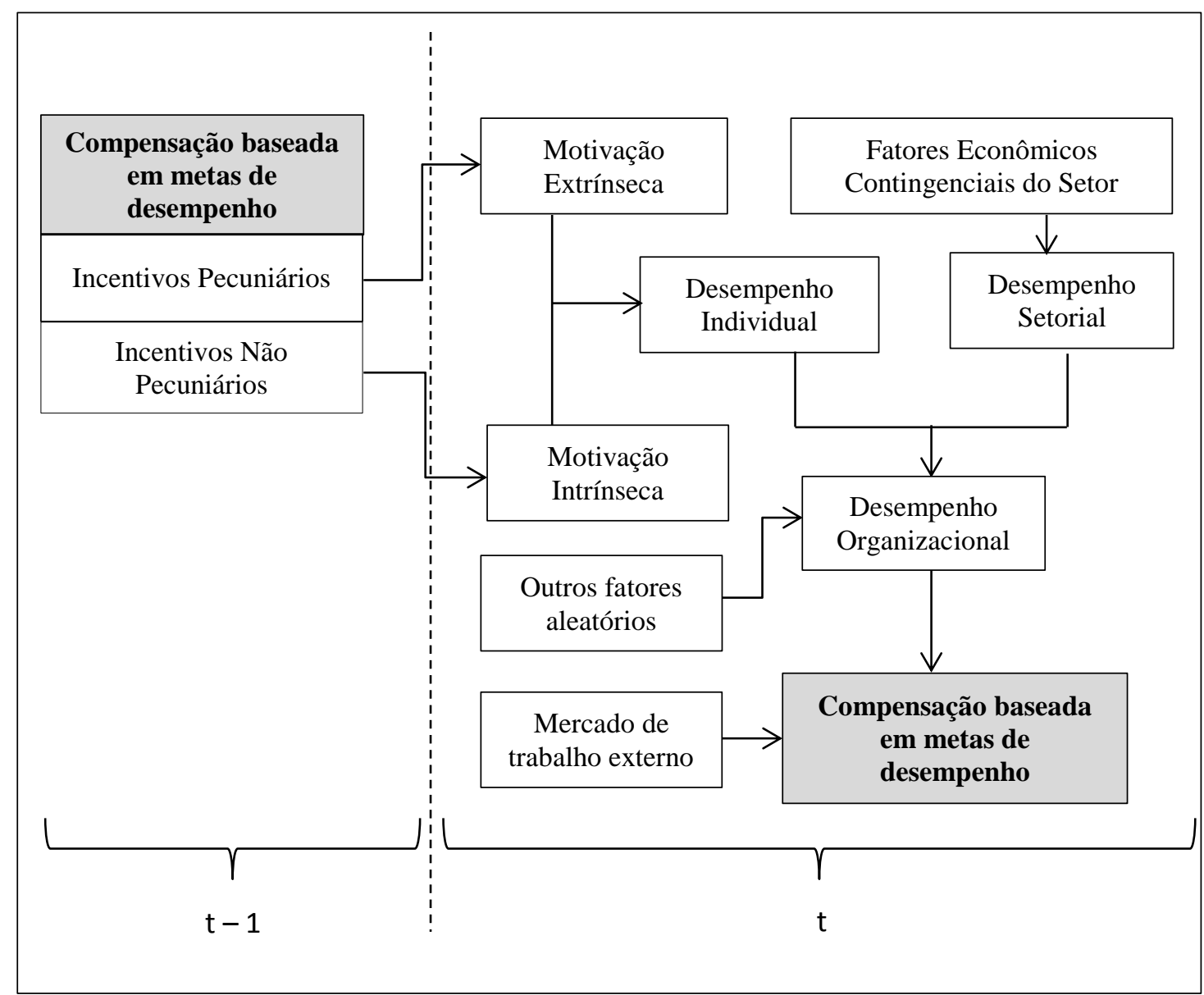

Fonte: Elaboração própria.

\subsubsection{Estimação da Fronteira Estocástica}

Para a primeira parte da análise será feita a estimação de uma função estocástica de utilidade para firmas, utilizando-se modelos que consideram como produto final gerado a receita das firmas, cujo objetivo é identificar se as firmas se tornam mais eficientes ao passar dos anos, e viabilizar a estimação de suas eficiências técnicas.

Esta metodologia, que foi proposta quase que simultaneamente por Aigner, Lovell e Schmidt (1977) e por Meeusen e van den Broeck (1977), partiu inicialmente 
dos modelos de fronteira de eficiência que tinham em sua formulação base a função Cobb - Douglas ${ }^{12}$.

$$
Y_{i}=\left(X_{i k} ; \beta\right)+\varepsilon_{i}
$$

Onde $Y=\ln (y)$, sabendo-se que y é o vetor de produtos gerados pelas Decision Making Units (DMU) de $i ; \beta$ é o vetor de parâmetros a serem estimados; $X=\ln (x)$ considerando-se que $x$ representa a matriz de insumos consumidos pela DMU $i$ no período $k$ para gerar o produto $y$; e, por fim, o termo de erro aleatório representado por $\varepsilon_{i}$ que é o estimador da fronteira de eficiência.

O modelo parte de uma análise dos produtos gerados com base nos insumos consumidos pelas DMU. Neste estudo, os insumos são o capital e a mão-de-obra investidos e as DMU são as firmas, conforme definição de Kassai (2002). Este consumo deverá gerar um resultado que servirá como parâmetro para se definir uma fronteira de eficiência.

A postulação principal de Aigner, Lovell e Schmidt (1977) e Meeusen e van den Broeck (1977) é que neste modelo todo o erro mensurado era interpretado como ineficiência, logo acabava desconsiderando fatores aleatórios que estão fora do controle das firmas. Sendo assim, estes autores decompuseram o termo de erro $\varepsilon_{i}$ em dois termos de erro aleatórios que são idêntica e independentemente distribuídos (i.i.d.) entre si no modelo. Logo, $\varepsilon_{i}=v_{i}+v_{i}$ onde $v_{i}$ reflete os choques aleatórios a que a firma $i$ está sujeita e segue uma distribuição normal $\mathrm{N}\left(0, \delta^{2}\right)$, enquanto que o termo $v_{i}$ é o indicativo da ineficiência técnica, seguindo uma distribuição semi-normal e assumindo valores menores que zero para os desvios em relação à fronteira eficiente.

A estimação da fronteira estocástica para as firmas partirá da relação definida por Aigner, Lovell e Schmidt (1977) e Meeusen e van den Broeck (1977) apresentada na Equação 11, adotando tanto o modelo funcional Cobb-Douglas, como o Translog

\footnotetext{
${ }^{12}$ Neste caso, a função Cobb-Douglas, representa uma relação linear de produção entre os inputs e outputs da relação. Os estimadores indicam a elasticidade do produto em relação a cada insumo, e a soma dos estimadores evidencia o retorno de escala.
} 
proposto por Kumbhakar (1990), Lee e Schimdt (1993), Battese e Coelli (1995), Baek e Pagán (2002) e Yang e Regis (2011), conforme pode ser visto na equação $12^{13}$ e 13:

$$
\begin{aligned}
& \text { Receita }_{i t}=\beta_{0}+\beta_{1} K_{i t}+\beta_{2} L_{i t}+\beta_{3} K_{i t}^{2}+\beta_{4} L_{i t}^{2}+\beta_{5} K_{i t} L_{i t}+\eta S_{i t}+v_{i t}-u_{i t} \\
& \text { Receita }_{i t}=\beta_{0}+\beta_{1} K_{i t}+\beta_{2} L_{i t}+\eta S_{i t}+v_{i t}-u_{i t}
\end{aligned}
$$

As equações 12 e 13 representam os modelos funcionais Translog e CobbDouglas, respectivamente, da relação esperada. Nelas a Receita $_{i t}$ representa a receita líquida da firma $i$ no período $t ; \beta_{0}$ é o intercepto do modelo; $K_{i t}$ é o capital total investido, representado pelo Ativo Total da firma $i$ no ano $t ; L_{i t}$ é a mão-de-obra investida, representada pelo total de funcionários contratados (próprios mais terceirizados) da firma $i$ no ano $t$; o vetor $S_{i t}$ representa as variáveis dummies que capturam o setor de atuação da firma, o qual de acordo com Baek e Págan (2002) permite absorver diferenças na tecnologia de produção entre os setores analisados; e o termo $v_{i t}-u_{i t}$ apresenta os termos de erro aleatório.

Nesta tese foram testados - especificamente - os modelos de Kumbhakar (1990), Lee e Schimdt (1993) e Battese e Coelli (1995). Ambos os modelos assumem o pressuposto de dados em painel cuja eficiência técnica estimada é variante no tempo. $\mathrm{O}$ modelo de Kumbhakar (1990) adiciona um termo na equação $11\left(\alpha_{i t}=\gamma(t) \delta_{i}\right)$, onde $\gamma(t)$ é especificado para alguns parâmetros permitindo que o nível de ineficiência técnica não seja constante, porém, tenha padrão temporal idêntico para todas as firmas. Sua sugestão assume a forma $\gamma(t)=\left[1+\exp \left(b t+c t^{2}\right)\right]^{-1}$, entretanto, os parâmetros $b$ e $c$ são desconhecidos, comprometendo discussões mais incisivas acerca de seus resultados.

Lee e Schimdt (1993) relaxaram a estrutura definida por Kumbhakar (1990) ao permitir qualquer padrão arbitrário de mudança temporal, sujeito à restrição que o padrão da mudança é o mesmo para todas as firmas. De acordo com os autores, o parâmetro $\gamma(t)$ desenvolvido por Kumbhakar (1990) foi representado em seu modelo por um conjunto de variáveis dummies de tempo, garantindo que o padrão de

\footnotetext{
${ }^{13}$ A equação 12 propõe como modelo funcional uma função de produção translog, semelhantemente aos desenvolvimentos de Baek e Pagán (2002) e Yang e Regis (2011). Esta função translog é uma alternativa à função Cobb-Douglas que incorpora relações não-lineares entre os inputs e outputs analisados na estimação da fronteira de eficiência.
} 
ineficiência técnica seja completamente irrestrito. O modelo de Lee e Schmidt (1993) foi desenvolvido para ser aplicável em amostras com grande número de indivíduos e pequena quantidade de tempo, pois o padrão de ineficiência técnica é o mesmo para todas as firmas.

Já o modelo de Battese e Coelli (1995) parte do mesmo ponto de partida de Kumbhakar (1990) e Lee e Schimdt (1993), porém possui parâmetros claramente definidos na estimação da eficiência técnica (conforme apresentado na seção 3.1.2) e tem sido amplamente utilizado na literatura como base para estudos de fronteira de eficiência para dados em painel (BAEK; PAGÁN, 2002; YANG; REGIS, 2011).

\subsubsection{Diversificação e Nível de Incentivos vs. Desempenho Organizacional}

A segunda parte da análise considerou os efeitos motivacionais que os incentivos divulgados através do Formulário de Referência (ver Quadro 2) geram no desempenho organizacional estimado pelo termo de eficiência técnica e tem como objetivo analisar se os tipos de incentivos pecuniários concedidos aos executivos influenciam o desempenho organizacional das firmas.

Battese e Coelli (1995) adaptaram o modelo proposto por Aigner, Lovell e Schmidt (1977) e Meeusen e van den Broeck (1977) desenvolvendo a aplicação para dados em painel, partindo da seguinte função de produção de fronteira estocástica:

$Y_{i t}=e\left(X_{i t} \beta+v_{i t}-v_{i t}\right)$

O efeito de ineficiência técnica capturado em $v_{i t}$ é obtido truncando (em zero) a distribuição normal com média $z_{i t} \delta$, e variância $\sigma^{2} . z_{i t}$ é um vetor $(1 \mathrm{x} \mathrm{m})$ de variáveis explanatórias associadas a ineficiência técnica das firmas durante o tempo e $\delta$ é um vetor (m x 1) de variáveis aleatórias e desconhecidas. Logo, o efeito de ineficiência técnica pode ser assim descrito: 
$v_{i t}=z_{i t} \delta+W_{i t}$

Onde, a variável aleatória, $W_{i t}$, é definida truncando a distribuição normal com média zero e variância, $\sigma^{2}$. Desta forma, o ponto de interrupção é $-z_{i t} \delta$, que para Battese e Coelli (1995) é consistente com $v_{i t}$ sendo uma truncagem não negativa de $N\left(z_{i t} \delta, \sigma^{2}\right)$. A função de verossimilhança é expressa nos termos da variância dos parâmetros, $\sigma_{S}^{2} \equiv \sigma_{v}^{2}+\sigma_{v}^{2}$ e $\gamma \equiv \sigma_{v}^{2} / \sigma_{S}^{2}$ (AIGNER; LOVELL; SCHMIDT, 1977).

Com base nestes pressupostos, Battese e Coelli (1995) descrevem a eficiência técnica como:

$E T_{i t}=e\left(-v_{i t}\right)=e\left(-z_{i t} \delta-W_{i t}\right)$

Sendo assim, a eficiência técnica é estimada a partir da ineficiência técnica específica da firma, representada pelo termo $v_{i t}$ descrito na equação 15 . Além disso, e ainda de acordo com Battese e Coelli (1995), no modelo time-varying decay os efeitos de ineficiência são estimados da seguinte forma:

$v_{i t}=e\left\{-\eta\left(t-T_{i}\right\} v_{i}\right.$

Onde, $T$ é o último ano do painel, e $\eta$ é o parâmetro de decaimento do modelo. Como $t=T_{i}$ no último período, o ano de 2014 (último ano estudado nesta pesquisa) contém o nível base de ineficiência da firma $i$. Além disso, Battese e Coelli (1995) afirmam que se $\eta>0$ o nível de ineficiência diminui em comparação ao ano base, logo, $\eta>0$ representa que o nível de ineficiência aumentou ao passar do tempo, pois tem-se que $v_{\text {it }}>0$. Esta informação servirá para testar a hipótese 1 desta tese.

A partir da definição proposta na Equação 16 foram elaborados dois modelos (Equações 18 e 19) com base nos trabalhos de Conyon (1997), Baek e Pagán (2002), Buck, Liu e Skovoroda (2008), e Chen (2010), aplicando adaptações para o mercado brasileiro. 


$$
\begin{aligned}
& E T_{i t}=\alpha_{1} R F_{i t-1}+\alpha_{2} R V_{i t-1}+\alpha_{3} O B R_{i t-1}+\alpha_{4} \text { Dsetor }_{i t}+\alpha_{5} \text { DCtlEst }_{i t}+w_{i t} \\
& E T_{i t}=\alpha_{1} \text { RemTot }_{i t-1}+\alpha_{2} \text { DAno }_{i t}+\alpha_{3} \text { Dsetor }_{i t}+\alpha_{4} \text { DCtlEst }_{i t}+w_{i t}
\end{aligned}
$$

Onde, $E T_{i t}$ representa a eficiência técnica estimada da firma $i$ no período $t$; $R F_{i t-1}$ é o logaritmo natural do percentual da remuneração total, pago a título de remuneração fixa ao executivo, pela firma $i$ no período $t-1 ; R V_{i t-1}$ é o logaritmo natural do percentual da remuneração total, pago a título de remuneração variável ao executivo, pela firma $i$ no período $t-1 ; O B R_{i t-1}$ é o logaritmo natural do percentual, da remuneração total, pago a título de remuneração outras remunerações e benefícios ao executivo, pela firma $i$ no período $t-1$; $\operatorname{RemTot}_{i t-1}$ é o nível de incentivos pagos ao executivo pela empresa $i$ no ano $t-1$, medido pelo somatório das remunerações fixa, variável e outras; Dsetor Dé $_{\text {é }}$ uma variável dummy para cada setor das empresas componentes da amostra; DCtlEst $t_{i t}$ é uma variável dummy que assume valor 1 quando o controle acionário da firma é estatal e 0 quando não o é. O Quadro 5 apresenta uma síntese das variáveis utilizadas, a proxies empregadas e relações esperadas.

A separação entre o nível e os tipos de incentivo é decorrente da expectativa da ocorrência de multicolinearidade caso todas estas variáveis estejam presentes em um

\begin{tabular}{|c|c|c|c|}
\hline VARIÁVEL & DESCRIÇÃO & PROXY & $\begin{array}{r}\text { RELAÇÃO } \\
\text { ESPERADA } \\
\end{array}$ \\
\hline ET & Eficiência técnica & Eficiência técnica estimada & (indefinido) \\
\hline$R F_{i t-1}$ & $\begin{array}{l}\text { Remuneração fixa defasada } 1 \\
\text { período }\end{array}$ & $\begin{array}{l}\text { Logaritmo do percentual da } \\
\text { remuneração fixxa sobre a } \\
\text { remuneração total }\end{array}$ & Positiva \\
\hline$R V_{i t-1}$ & $\begin{array}{l}\text { Remuneração variável } \\
\text { defasada } 1 \text { período }\end{array}$ & $\begin{array}{l}\text { Logaritmo do percentual da } \\
\text { remuneração variável sobre a } \\
\text { remuneração total }\end{array}$ & Positiva \\
\hline$O B R_{i t-1}$ & $\begin{array}{l}\text { Outras remunerações e } \\
\text { benefícios defasado } 1 \text { período }\end{array}$ & $\begin{array}{l}\text { Logaritmo do percentual de outras } \\
\text { remunerações e benefícios sobre a } \\
\text { remuneração total }\end{array}$ & Positiva \\
\hline RemTot $_{i t-1}$ & $\begin{array}{l}\text { Remuneração total defasada } 1 \\
\text { período }\end{array}$ & $\begin{array}{l}\text { Logaritmo do valor médio pago a } \\
\text { diretoria estatutária }\end{array}$ & Positiva \\
\hline Dsetor $_{i t}$ & $\begin{array}{l}\text { Setor ao qual a firma está } \\
\text { classificada }\end{array}$ & 1 para cada setor e 0 caso contrário & (indefinido) \\
\hline DCtlEst $_{i t}$ & Controle estatal & $\begin{array}{l}1 \text { se a firma for controlada pelo } \\
\text { governo, } 0 \text { caso contrário }\end{array}$ & negativo \\
\hline
\end{tabular}
mesmo modelo funcional.

Quadro 5 - Relação esperada do efeito motivacional na eficiência técnica das firmas Fonte: Elaboração própria com base na revisão da literatura. 
3.1.3 Sensibilidade dos Incentivos a Executivos ao Desempenho Organizacional

A terceira análise desenvolvida busca fechar o ciclo descrito na Figura 9 ao analisar a sensibilidade da remuneração dos executivos à eficiência técnica das firmas. Sendo assim, espera-se que a motivação gerada no executivo por meio dos incentivos pagos no período anterior gere esforços do agente para a maximização da utilidade dos acionistas. Logo, uma maior eficiência técnica de produção de receita da firma influencia o pagamento de maiores remunerações.

Através da técnica de dados em painel estima-se o modelo descrito na Equação 20.

$\Delta \operatorname{Rem}_{i t}=\delta_{0}+\delta_{1} \Delta$ Rem $_{i t-1}+\delta_{2}$ ET $_{i t}+\delta_{3}$ Dsetor $_{i t}+\delta_{4}$ DTempo $+\delta_{5}$ Tam $_{i t}+\varepsilon_{i t}$

Onde $\Delta R e m_{i t}$ representa o logaritmo natural da variação da remuneração total paga ao executivo da firma $i$ entre os períodos $t-1$ e $t$ (neste estudo, entende-se por executivo a Diretoria Estatutária da firma); $\Delta R e m_{i t-1}$ representa o logaritmo natural da variação da remuneração total paga ao executivo da firma $i$ entre os períodos $t-2$ e $t-1$; $E T_{i t}$ é a eficiência técnica da firma $i$ no período $t$; Dsetor ${ }_{i t}$ é uma variável dummy para cada setor das empresas componentes da amostra; DTempo é uma variável dummy temporal; é o tamanho da firma $i$, representado pelo logaritmo natural do seu ativo total, no ano $t$.

Em resumo, o Quadro 6 apresenta uma síntese das variáveis utilizadas, as proxies empregadas e relações esperadas.

\begin{tabular}{|l|l|l|c|}
\hline \multicolumn{1}{|c|}{ Variável } & \multicolumn{1}{|c|}{ Descrição } & \multicolumn{1}{c|}{ Proxy } & \multicolumn{1}{c|}{$\begin{array}{c}\text { Relação } \\
\text { Esperada }\end{array}$} \\
\hline$\Delta R e m_{i t}$ & Variação da remuneração & $\begin{array}{l}\text { Variação da remuneração total } \\
\text { entre t e } \mathrm{t}-1 .\end{array}$ & - \\
\hline$\Delta R e m_{i t-1}$ & $\begin{array}{l}\text { Variação da remuneração } \\
\text { defasada 1 período }\end{array}$ & $\begin{array}{l}\text { Variação da remuneração total } \\
\text { entre } \mathrm{t}-1 \mathrm{e} \mathrm{t}-2 .\end{array}$ & Positiva \\
\hline$E T_{i t}$ & Eficiência técnica estimada. & $\begin{array}{l}\text { Logaritmo da eficiência técnica } \\
\text { estimada. }\end{array}$ & Positiva \\
\hline Dsetor $_{i t}$ & $\begin{array}{l}\text { Setor ao qual a firma está } \\
\text { classificada }\end{array}$ & 1 para cada setor e 0 caso contrário & (Indefinido) \\
\hline DTempo & Ano & 1 para o ano, 0 caso contrário & (Indefinido) \\
\hline Tam $_{i t}$ & $\begin{array}{l}\text { Logaritmo do ativo total da } \\
\text { firma }\end{array}$ & Logaritmo do ativo total da firma & Positiva \\
\hline
\end{tabular}

Quadro 6 - Relação esperada da sensibilidade da remuneração à eficiência técnica das firmas. Fonte: Elaboração própria com base na revisão da literatura. 
De acordo com Brooks (2008), a utilização de dados em painel apresenta três vantagens: 1) possibilita resolver uma maior gama de questões e tratar com problemas mais complexos do que se fossem utilizados exclusivamente dados em corte transversal, ou séries temporais; 2) permite analisar como as variáveis, ou as relações entre elas, se alteram dinamicamente; e 3) a estruturação de um modelo apropriado auxilia a remover o impacto de algumas formas de vieses por omissão de variáveis.

Sendo assim, o modelo será composto por N x T observações, onde T representa a quantidade de períodos de tempo que foram incluídos na análise, e $\mathrm{N}$ a quantidade de empresas, e será consistente se $\mathrm{N} \rightarrow \infty$ e T for fixo (BROOKS, 2008).

Um problema que pode ocorrer no uso de modelos de dados em painel é a correlação entre o termo de erro e as variáveis, o que enviesa os erros-padrão e é conhecido como heterogeneidade não observada. Esse viés pode ser decorrente de fatores não especificados no modelo e que podem influenciar o desempenho de uma organização, como a sua reputação. Para corrigir situações semelhantes a estas, utilizase a incorporação de efeitos fixos, ou de efeitos aleatórios, na estimação de modelos em dados em painel, como o apresentado na Equação 17. (BROOKS, 2008; WOOLDRIDGE, 2010).

Tal incorporação é dada por meio da inclusão de um intercepto para cada empresa $i$ com valor igual em todos os períodos $t$. Ao assumir que o efeito não observado não é correlacionado com os regressores, utiliza-se efeitos aleatórios. Por outro lado, os efeitos fixos assumem a correlação entre o efeito não observado e os regressores. Wooldridge (2010) afirma que independentemente do efeito optado para a estimação do modelo, a exogeneidade estrita dos regressores é um pressuposto no uso de dados em painel e pode ser testada por meio do uso do teste de Hausman (BROOKS, 2008). 


\subsection{Base de Dados}

Em razão da dificuldade na obtenção de dados, em uma única fonte, referentes a incentivos pecuniários e desempenho organizacional de empresas listadas na BM\&FBOVESPA, optou-se pela coleta em dois bancos de dados distintos, sendo consolidados e utilizados em um painel balanceado englobando os anos de 2010 - 2014.

Foram coletados do Economática ${ }^{\circledR}$ as seguintes informações de cada firma ${ }^{14}$ :

- Ativo total;

- Lucro Líquido;

- Receita Líquida;

- Setor;

- Controle acionário.

Foram coletados do Formulário de Referências, utilizando-se o software Empresas.Net, os seguintes dados:

- Tipos de remunerações pagas;

- Montante total e de cada remuneração;

- Quantidade de membros da Diretoria Estatutária;

- Quantidade de funcionários contratados (próprios e terceirizados).

O universo estudado compreende todas as empresas listadas na BM\&FBOVESPA e que estavam com o cadastro ativo em todo o período analisado, o que totalizou 371 empresas. Seguindo os trabalhos de Baek e Pagán (2002) e Habib e Ljungqvist (2005) optou-se pela manutenção de todos os setores listados na bolsa brasileira. Durante a coleta dos dados identificou-se que algumas empresas não apresentaram os dados conforme orienta a Instrução CVM 480/2009, o que causou a exclusão destas empresas da amostra. Os principais problemas encontrados foram:

- Justificativa cadastrada para não apresentar informações sobre remuneração;

- O arquivo entregue à CVM não continha dados do período que deveria conter, e os anteriores e posteriores não cobriram a lacuna de informação;

- Não apresentação de informações sobre a Diretoria Estatutária;

\footnotetext{
${ }^{14}$ Estes dados foram coletados das demonstrações consolidadas.
} 
- Campos das informações sobre remuneração no Formulário de Referência apresentaram valores zerados;

- Não divulgação de informações sobre quantidade de funcionários, ou informação zerada.

A não disponibilidade de dados em algum dos períodos analisados limitou a amostra em 269 empresas. Após isso foram ainda excluídas da amostra as empresas sem características produtivas, como holdings e firmas de investimento, pois não se adequam aos pressupostos do modelo proposto na equação 12 , por não terem a necessidade de contratar funcionários ou terem uma necessidade mínima. Logo, não carecem de investimento em mão-de-obra de modo semelhante às firmas industriais e comerciais. Essa exclusão definiu a amostra em 239 firmas, totalizando 47.800 observações, o que é aceitável estimando-se um erro máximo de estimativa de 5\% a um nível de confiança de $1 \% .^{15}$

Entretanto, algumas estimações não utilizaram a amostra em sua totalidade. Características distintas das firmas que implicam em expectativas distintas dos resultados fizeram com que três amostras fossem analisadas:

- Amostra 1: compreende as 239 firmas por ano já descritas abrangendo todos os setores listados na BM\&FBOVESPA;

- Amostra 2: exclui o setor Finanças e Seguros e totaliza 214 firmas por ano;

- Amostra 3: considera apenas o setor industrial, englobando 172 empresas por ano.

Os dados acerca dos valores absolutos de remuneração e do ativo total das firmas foram deflacionados com base no Índice de Preços ao Consumidor Amplo (IPCA) - o indicador oficial da inflação média no Brasil. Após a deflação, estes dados foram transformados em logaritmos naturais.

\footnotetext{
${ }^{15} \mathrm{O}$ cálculo do tamanho da amostra considerou o método para populações finitas, dado pela seguinte equação: $n=\frac{N \hat{p} \hat{q}\left(Z_{\alpha} / 2\right)^{2}}{(N-1) E^{2}+\hat{p} \hat{q}\left(Z_{\alpha / 2}\right)^{2}}$, onde $\mathrm{N}$ é o tamanho da população; $\hat{p}$ é o valor amostral da proporção populacional de indivíduos que pertencem a categoria desejada, o valor assumido no cálculo foi de $50 \%$ pois resulta no maior tamanho da amostra; $\hat{q}$ valor amostral da proporção de indivíduos que não pertencem a categoria desejada; $(Z \alpha / 2)^{2}$ é o valor crítico correspondente ao grau de confiança desejado, neste caso $99 \%$, logo o valor crítico é igual a 2,575; E é o erro máximo de estimativa utilizado. O tamanho da amostra corrigida pela população foi de 238 empresas, e foi utilizada a técnica de aleatoriedade simples, pois todas a empresas tinham igual probabilidade de ser selecionadas.
} 


\section{ANÁLISE DOS RESULTADOS}

A análise dos resultados foi organizada de forma a permitir uma relação direta com os objetivos específicos da pesquisa. Sua subdivisão inicia-se com a análise descritiva dos dados, e em seguida dos testes e modelos descritos na metodologia.

\subsection{Análise Descritiva}

A Tabela 2 descreve a amostra utilizada no estudo conforme setor de atividade, que teve como base a classificação setorial do Economática ${ }^{\circledR}$, incluindo-se o setor Imobiliário pela sua representatividade dentro da classificação anterior (Outros).

Dentre os setores descritos na Tabela 2, percebe-se que a maior quantidade das empresas analisadas está elencada no rol de Engenharia elétrica (12,97\%), Finanças e seguros (10,46\%) e Outros (13,39\%), composto por firmas das áreas de Educação (2), Brinquedos (2), Hotel (2), Serviços de locação (2), Serviços profissionais, científicos e técnicos (2), Telecomunicações (1) e Indústria de bebidas e fumo (1).

Tabela 2 - Descrição da amostra 1 - todos os setores: Distribuição das empresas por setor. 2010 a 2014

\begin{tabular}{l|cc}
\hline \multicolumn{1}{c|}{ Setor de atividade } & Absoluto & Percentual \\
\hline Agropecuária e pesca & 2 & 0,84 \\
Alimentos e bebidas & 12 & 5,02 \\
Comércio & 17 & 7,11 \\
Construção & 17 & 7,11 \\
Eletroeletrônicos & 4 & 1,67 \\
Energia elétrica & 31 & 12,97 \\
Finanças e seguros & 25 & 10,46 \\
Imobiliária & 9 & 3,77 \\
Máquinas industriais & 4 & 1,67 \\
Mineração & 3 & 1,26 \\
Minerais não metálicos & 2 & 0,84 \\
Papel e celulose & 5 & 2,09 \\
Petróleo e gás & 4 & 1,67 \\
Química & 7 & 2,93 \\
Siderurgia e metalurgia & 15 & 6,28 \\
Software e dados & 4 & 1,67 \\
Telecomunicações & 4 & 1,67 \\
Têxtil & 19 & 7,95 \\
Transporte e serviços & 12 & 5,02 \\
Veículos e peças & 11 & 4,60 \\
Outros & 32 & 13,39 \\
\hline & 239 & $100 \%$ \\
\hline
\end{tabular}

Fonte: Elaboração própria com base no Economática ${ }^{\circledR}$ 
A Tabela 3 faz uma descrição dos dados de remuneração das empresas analisadas. Percebe-se, inicialmente, acerca do perfil de remuneração pago pelas empresas listadas na BM\&FBOVESPA, que 2012 foi o ano no qual as firmas pagaram menores remunerações variáveis para seus executivos (0,2433). Além disso, 2014 também foi o ponto de inflexão no pagamento de outros benefícios e remunerações, invertendo a tendência de crescimento.

No estudo de Baek e Pagan (2002) pode-se ver que o perfil da remuneração paga pelas empresas norte-americanas é diferente. A remuneração fixa representa cerca de $38 \%$ da remuneração total, enquanto que nas empresas listadas na BM\&FBOVESPA esse tipo de remuneração representa mais que $60 \%$ em todos os períodos analisados nesta tese. Outro fator de destaque é o comportamento da remuneração total que após um ano de crescimento apresenta redução e novo crescimento em seguida. A pesquisa de Angelis e Gristein (2011) mostra uma evolução da fórmula de remuneração que é utilizada nas empresas listadas na Bolsa de Nova Iorque (NYSE). Estes autores identificaram que $86 \%$ das empresas estudadas pagaram algum tipo de remuneração variável enquanto que $78 \%$ pagaram remunerações baseadas em ações. Esta modificação do perfil da remuneração evidencia um maior compartilhamento do risco do atingimento das metas entre agente e principal do que nas empresas brasileiras.

Especificamente no que concerne a remuneração total paga pelas empresas brasileiras, percebe-se que 2011 apresenta maiores médias (R\$ 2.119.275,00) e desvio padrão (R\$ 3.041.371) (ver Tabela 3). A média alta de 2011 é decorrente do maior valor máximo do período estudado. Os valores mínimos médios pagos nos anos de 2014, 2013, 2012 e 2011 remetem a uma mesma empresa (Trevisa S/A), enquanto que o de 2010 refere-se à Cambuci. Já os valores máximos médios foram pagos pelas seguintes empresas: ItauUnibanco em 2014, Eneva em 2013, Vale em 2012 e 2011 e OSX em 2010 (ver Tabela 6).

Diferentemente dos achados de Frydman e Jenter (2010), percebe-se que a principal forma de compensação em uso pelas empresas listadas na BM\&FBOVESPA, é a remuneração fixa. Além disso, outros benefícios e remunerações médios que incluem incentivos com visão de longo prazo, como pode ser visto no Quadro 3, apresentou redução do seu valor entre os anos de 2012 a 2014. Mesmo que este fato 
possa ser uma característica das fórmulas de incentivo pagas pelas empresas listadas na BM\&FBOVESPA a seus executivos, também pode haver impactos do cenário econômico nacional no período, levando as organizações a piores desempenhos, pois colabora para o fortalecimento de uma visão de curto prazo nos gestores (MERCHANT; STEDE, 2012).

Tabela 3 - Descrição dos dados de remuneração atualizados pelo IPCA para as firmas da amostra 1 com todos os setores. 2010 a 2014

\begin{tabular}{|c|c|c|c|c|c|}
\hline Variável & Ano & Média & Desvio Padrão & Mínimo & Máximo \\
\hline \multirow{5}{*}{ Remuneração Total } & 2010 & $1.938 .297,00$ & $2.313 .099,00$ & $51.087,79$ & $16.200 .000,00$ \\
\hline & 2011 & $2.119 .275,00$ & $3.041 .371,00$ & $54.673,98$ & $30.100 .000,00$ \\
\hline & 2012 & $1.965 .310,00$ & $1.949 .600,00$ & $63.241,22$ & $14.800 .000,00$ \\
\hline & 2013 & $2.086 .034,00$ & $2.180 .914,00$ & $71.894,55$ & $14.300 .000,00$ \\
\hline & 2014 & $2.077 .874,00$ & $2.110 .814,00$ & $70.424,50$ & $15.300 .000,00$ \\
\hline \multirow{5}{*}{$\begin{array}{l}\text { Percentual da Remuneração } \\
\text { Fixa }^{\psi}\end{array}$} & 2010 & $62,87 \%$ & $25,92 \%$ & $0 \%$ & $100 \%$ \\
\hline & 2011 & $63,83 \%$ & $26,83 \%$ & $4,58 \%$ & $100 \%$ \\
\hline & 2012 & $65,30 \%$ & $26,37 \%$ & $2,98 \%$ & $100 \%$ \\
\hline & 2013 & $65,10 \%$ & $26,90 \%$ & $5,11 \%$ & $100 \%$ \\
\hline & 2014 & $65,13 \%$ & $26,08 \%$ & $5,40 \%$ & $100 \%$ \\
\hline \multirow{5}{*}{$\begin{array}{l}\text { Percentual da Remuneração } \\
\text { Variável }^{\psi}\end{array}$} & 2010 & $27,25 \%$ & $21,12 \%$ & $0 \%$ & $86 \%$ \\
\hline & 2011 & $25,90 \%$ & $21,96 \%$ & $0 \%$ & $83 \%$ \\
\hline & 2012 & $24,33 \%$ & $20,79 \%$ & $0 \%$ & $87 \%$ \\
\hline & 2013 & $24,51 \%$ & $21,10 \%$ & $0 \%$ & $81 \%$ \\
\hline & 2014 & $25,62 \%$ & $21,52 \%$ & $0 \%$ & $95 \%$ \\
\hline \multirow{5}{*}{ 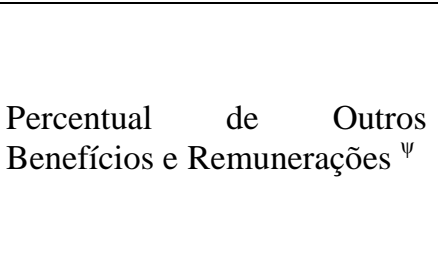 } & 2010 & $9,88 \%$ & $18,74 \%$ & $0 \%$ & $100 \%$ \\
\hline & 2011 & $10,28 \%$ & $18,09 \%$ & $0 \%$ & $89 \%$ \\
\hline & 2012 & $10,38 \%$ & $16,13 \%$ & $0 \%$ & $78 \%$ \\
\hline & 2013 & $10,40 \%$ & $17,18 \%$ & $0 \%$ & $90 \%$ \\
\hline & 2014 & $9,25 \%$ & $15,16 \%$ & $0 \%$ & $68 \%$ \\
\hline \multirow{5}{*}{$\begin{array}{l}\text { Membros da } \quad \text { Diretoria } \\
\text { Estatutária }\end{array}$} & 2010 & 62,187 & 67,714 & 2 & 82,08 \\
\hline & 2011 & 63,537 & 70,805 & 2 & 87,75 \\
\hline & 2012 & 64,744 & 73,497 & 2 & 90,75 \\
\hline & 2013 & 64,767 & 72,175 & 2 & 88,83 \\
\hline & 2014 & 63,470 & 71,803 & 2 & 88,42 \\
\hline
\end{tabular}

Fonte: Elaboração própria com base no Formulário de Referência.

${ }^{\psi}$ Valores percentuais da remuneração total.

Quanto ao tamanho da firma, medido por seu Ativo Total, a Tabela 4 evidencia que todos os valores aumentaram ano após ano, com exceção da mediana que em 2012 apresentou seu maior valor. Diferentemente dos dados de remuneração, os valores máximos e mínimos acerca do porte da empresa estão concentrados em duas empresas. 
Todos os valores máximos se referem ao Banco do Brasil, enquanto que os mínimos à Construtora Adolpho Lindemberg (Tabela 6). Analisando conjuntamente os dados descritivos de remuneração, percebe-se que o Banco do Brasil teve o segundo maior ativo em todos os anos analisados, enquanto que a Construtora Adolpho Lindemberg o segundo menor.

Tabela 4 - Descrição dos dados acerca do Ativo Total das firmas da amostra 1, em Reais (R\$) - com todos os setores. $2010-2014$

\begin{tabular}{cccccc}
\hline Ano & Média & Mediana & Desvio Padrão & Valor Máximo & Valor Mínimo \\
\hline 2010 & $25.474 .108,54$ & $3.261 .206,98$ & $117.750 .580,31$ & $1.028 .929 .132,18$ & $15.747,77$ \\
2011 & $27.872 .345,51$ & $3.548 .749,39$ & $128.981 .489,57$ & $1.167 .130 .673,56$ & $29.114,34$ \\
2012 & $30.370 .192,36$ & $3.936 .659,56$ & $141.859 .037,58$ & $1.296 .694 .115,65$ & $32.621,18$ \\
2013 & $30.776 .496,41$ & $3.776 .989,49$ & $146.818 .707,77$ & $1.389 .392 .418,30$ & $36.838,34$ \\
2014 & $32.040 .457,63$ & $3.872 .547,00$ & $152.436 .354,42$ & $1.437 .485 .512,00$ & $44.050,00$ \\
\hline
\end{tabular}

Conforme pode ser visto na Tabela 5, a receita líquida, produto gerado pelas firmas na estimação da Equação 12, apresentou tendência semelhante à do Ativo Total. A média da Receita Líquida aumentou no período similarmente aos valores da mediana e do desvio padrão. Entretanto, ambas medidas sofreram redução em 2013 e recuperação em 2014 a um valor superior ao do ano imediatamente anterior.

Partindo-se do pressuposto que a receita seria função do capital e mão-de-obra investidos (conforme proposta na Equação 12), poder-se-ia esperar que, se há uma redução do capital investido no período analisado, o aumento do produto gerado seria decorrente de uma melhor aplicação da mão-de-obra. Por outro lado, a intercorrência de dados extremos pode influenciar ambas as variáveis, desta forma, o conhecimento acerca de quem gerou os maiores e menores volumes de receita, pode influenciar a interpretação dos resultados.

Os valores máximos das receitas sofreram um aumento próximo a $25 \%$ no período, totalizando uma variação de $\mathrm{R}$ \$ 66.733.607,46 (saindo de R \$ 270.526.392,54 em 2010 para R\$337.260.000,00 em 2014). Analisando-se os dados da Tabela 5 juntamente com os da Tabela 3, verifica-se que a receita aparenta ter relação inversa da remuneração a partir de 2011. Por outro lado, Receita e Ativo Total médios apresentaram comportamentos similares, o que implica que a remuneração total tem sofrido pouca, ou nenhuma, influência dos valores de ativo e receita. Outra possibilidade é a influência de que a remuneração fixa possui ao se estabelecer as 
fórmulas de compensação dos executivos das empresas listadas na BM\&FBOVESPA, além de outras variáveis indicadoras de desempenho que melhor especifiquem esta relação.

Tabela 5 - Descrição dos dados acerca da receita das firmas da amostra 1 - todos os setores, em Reais (R\$). $2010-2014$

\begin{tabular}{cccccc}
\hline Ano & Média & Mediana & Desvio Padrão & Valor Máximo & Valor Mínimo \\
\hline 2010 & $6.881 .513,90$ & $1.216 .418,05$ & $22.864 .497,51$ & $270.526 .392,54$ & - \\
2011 & $7.844 .918,51$ & $1.366 .016,30$ & $26.127 .276,62$ & $290.436 .994,48$ & 117,76 \\
2012 & $8.043 .173,42$ & $1.527 .654,75$ & $26.425 .614,36$ & $317.138 .199,54$ & $2.583,28$ \\
2013 & $7.882 .510,11$ & $1.533 .152,62$ & $26.382 .527,47$ & $324.876 .792,40$ & $4.683,11$ \\
2014 & $8.403 .228,24$ & $1.587 .674,00$ & $28.293 .423,83$ & $337.260 .000,00$ & $9.713,00$ \\
\hline
\end{tabular}

Fonte: Elaboração própria com base no Economática ${ }^{\circledR}$.

Pode-se verificar, com base na Tabela 6, que todos os valores máximos apresentados remetem à receita da Petrobrás. Já os valores mínimos de 2010, 2011 e 2012 referem-se à receita da Telebrás, enquanto que em 2013 e 2014 à da HRT Petróleo e da CR2, respectivamente. Para os valores mínimos, três setores são representados: Telecomunicações, Petróleo e Gás e Construção. Destaca-se ainda o fato do governo ser o controlador das empresas Petrobrás e Telebrás, fator que pode impactar resultados operacionais destas firmas e que será testado nas próximas subseções.

No que se refere à quantidade de funcionários contratados, verifica-se na Tabela 6 que a Petrobrás apresentou o maior valor em todos os anos analisados, enquanto que os valores mínimos se referem à Unipar, entre 2010 e 2012, à CR2 em 2013 e à Bicicletas Monark em 2014, representando os setores de Química, Construção e Veículos e peças, respectivamente. Ressalvado o fato dos setores de atuação distintos, percebe-se ainda que a empresa com maior quantidade de funcionários é de controle do Estado, enquanto que as de menor quantidade são privadas. 
Tabela 6 - Valor médio das variáveis das firmas da amostra 1 - com todos os setores. 2010 a 2014

\begin{tabular}{|c|c|c|c|c|c|}
\hline \multirow{2}{*}{ Variáveis } & 2010 & 2011 & 2012 & 2013 & 2014 \\
\hline & \multicolumn{5}{|c|}{ Valor Máximo } \\
\hline Remuneração & OSX & Vale & Vale & Eneva & ItauUnibanco \\
\hline Ativo & $\begin{array}{c}\text { Banco do } \\
\text { Brasil }\end{array}$ & $\begin{array}{c}\text { Banco do } \\
\text { Brasil }\end{array}$ & $\begin{array}{c}\text { Banco do } \\
\text { Brasil }\end{array}$ & $\begin{array}{c}\text { Banco do } \\
\text { Brasil }\end{array}$ & $\begin{array}{c}\text { Banco do } \\
\text { Brasil }\end{array}$ \\
\hline Receita & Petrobrás & Petrobrás & Petrobrás & Petrobrás & Petrobrás \\
\hline \multirow[t]{2}{*}{$\begin{array}{l}\text { Quantidade de } \\
\text { funcionários }\end{array}$} & Petrobrás & Petrobrás & Petrobrás & Petrobrás & Petrobrás \\
\hline & \multicolumn{5}{|c|}{ Valor Mínimo } \\
\hline Remuneração & Cambuci & Trevisa & Trevisa & Trevisa & Trevisa \\
\hline Ativo & $\begin{array}{l}\text { Construtora } \\
\text { Adolpho } \\
\text { Lindemberg }\end{array}$ & $\begin{array}{l}\text { Construtora } \\
\text { Adolpho } \\
\text { Lindemberg }\end{array}$ & $\begin{array}{l}\text { Construtora } \\
\text { Adolpho } \\
\text { Lindemberg }\end{array}$ & $\begin{array}{c}\text { Construtora } \\
\text { Adolpho } \\
\text { Lindemberg }\end{array}$ & $\begin{array}{c}\text { Construtora } \\
\text { Adolpho } \\
\text { Lindemberg }\end{array}$ \\
\hline Receita & Telebrás & Telebrás & Telebrás & HRT & CR2 \\
\hline $\begin{array}{l}\text { Quantidade de } \\
\text { funcionários }\end{array}$ & Unipar & Unipar & Unipar & $\mathrm{CR} 2$ & $\begin{array}{l}\text { Bicicletas } \\
\text { Monark }\end{array}$ \\
\hline
\end{tabular}

Fonte: Elaboração própria com base no Economática® e Formulário de Referência.

A Tabela 7 evidencia que a partir de 2012 houve um ponto de inflexão na quantidade média de funcionários das firmas estudadas, tendo uma redução a partir de então. Fato semelhante ocorreu com as receitas, porém em 2014 as mesmas apresentaram seu maior valor ( $\mathrm{R} \$ 8.403 .228,24)$, como pode ser visto na Tabela 5, indicando que as firmas possam ter se tornado mais eficientes quanto à aplicação de mão-de-obra. Tais resultados são coerentes com o modelo formulado na Equação 12.

Tabela 7 - Descrição dos dados acerca do número de funcionários das firmas da amostra 1 - todos os setores. 2010 a 2014

\begin{tabular}{cccccc}
\hline Ano & Média & Mediana & Desvio Padrão & Valor Máximo & Valor Mínimo \\
\hline 2010 & $12.754,62$ & 3.020 & $33.238,41$ & 372.098 & 22 \\
2011 & $14.350,07$ & 3.559 & $37.426,80$ & 410.051 & 22 \\
2012 & $14.947,78$ & 3.597 & $39.055,82$ & 445.437 & 19 \\
2013 & $14.921,88$ & 3.629 & $39.719,04$ & 446.291 & 53 \\
2014 & $14.594,18$ & 3.610 & $36.602,33$ & 371.982 & 73 \\
\hline
\end{tabular}

Fonte: Elaboração própria com base no Formulário de Referência. 


\subsection{Estimação da Fronteira Estocástica}

Para estimação da fronteira de eficiência optou-se pela utilização de uma função de produção. A Função de Produção representa o caso em que uma única saída (variável Y das Equações 12 e 13) indica satisfatoriamente a tecnologia da firma em uma função matemática que fornece uma saída máxima alcançável a partir de um dado vetor de entradas (variáveis $\mathrm{X}$ das Equações 12 e 13). (KUMBHAKAR; HORNCASTLE; WANG, 2015)

Após a definição do uso de uma função de produção, foram realizados testes para verificar a função que melhor se ajusta ao modelo empírico desenvolvido. Foram testadas as funções Cobb-Douglas e Translog, para as amostras 1 (com todos os setores), 2 (sem o setor financeiro) e 3 (setor industrial), no entanto, com base no teste da função de verossimilhança (Tabela 8) a hipótese nula da função Cobb-Douglas é fortemente rejeitada para as três amostras (amostra 1: $\operatorname{LR~} X^{2}(3)=17,90$ e p-valor $=$ 0,0005; amostra 2: $\operatorname{LR~X}^{2}(2)=19,27$ ep-valor = 0,0001; amostra 3: $\operatorname{LR} X^{2}(2)=19,08 \mathrm{e}$ p-valor $=0,0001)$. Com base neste critério de decisão, optou-se por desenvolver a análise apenas sobre o modelo funcional Translog. ${ }^{16}$

Tabela 8 - Teste da função de verossimilhança das funções Cobb-Douglas e Translog para as amostras 1, 2 e 3 .

\begin{tabular}{|c|c|c|c|c|c|c|}
\hline Modelo & Obs. & 1l(nulo) & 1l(modelo) & $\begin{array}{l}\text { Graus de } \\
\text { liberdade }\end{array}$ & $\mathrm{AIC}$ & $\mathrm{BIC}$ \\
\hline \multicolumn{7}{|c|}{ Amostra 1 - Todos os setores } \\
\hline Cobb-Douglas & 1.195 & - & $-821,195$ & 26 & $1.694,39$ & $1.826,62$ \\
\hline Translog & 1.195 & - & $-812,248$ & 29 & $1.682,49$ & $1.829,99$ \\
\hline \multicolumn{7}{|c|}{ (Pressuposto: Cobb-Douglas aninhado no Translog) } \\
\hline \multicolumn{7}{|c|}{ Amostra $2-$ Sem o setor financeiro } \\
\hline Cobb-Douglas & 1.070 & & $-735,8889$ & 25 & $1.521,78$ & $1.646,163$ \\
\hline Translog & 1.070 & & $-726,2549$ & 27 & $1.506,51$ & $1.640,846$ \\
\hline \multicolumn{7}{|c|}{ (Pressuposto: Cobb-Douglas aninhado no Translog) } \\
\hline \multicolumn{7}{|c|}{ Amostra 3 - Setor industrial } \\
\hline Cobb-Douglas & 860 & - & $-485,761$ & 21 & $1.013,523$ & $1.113,418$ \\
\hline Translog & 860 & - & $-476,224$ & 23 & 998,4475 & $1.107,857$ \\
\hline \multicolumn{7}{|c|}{ (Pressuposto: Cobb-Douglas aninhado no Translog) } \\
\hline
\end{tabular}

\footnotetext{
${ }^{16}$ A estimação do modelo utilizando a função Cobb-Douglas está no APÊNDICE B - ESTIMAÇÃO DA FRONTEIRA DE EFICIÊNCIA COM USO DA FUNÇÃO
} 
Ao analisar o modelo estimado pela função translog para a amostra 1 (na primeira coluna da Tabela 9), e tendo como base a análise da matriz de covariância (ver Apêndice A), pode-se inferir a não ocorrência de multicolinearidade entre os parâmetros. Percebe-se ainda (na Tabela 9) que a hipótese que as firmas seriam tecnicamente eficientes ao passar do tempo não pode ser rejeitada, pois $\eta>0$ ao nível de significância de 1\% (0,1422). Para as amostras 2 e 3 os resultados são semelhantes, evidenciando que as conclusões acerca da eficiência das firmas feitas para a amostra 1 são consistentes $(\eta$ : amostra $2=0,1495$, amostra $3=0,0579 ; \lambda$ : $\operatorname{amostra} 2=0,9994$, amostra $3=0,9998)$.

Com base no modelo estimado com uso da função translog para a amostra 1, os resultados revelam também que como $\gamma$ é próximo de 1 para as três amostras, semelhantemente ao identificado por Battese e Coelli (1995), Amornkitvikai e Harvie (2011) e Yang e Regis (2011), os efeitos de ineficiência são altamente significativos na análise do valor das receitas das firmas. Logo, é possível afirmar que a ineficiência geral das firmas decorre, principalmente, da ineficiência técnica $\left(v_{i t}\right)$, enquanto que os termos de erro aleatórios $\left(v_{i t}\right)$ não possuem efeitos significativos sobre o resultado apresentado na Tabela 9. Pode-se, então, afirmar que as variáveis específicas da firma, conjuntamente com as gerais, explicam os efeitos de ineficiência do modelo, semelhante aos resultados e interpretações evidenciados por Amornkitvikai e Harvie (2011).

Considerando que as empresas estão se tornando mais eficientes ao passar do tempo, estes primeiros resultados indicam ainda uma relação não linear entre as receitas e a mão-de-obra (-0,3319). Resultados semelhantes foram encontrados no mercado chinês por Yang e Régis (2011), enquanto que Chen (2010) encontrou relações negativas lineares e não lineares no mercado tailandês. Por outro lado, a relação da receita com o capital investido é estritamente linear e positiva $(0,8988)$.

O sentido da relação linear (-0,3319), bem como a relação não-linear positiva $(0,0253)$, entre a receita líquida e a mão-de-obra, pode ser decorrente de uma curva de aprendizagem média dos funcionários, sugerindo que seria necessário contratar uma maior quantidade de colaboradores nos primeiros momentos de atividade da empresa e, à medida que os funcionários fossem adquirindo conhecimentos mais profundos acerca da função exercida, uma menor quantidade de funcionários seria demandada. Outra explicação possível seria o surgimento de novas tecnologias reduzindo a necessidade de utilização de empregados. 
Observa-se também que não é possível afirmar que o capital e a mão-de-obra investidos são mutuamente influenciáveis $(0,0050)$, além disso, o fato do capital não ter relação não linear estatisticamente significativa implicaria em uma variação proporcional da receita ao mesmo tempo em que ocorrem alterações no nível de investimento de capital. Este resultado pode ser decorrente da opção de não se excluir o setor de finanças e seguros da análise, pois as instituições financeiras possuem algumas características específicas, como: não necessitar de estoques, ativos grandes sem a necessidade de uma maior contratação de funcionários, receitas grandes frente ao investimento de capital próprio e regulações específicas.

$\mathrm{Na}$ sequência, as segunda e terceira colunas apresentam os resultados das estimações realizadas para a amostra 2 (sem o setor de finanças e seguros) e a amostra 3 (apenas o setor industrial) com o objetivo de investigar possíveis vieses causados nos resultados evidenciados para a amostra 1 (todos os setores). Os vieses poderiam ocorrer do fato que os modelos de estimação de fronteira estocástica utilizados nesta tese foram, inicialmente, desenvolvidos para aplicação em entidades industriais, e a amostra completa inclui empresas de comércio e serviço.

Especificamente no que tange aos parâmetros estimados, verificou-se que, ao excluir apenas o setor financeiro, o capital investido manteve significância e sentido da relação (1,0780), enquanto que para o modelo estimado apenas com empresas industriais, a significância da relação foi reduzida (0,5152). Além disso, a mão-de-obra deixou de apresentar relação estatisticamente significativa (amostra $2=-0,2878$; amostra $3=-0,2284)$, enquanto que Capital ${ }^{2}$ (amostra $2=-0,0106$; amostra $\left.3=0,0105\right)$, Mão-de-obra $^{2}(\operatorname{amostra} 2=0,0337$; $\operatorname{amostra} 3=0,0297)$ e Capital x Mão-de-obra (amostra $2=-0,0071$; amostra $3=-0,0091)$ mantiveram os mesmos resultados obtidos para a amostra completa, no que concerne à significância da relação.

Sendo assim, apenas o capital investido apresenta relação linear com a receita. Por outro lado, apenas a mão-de-obra apresenta relação não-linear. O efeito moderador inserido no modelo (Capital x Mão-de-obra) não foi significativo, o que não permite afirmar que há uma influência mútua entre estas duas variáveis. Sendo assim, linearmente a mão-de-obra parece indicar que o custo de sua alocação supera as produções geradas pelo seu investimento. 
A exclusão de empresas atuantes nos setores financeiro, comercial ou de serviços, portanto, evidencia que a mão-de-obra não possui relação significativa com a receita gerada pelas firmas restantes na análise. Além disso, o capital não possui relação não-linear com a receita, diferentemente dos resultados encontrados nos estudos de Yang e Regis (2011) e Amornkitvikai e Harvie (2011).

Tabela 9 - Estimativa para os parâmetros da função de fronteira estocástica (Battese e Coelli, 1995) em painel das firmas da amostra 1, 2 e 3.2010 a 2014

\begin{tabular}{|c|c|c|c|}
\hline \multirow[b]{2}{*}{ Variáveis } & \multicolumn{3}{|c|}{ Função Translog } \\
\hline & $\begin{array}{c}\text { Amostra } 1 \\
\text { (Todos os setores) }\end{array}$ & $\begin{array}{c}\text { Amostra } 2 \\
\text { (Sem o setor financeiro) }\end{array}$ & $\begin{array}{c}\text { Amostra } 3 \\
\text { (Setor industrial) }\end{array}$ \\
\hline Capital & $0,8988 * * *$ & $1,0780 * * *$ & $0,5152 *$ \\
\hline Mão-de-obra & $-0,3319^{*}$ & $-0,2878$ & $-0,2284$ \\
\hline Capital $^{2}$ & $-0,0076$ & $-0,0106$ & 0,0105 \\
\hline Mão-de-obra ${ }^{2}$ & $0,0253 * * *$ & $0,0337 * * *$ & $0,0297 * * *$ \\
\hline Capital x Mão-de-obra & 0,0050 & $-0,0071$ & $-0,0091$ \\
\hline Finanças e seguros & $-0,9995 * * *$ & $-0,8529 * * *$ & $-0,9103 * * *$ \\
\hline Agropecuária e pesca & $-0,8519 * * *$ & $0,2750 * *$ & 0,1531 \\
\hline Alimentos e bebidas & $0,2324 * *$ & $0,6037 * * *$ & - \\
\hline Comércio & $0,5992 * * *$ & $-0,4788 * * *$ & $-0,5012 * * *$ \\
\hline Construção & $-0,4810 * * *$ & $0,3576^{* *}$ & $0,3619 * *$ \\
\hline Eletroeletrônicos & $0,3654 * *$ & 0,0731 & $-0,0096$ \\
\hline Energia elétrica & 0,0576 & $-0,3215^{*}$ & $-0,6256 * * *$ \\
\hline Mineração & $-0,4383 * *$ & 0,1311 & 0,0519 \\
\hline Minerais não-metálicos & 0,1370 & $-0,6590 * * *$ & $-0,8367 * * *$ \\
\hline Papel e celulose & $-0,6955 * * *$ & $0,5343 * * *$ & $0,5102 * *$ \\
\hline Petróleo e gás & $0,5381 * * *$ & $1,3358 * * *$ & $1,4515^{* * *}$ \\
\hline Química & $1,3049 * * *$ & $-0,1527$ & $-0,1020$ \\
\hline Siderurgia e metalurgia & $-0,1618$ & 0,0630 & $-0,0266$ \\
\hline Software e dados & 0,0698 & $1,7593 * * *$ & - \\
\hline Telecomunicações & $1,7115 * * *$ & $-0,1375$ & $-0,1412$ \\
\hline Têxtil & $-0,1214$ & $-0,0355$ & - \\
\hline Transporte e serviços & $-0,0458$ & 0,0445 & $-0,0193$ \\
\hline Veículos e peças & 0,0362 & $-1,0399 * * *$ & - \\
\hline Imobiliária & $-1,0165 * * *$ & 1,9730 & $5,7923 * * *$ \\
\hline Constante & $3,4125 * * *$ & $0,1495^{* * *}$ & $0,0579 * * *$ \\
\hline$\eta$ & $0,1422 * * *$ & $0,1595 * * *$ & $0,0579 * * *$ \\
\hline$\sigma^{2}$ & 246,4145 & 253,9106 & 494,2974 \\
\hline$\gamma$ & 0,9994 & 0,9994 & 0,9998 \\
\hline$\sigma_{u}^{2}$ & 246,2673 & 253,7662 & 494,1918 \\
\hline$\sigma_{v}^{2}$ & 0,1472 & 0,1444 & 0,1057 \\
\hline Modelo & $\begin{array}{l}\text { Modelo Time- } \\
\text { (Normal- }\end{array}$ & $\begin{array}{l}\text { Modelo Time-varying } \\
\text { (Normal-Truncado) }\end{array}$ & $\begin{array}{l}\text { Modelo Time-varying } \\
\text { (Normal-Truncado) }\end{array}$ \\
\hline Núm. Observações & 1.195 & 1.070 & 860 \\
\hline Núm. Grupos & 239 & 214 & 172 \\
\hline Log de probabilidade & $-812,2475$ & $-726,1646$ & $-476,1120$ \\
\hline
\end{tabular}

Fonte: Elaboração própria com base nos dados do Economática ® e Formulário de Referência.

Nível de significância: $* * *<1 \%$; $* * 5 \%$; $* 10 \%$. 
A fim de possibilitar outras distribuições e fortalecer a análise, os modelos de Kumbhakar (1990) e Lee e Schmidt (1993) também foram estimados. As diferenças entre estes modelos citados anteriormente e o modelo adaptado por Battese e Coelli (1995) não permitem comparações de resultados, pois cada modelo a estima de forma distinta, logo, este ponto não será debatido. Em contrapartida, essa estimação permite a comparação das Decision Making Units (DMU), o que agrega valor à análise.

Por meio da Tabela 10 é possível constatar que os resultados obtidos para as variáveis de interesse por meio da estimação do modelo de fronteira de eficiência proposto por Kumbhakar (1990) é consistente com a função translog do modelo de Batese e Coelli (1995) no que concerne ao sentido da relação e significância estatística das variáveis de interesse (capital e mão-de-obra lineares e não-lineares). A única alteração se deu na forma linear da variável mão-de-obra que era significativa a $10 \%$ e não a é no modelo de Kumbhakar (1990), embora o sentido da relação tenha permanecido.

Em relação a amostra 1 (todos os setores), percebe-se que todas as dummies setoriais mantiveram o sentido da relação. Os setores de Alimento e Bebidas, Eletroeletrônicos, Petróleo e Gás, e Telecomunicações tiveram redução no nível de significância, entretanto, permaneceram relevantes na estimação. A significância da variável ' $b$ ' indica que o fator tempo é importante da estimação da eficiência técnica, corroborando com os resultados anteriores de que a ineficiência reduziu ao passar dos anos. Por outro lado, a estimação de Lee e Schmidt (1993) é restringida pela censura da constante (BELOTTI et al., 2013) que pode ter interferido nos resultados obtidos após a estimação do modelo. Neste caso, apenas a forma linear da variável Capital Investido manteve tanto o sentido da relação, como o nível de significância $(0,9684)$. A variável mão-de-obra deixou de ser significativa em ambas as formas $(0,2404$ e 0,0350) e passou a ser positiva na sua postulação linear. Já a variável capital quadrática $(0,0042)$ continuou sem ser estatisticamente significativa, mas passou a apresentar sinal positivo.

Em relação a amostra 2 (sem o setor de finanças), é possível verificar que os resultados do capital investido em sua função linear (Kumbhakar =0,9237; Lee e Schmidt $=0,9917)$ e da mão-de-obra não-linear $($ Kumbhakar $=0,0353$; Lee e Schmidt $=$ 0,0412) foram significativos. Por outro lado, os resultados da estimação para a amostra 3 (restrita ao setor industrial) apresentaram diferenças acerca da relação entre a forma do capital (se linear ou não) e a receita. No modelo de Battese e Coelli (1995), a forma 
linear do capital investido foi significativo $(0,5152)$ enquanto que pelo modelo de Kumbhakar (1990) foi a forma não-linear do capital que apresentou relação significativa (0,0277). Já a mão de obra não-linear obteve resultados semelhantes tanto para o nível de significância quanto para o valor absoluto do estimador (Battese e Coelli = 0,0297; Kumbhakar =0,0258). O modelo de Lee e Schmidt (1993) não foi capaz de apresentar estimativas para a amostra 3 , logo não apresenta resultados para este caso específico.

Tabela 10 - Estimação das fronteiras formuladas por Kumbhakar (1990) e Lee e Schmidt (1993) para as firmas da amostra 1, 2 e 3. 2010 a 2014

\begin{tabular}{|c|c|c|c|c|c|c|}
\hline \multirow[b]{2}{*}{ Variáveis } & \multicolumn{3}{|c|}{ Kumbhakar (1990) } & \multicolumn{3}{|c|}{ Lee e Schmidt (1993) } \\
\hline & $\begin{array}{c}\text { Amostra } 1 \\
\text { (Todos os } \\
\text { setores) }\end{array}$ & $\begin{array}{c}\text { Amostra } 2 \\
\text { (Sem o setor } \\
\text { financeiro) }\end{array}$ & $\begin{array}{c}\text { Amostra } 3 \\
\text { (Setor } \\
\text { industrial) }\end{array}$ & $\begin{array}{c}\text { Amostra } 1 \\
\text { (Todos os } \\
\text { setores) }\end{array}$ & $\begin{array}{l}\text { Amostra } 2 \\
\text { (Sem o setor } \\
\text { financeiro) }\end{array}$ & $\begin{array}{c}\text { Amostra } 3 \\
\text { (Setor } \\
\text { industrial) }\end{array}$ \\
\hline Capital & $0,8396 * * *$ & $0,9684 * * *$ & $0,9237 * * *$ & $0,9917 * *$ & 0,0730 & - \\
\hline Mão-de-obra & $-0,2344$ & 0,2404 & $-0,1881$ & 0,2017 & 0,0361 & - \\
\hline Capital $^{2}$ & $-0,0029$ & 0,0042 & $-0,0031$ & 0,0043 & $0,0277 *$ & - \\
\hline Mão-de-obra ${ }^{2}$ & $0,0294 * * *$ & 0,0350 & $0,0353 * * *$ & $0,0412 *$ & $0,0258 * *$ & - \\
\hline Capital x Mão-de- & $-0,0055$ & $-0,0444$ & $-0,0153$ & $-0,0483$ & $-0,0196$ & - \\
\hline Finanças e seguros & $-0,9996 * * *$ & $-0,7770^{*}$ & $-0,8995 * * *$ & $-0,9411$ & $-0,9944 * * *$ & - \\
\hline Agropecuária e pesca & $-0,9003 * * *$ & $-0,9275$ & $0,2660^{* *}$ & 0,4438 & 0,0794 & - \\
\hline Alimentos e bebidas & $0,2371^{*}$ & 0,4468 & $0,6173 * * *$ & $0,7038 *$ & - & - \\
\hline Comércio & $0,6139 * * *$ & 0,7036 & $-0,4443 * * *$ & $-0,7535^{*}$ & $-0,3526 * *$ & - \\
\hline Construção & $-0,4374 * * *$ & $-0,8208 *$ & $0,3290^{*}$ & $-0,0063$ & 0,2722 & - \\
\hline Eletroeletrônicos & $0,3303^{*}$ & $-0,0580$ & 0,0497 & 0,1252 & $-0,0575$ & - \\
\hline Energia elétrica & 0,0398 & 0,1336 & - & $-0,0267$ & $-0,3343$ & - \\
\hline Mineração & $-0,4723 * *$ & $-0,7271$ & $-0,4020 *$ & $-0,6847$ & $-0.7,67 * * *$ & - \\
\hline Minerais não- & 0,1176 & 0,3599 & 0,1204 & 0,3723 & $-0,0110$ & - \\
\hline Papel e celulose & $-0,7189 * * *$ & $-0,4343$ & $-0,6951 * * *$ & $-0,4371$ & $-0,8788 * * *$ & - \\
\hline Petróleo e gás & $0,4626 * *$ & 0,9913 & $0,4749 * *$ & 0,8683 & $0,5091 * *$ & - \\
\hline Química & $1,3291 * * *$ & $1,0058 *$ & $1,3428 * * *$ & $1,0080 *$ & $1,3230 * * *$ & - \\
\hline Siderurgia e & $-0,0885$ & $-0,1896$ & $-0,0897$ & $-0,1710$ & $-0,0365$ & - \\
\hline Software e dados & 0,0542 & $-0,4482$ & 0,0438 & $-0,3704$ & $-0,0592$ & - \\
\hline Telecomunicações & $1,0109 * *$ & $3,0098 * * *$ & $1,1067 * * *$ & $2,5550 * *$ & - & - \\
\hline Têxtil & $-0,1364$ & $-0,1621$ & $-0,1407$ & $-0,1407$ & $-0,1721$ & - \\
\hline Transporte e serviços & $-0,0093$ & 0,0288 & $-0,0022$ & 0,0453 & - & - \\
\hline Veículos e peças & $0,0187 * *$ & 0,3652 & 0,0280 & 0,3078 & $-0,0961$ & - \\
\hline Imobiliária & $-1,0122 * * *$ & $-1,3198 * *$ & $-1,0288 * * *$ & - & - & - \\
\hline Constante & $3,5740 * * *$ & - & $2,7755^{*}$ & - & $8,0782 * * *$ & - \\
\hline $\mathrm{Bt}$ & & & & & & \\
\hline B & 0,2021 & - & $0,1893 * * *$ & - & $-0,1747 * *$ & - \\
\hline $\mathrm{C}$ & $-0,0013$ & - & 0,0033 & - & $0,0452 * * *$ & - \\
\hline$\sigma_{v}$ & 2,9407 & 1,0201 & $3,0281 * * *$ & 1,0064 & $2,0999 * * *$ & - \\
\hline$\sigma_{v}$ & 0,3856 & 0,3509 & $0,3826 * * *$ & 0,3412 & $0,3178 * * *$ & - \\
\hline Modelo & \multicolumn{3}{|c|}{ Modelo Time-varying parametric } & \multicolumn{2}{|c|}{ Modelo Time-varying } & \\
\hline Núm. Observações & 1.195 & 1.070 & 860 & 1.195 & 1.070 & 860 \\
\hline Núm. de grupos & 5 & 5 & 5 & 5 & 5 & 5 \\
\hline Log proba. & $-868,4075$ & $-778,0217$ & $-481,2167$ & - & - & - \\
\hline Prob $>$ Chi2 & $4.051,79$ & $3.590,46$ & $2.218,41$ & - & - & - \\
\hline Wald chi2 & 0,0000 & 0,000 & 0,0000 & - & - & - \\
\hline
\end{tabular}

Fonte: Elaboração própria com base nos dados do Economática ${ }^{\circledR}$ e Formulário de Referência. Nível de significância: $* * *<1 \%$; $* *<\%$; $* 10 \%$. 
Os resultados do modelo de Lee e Schmidt (1993) não foram consistentes com os dos outros dois modelos (KUMBHAKAR, 1990; BATTESE; COELLI, 1995), fazendo com que fosse preterido em relação aos outros dois. Portanto, os resultados obtidos no modelo de Battese e Coelli (1995) são consistentes com os obtidos após estimação do modelo de Kumbhakar (1990), permitindo uma interpretação mais acurada dos fatores que compõem a estimação da eficiência técnica e possibilitando inferir que seja o modelo mais apropriado para dar sequência ao estudo, dado que as variáveis componentes do termo de ineficiência do modelo de Battese e Coelli (1995) são claramente especificadas pelos autores $(\eta$ e $\lambda)$.

A Tabela 11 apresenta um resumo geral dos resultados obtidos na estimação da fronteira estocástica utilizando a função translog e o modelo de Battese e Coelli (1995) para as três amostras da pesquisa. Nesta, pode-se verificar que ambos os fatores $\eta$ e $\gamma$ são consistentes, haja vista que nas três amostras $\eta$ é maior do que zero (e significativo) e $\gamma$ está próximo a 1. Quanto aos insumos da fronteira a relação linear do capital na amostra 3 reduziu o seu nível de significância (0,5152), mas manteve o sentido da relação, indicando que em firmas industriais a relação entre receita e capital investido estaria sujeita a uma gestão mais eficiente dos recursos do que em outros setores onde a relação foi significativa a $1 \%$. A mão-de-obra apresentou relação linear significativa apenas na estimação para a amostra $1(-0,3319)$, enquanto que sua relação não-linear foi positiva e significativa a $1 \%$ nas três estimações. Como a amostra 2 e a 3 convergem no fato de não conterem o setor financeiro, presente apenas na amostra 1, pode-se inferir que a relação linear da mão-de-obra com a receita foi influenciada pela presença do setor de Finanças e Seguros no qual a mão-de-obra teria relação mais estreita com a receita.

Tabela 11 - Resumo dos resultados das estimações da fronteira estocástica com todos os setores, sem o setor financeiro e apenas com indústrias. 2010 a 2014

\begin{tabular}{|c|c|c|c|}
\hline Variável & $\begin{array}{c}\text { Amostra } 1- \\
\text { Todos os setores }\end{array}$ & $\begin{array}{c}\text { Amostra } 2- \\
\text { Sem o setor financeiro }\end{array}$ & $\begin{array}{c}\text { Amostra } 3- \\
\text { Setor industrial }\end{array}$ \\
\hline Capital & $0,8988 * * *$ & $1,0780 * * *$ & $0,5152 *$ \\
\hline Mão-de-obra & $-0,3319^{*}$ & $-0,2878$ & $-0,2284$ \\
\hline Capital $^{2}$ & $-0,0076$ & $-0,0106$ & 0,0105 \\
\hline Mão-de-obra ${ }^{2}$ & $0,0253 * * *$ & $0,0337 * * *$ & $0,0297 * * *$ \\
\hline Capital x Mão-de-obra & 0,0050 & $-0,0071$ & $-0,0091$ \\
\hline Dummies setoriais & Sim & Sim & Sim \\
\hline$\eta$ & $0,1422 * * *$ & $0,1595 * * *$ & $0,0579 * * *$ \\
\hline$\gamma$ & 0,9994 & 0,9994 & 0,9998 \\
\hline
\end{tabular}




\subsection{Desempenho Organizacional vs. Nível e Diversificação de Incentivos}

Esta seção objetiva analisar a Hipótese 2 da pesquisa que pressupõe que o desempenho organizacional das firmas, medido por suas eficiências técnicas, seria influenciado pela diversificação dos incentivos pecuniários pagos aos executivos.

Para testar a Hipótese 2 foi necessário estimar a eficiência técnica com base nas fronteiras de eficiência estimadas na seção 4.2. O cálculo da eficiência técnica estimada das firmas $\left(E T_{i t}\right)$ foi desenvolvido através do exponencial dos termos de ineficiência, conforme descrito na Equação 16. Porém, dada a expectativa de que os resultados para a amostra completa (amostra 1) possam ser enviesados pela presença do setor financeiro e do setor industrial, testou-se a hipótese de que a exclusão dos respectivos setores impactaria nos resultados estimados. Outra justificativa advém do fato de que os modelos de fronteira foram desenvolvidos com base em organizações industriais, enquanto que a amostra completa da pesquisa considera também os setores comerciais e de serviço.

A Tabela 12 mostra que existem diferenças entre as médias das eficiências técnicas das amostras. Ao se excluir o setor de finanças e seguros da amostra total o pvalor foi de 0,9068, ao comparar-se a eficiência técnica da amostra 3 com a da amostra 1 o p-valor foi de 0,9016 e na comparação da eficiência das amostras 2 e 3 o p-valor foi igual a 0,8992 . Portanto, decidiu-se que os modelos estimados e os testes realizados a partir deste momento devem permanecer com estimações distintas para as três amostras. A composição das amostras também é variada na literatura, Battese e Coelli (1995) testaram seu modelo em entidades produtivas, Aigner, Lovell e Schmidt (1977), Amornkitvikai e Harvie (2011) e Yang e Regis (2011) excluíram o setor financeiro da amostra, e Baek e Págan (2002) mantiveram a análise para todos os setores conjuntamente. 
Tabela 12 - Resultados do Teste-F para variâncias das amostras 1, 2 e 3. 2010 a 2014

\begin{tabular}{l|ccc}
\hline \multicolumn{1}{c}{ Variável } & $\begin{array}{c}\text { Eficiência Técnica } \\
\text { Amostra 1 } \\
\text { (Todos os setores) }\end{array}$ & $\begin{array}{c}\text { Eficiência Técnica } \\
\text { Amostra 2 } \\
\text { (Sem o Setor Financeiro) }\end{array}$ & $\begin{array}{c}\text { Eficiência Técnica } \\
\text { Amostra 3 } \\
\text { (Setor industrial) }\end{array}$ \\
\hline Média & 0,6699 & 0,6649 & 0,6089 \\
Variância & 0,0548 & 0,0576 & 0,0600 \\
Observações & 1.195 & 1.070 & 860 \\
Graus de liberdade & 1.194 & 1.069 & 859 \\
\hline F crítico uni-caudal & & & \\
Amostra 1 vs. Amostra 2 & 0,9068 & & \\
Amostra 1 vs. Amostra 3 & 0,9016 & & \\
Amostra 2 vs. Amostra 3 & 0,8992 & & \\
\hline
\end{tabular}

Fonte: Elaboração própria com base nos dados do Economática ${ }^{\circledR}$ e Formulário de Referência.

$\mathrm{Na}$ sequência, os dados contidos na Tabela 13 apresentam o sumário do logaritmo das variáveis utilizadas para a estimação descrita na Equação 18, que analisa a influência dos tipos de remuneração no desempenho da organização. Para esta fase da análise dos resultados foi necessário excluir o ano de 2010 por conta da defasagem das variáveis explicativas do modelo. Logo, são apresentados resultados para os 4 períodos compreendendo os anos de 2011 - 2014.

Quanto à eficiência técnica, é possível perceber que o desvio padrão é maior entre as firmas do que entre os períodos (amostra 1: entre firmas $=0,2256$, entre períodos $=0,0361$; amostra 2 : entre firmas $=0,2307$, entre períodos $=0,0382$; amostra 3: entre firmas $=0,2429$, entre períodos $=0,0165$ ). Logo, considerando que as empresas aumentam suas eficiências técnicas ao passar dos anos (ver Tabela 9 e Figura 10), percebe-se que fatores como porte ou setor podem estar impactando a eficiência técnica das firmas, dado que a mesma varia menos entre os períodos do que entre as firmas. Esta constatação deve ser decorrente de fatores como tecnologia específica do setor, ou mesmo do tamanho da empresa.

As remunerações fixa, variável e outras remunerações e benefícios são expressas em percentuais do valor da remuneração total. Como a maioria das empresas da amostra não paga todos os tipos de remuneração previstos no Formulário de Referência da CVM, o painel foi desbalanceado no momento em que se calculou o logaritmo natural das variáveis. Os valores "0" nos tipos de incentivos representam empresas que remuneram seus executivos apenas com este tipo de remuneração. Por exemplo, nas três amostras, o valor máximo do logaritmo do percentual da remuneração fixa do executivo 
é "0”, que significa dizer que $100 \%$ da sua remuneração total é fixa. Logo, pode-se perceber que há um único caso nas amostras 1 e 2 que não paga Remuneração Fixa a sua diretoria estatutária (deve-se observar que na amostra 1 o $\mathrm{N}$ total caiu de 956 para 955 e na amostra 2 de 856 para 855). O mesmo não ocorre na amostra 3, dado que o número de observações é igual na eficiência técnica e na remuneração fixa $(\mathrm{N}=688)$.

Analisando os tipos de incentivos, percebe-se que - assim como no caso da eficiência técnica -, o desvio padrão é maior entre as firmas do que entre os períodos, em todas as amostras, evidenciando que as firmas tendem a manter sua política de remuneração ao longo do tempo. O mesmo acontece com o nível de incentivos (entre firmas: 0,8627; entre períodos: 0,3013). 
Tabela 13 - Sumário dos logaritmos da eficiência técnica, nível e tipos de remuneração das amostras 1, 2 e 3.2011 a 2014

\begin{tabular}{|c|c|c|c|c|c|c|}
\hline \multicolumn{2}{|c|}{ Variável } & Média & Desvio & Mínimo & Máximo & Observações \\
\hline \multicolumn{7}{|c|}{ Amostra 1 - Todos os setores } \\
\hline \multirow{3}{*}{ Eficiência Técnica } & Geral & 0,6847 & 0,2281 & 0 & 0,9736 & $\mathrm{~N}=956$ \\
\hline & Firmas & & 0,2256 & 0,0006 & 0,9671 & $\mathrm{n}=239$ \\
\hline & Períodos & & 0,0361 & 0,6078 & 0,7617 & $\mathrm{~T}=4$ \\
\hline \multirow{3}{*}{ Remuneração Fixa } & Geral & $-0,5585$ & 0,5454 & $-3,5120$ & 0 & $\mathrm{~N}=955$ \\
\hline & Firmas & & 0,4953 & $-2,7488$ & 0 & $\mathrm{n}=239$ \\
\hline & Períodos & & 0,2311 & $-1,8287$ & 1,1023 & $\overline{\mathrm{T}}=3,9958$ \\
\hline \multirow{3}{*}{$\begin{array}{l}\text { Remuneração } \\
\text { Variável }\end{array}$} & Geral & $-1,4117$ & 0,9314 & $-7,5200$ & $-0,1368$ & $\mathrm{~N}=760$ \\
\hline & Firmas & & 0,8117 & $-5,3227$ & $-0,3116$ & $\mathrm{n}=213$ \\
\hline & Períodos & & 0,4830 & $-5,9477$ & 2,2915 & $\overline{\mathrm{T}}=3,5681$ \\
\hline \multirow{3}{*}{$\begin{array}{l}\text { Outras } \\
\text { Remunerações e } \\
\text { Benefícios }\end{array}$} & Geral & $-2,1517$ & 1,2891 & $-8,3706$ & 0 & $\mathrm{~N}=467$ \\
\hline & Firmas & & 1,1553 & $-5,5502$ & $-0,1596$ & $\mathrm{n}=137$ \\
\hline & Períodos & & 0,6186 & $-5,3135$ & $-0,4791$ & $\overline{\mathrm{T}}=3,4088$ \\
\hline \multirow{3}{*}{ Remuneração Total } & Geral & 14,1048 & 0,9125 & 10,8413 & 17,2203 & $\mathrm{~N}=956$ \\
\hline & Firmas & & 0,8627 & 11,1277 & 16,5564 & $\mathrm{n}=239$ \\
\hline & Períodos & & 0,3013 & 12,3311 & 16,0463 & $\mathrm{~T}=4$ \\
\hline \multicolumn{7}{|c|}{ Amostra $2-$ Sem o setor Financeiro } \\
\hline \multirow{3}{*}{ Eficiência Técnica } & Geral & 0,6810 & 0,2335 & 0,00004 & 0,9747 & $\mathrm{~N}=856$ \\
\hline & Firmas & & 0,2307 & 0,00059 & 0,9682 & $\mathrm{n}=214$ \\
\hline & Períodos & & 0,0382 & 0,60016 & 0,7621 & $\mathrm{~T}=4$ \\
\hline \multirow{3}{*}{ Remuneração Fixa } & Geral & $-0,5514$ & 0,5295 & $-3,5120$ & 0 & $\mathrm{~N}=855$ \\
\hline & Firmas & & 0,4777 & $-2,7488$ & 0 & $\mathrm{n}=214$ \\
\hline & Períodos & & 0,2313 & $-1,8217$ & 1,1094 & $\overline{\mathrm{T}}=3,9953$ \\
\hline \multirow{3}{*}{$\begin{array}{l}\text { Remuneração } \\
\text { Variável }\end{array}$} & Geral & $-1,3894$ & 0,8869 & $-6,7626$ & $-0,1369$ & $\mathrm{~N}=682$ \\
\hline & Firmas & & 0,7934 & $-5,3227$ & $-0,3116$ & $\mathrm{n}=191$ \\
\hline & Períodos & & 0,4414 & $-4,0680$ & 2,3138 & $\overline{\mathrm{T}}=3,5707$ \\
\hline \multirow{3}{*}{$\begin{array}{l}\text { Outras } \\
\text { Remunerações e } \\
\text { Benefícios }\end{array}$} & Geral & $-2,2042$ & 1,2931 & $-8,3706$ & 0 & $\mathrm{~N}=430$ \\
\hline & Firmas & & 1,1561 & $-5,5502$ & $-0,1596$ & $\mathrm{n}=126$ \\
\hline & Períodos & & 0,6281 & $-5,3660$ & $-0,5317$ & $\overline{\mathrm{T}}=3,4127$ \\
\hline \multirow{3}{*}{ Remuneração Total } & Geral & 14,0884 & 0,8999 & 10,8413 & 17,2203 & $\mathrm{~N}=856$ \\
\hline & Firmas & & 0,8537 & 11,1277 & 16,5564 & $\mathrm{n}=214$ \\
\hline & Períodos & & 0,2892 & 12,5592 & 15,9200 & $\overline{\mathrm{T}}=4$ \\
\hline \multicolumn{7}{|c|}{ Amostra 3 - Setor industrial } \\
\hline \multirow{3}{*}{ Eficiência Técnica } & Geral & 0,6158 & 0,2430 & 0,0037 & 0,9705 & $\mathrm{~N}=688$ \\
\hline & Firmas & & 0,2429 & 0,0062 & 0,9679 & $\mathrm{n}=172$ \\
\hline & Períodos & & 0,0165 & 0,5842 & 0,6474 & $\mathrm{~T}=4$ \\
\hline \multirow{3}{*}{ Remuneração Fixa } & Geral & $-0,5061$ & 0,5234 & $-3,5120$ & 0 & $\mathrm{~N}=688$ \\
\hline & Firmas & & 0,4671 & $-2,7488$ & 0 & $\mathrm{n}=172$ \\
\hline & Períodos & & 0,2381 & $-1,7763$ & 1,1547 & $\mathrm{~T}=4$ \\
\hline \multirow{3}{*}{$\begin{array}{l}\text { Remuneração } \\
\text { Variável }\end{array}$} & Geral & $-1,4821$ & 0,9497 & $-6,7626$ & $-0,1369$ & $\mathrm{~N}=533$ \\
\hline & Firmas & & 0,8471 & $-5,3227$ & $-0,3477$ & $\mathrm{n}=151$ \\
\hline & Períodos & & 0,4747 & $-4,1607$ & 2,2211 & $\overline{\mathrm{T}}=3,5298$ \\
\hline \multirow{3}{*}{$\begin{array}{l}\text { Outras } \\
\text { Remunerações e } \\
\text { Benefícios }\end{array}$} & Geral & $-2,2816$ & 1,3366 & $-8,3706$ & $-0,0511$ & $\mathrm{~N}=328$ \\
\hline & Firmas & & 1,2259 & $-5,5502$ & $-0,1596$ & $\mathrm{n}=97$ \\
\hline & Períodos & & 0,5896 & $-5,4434$ & $-0,7827$ & $\overline{\mathrm{T}}=3,3814$ \\
\hline \multirow{3}{*}{ Remuneração Total } & Geral & 13,9981 & 0,9263 & 10,8413 & 17,2203 & $\mathrm{~N}=688$ \\
\hline & Firmas & & 0,8794 & 11,1277 & 16,5564 & $\mathrm{n}=172$ \\
\hline & Períodos & & 0,2966 & 12,4690 & 15,8298 & $\mathrm{~T}=4$ \\
\hline
\end{tabular}

Fonte: Elaboração própria com base nos dados do Economática ${ }^{\circledR}$ e Formulário de Referência. 
Em seguida, a Figura 10 apresenta o comportamento da eficiência técnica média e os quantis inferior (25\%), médio (50\%) e superior $(75 \%)$ ao longo do tempo das firmas.

Nota-se que em todas as amostras as quatro retas apresentam comportamento ascendente indicando que as firmas têm sido mais eficientes ao passar dos anos. Na amostra 1 (todos os setores), a eficiência média inicia no maior nível entre as amostras e possui inclinação mais semelhante ao quantil médio, enquanto que o quantil inferior apresenta maior aclive do que nas demais amostras, evidenciando o impacto da eficiência técnica das firmas do setor de finanças e seguros na amostra completa.

Na amostra 2 (sem o setor financeiro), a mediana (Quantil Médio) e a média também possuem tendências semelhantes, porém com uma maior distância entre as retas. $\mathrm{O}$ quantil inferior tem aclive mais acentuado e o quantil superior mais suave, de forma que todos se aproximam da mediana. Como a maioria das empresas encontra-se entre os quantis médio e inferior, pode-se afirmar que as firmas que eram menos eficientes em 2010 conseguiram maior aumento de eficiência do que as que se encontram acima da mediana.

Já na amostra 3 (restrita ao setor industrial), pode-se verificar que há um maior distanciamento entre o quantil médio e o superior evidenciando que as firmas possuem eficiências menos díspares. Percebe-se ainda que a reta da média inicia-se mais próxima da mediana do que na amostra 2 , porém o aclive da média é mais suave causando um distanciamento do quantil médio no longo prazo. 


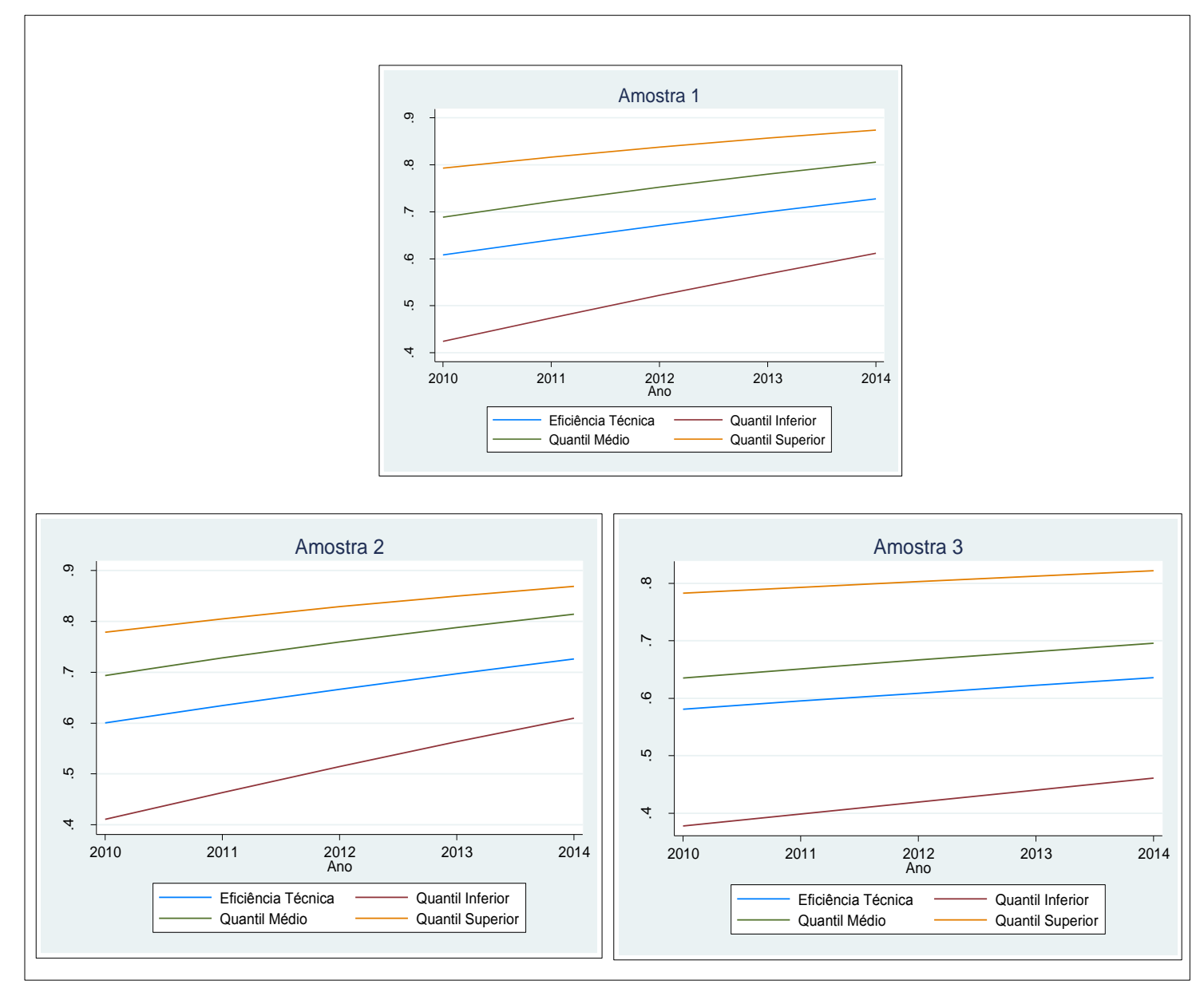

Figura 10 - Eficiência técnica média ao longo do tempo nas amostras 1, 2 e 3. 2010 a 2014 Fonte: Elaboração própria com base nos dados do Formulário de Referência.

A partir de então foi iniciada a análise dos pressupostos do modelo, com base nos resultados obtidos da estimação e testes apresentados na Tabela 14. Com relação às três amostras, o teste para Variance Inflation Factor ${ }^{17}$ (VIF) não apresenta evidências de multicolinearidade e os modelos funcionais foram estimados com uso da matriz robusta a heteroscedasticidade de Newey-West e com o estimador de Baltagi e Wu (1999) para painéis desbalanceados. Para o teste dos efeitos fixos vs. aleatórios foi utilizado o teste Sargan-Hansen como uma aplicação robusta do teste Hausman. ${ }^{18}$

\footnotetext{
${ }^{17}$ Fator de Inflação da Variância

${ }^{18}$ Para maiores informações acerca da aplicação e operacionalização deste teste, ver Schaffer e Stillman (2010).
} 
A Tabela 14 descreve a relação entre eficiência técnica e remuneração, por tipo de incentivo e nível de incentivos para as amostras 1, 2 e 3. Os resultados evidenciam que os padrões de remuneração na forma proposta pela CVM (remuneração fixa, remuneração variável e outras remunerações e benefícios) ${ }^{19}$, em seu Formulário de Referência, não influenciam o desempenho da organização, dada a não significância das variáveis Remuneração Fixa, Remuneração Variáveis e Outras Remunerações e Benefícios, levando a não-aceitação da Hipótese 2 desta tese.

O estudo de Baek e Pagán (2002) identificou uma relação significativa e negativa entre remuneração fixa e eficiência técnica, porém, as demais remunerações pecuniárias de curto prazo não foram significativas. Os próprios autores admitem que a relação negativa encontrada pode ser decorrente do foco no desempenho de curto prazo motivado por este incentivo. Já Yang e Régis (2011) encontraram relação significativa e positiva indicando que a remuneração fixa é utilizada pelas firmas e percebida pelos gestores como variável motivacional para se atingir as metas desempenho previamente estabelecidas. Nos resultados apresentados na Tabela 14, o sentido da relação embora tenha sido positivo para as três amostras (amostra $1=0,0048$; amostra $2=0,0042$; amostra $3=0,0059$ ), não foi estatisticamente significativo, impossibilitando maiores conclusões.

No que tange às outras remunerações e benefícios (incentivos de longo prazo), tanto o estudo de Baek e Pagán (2002) quanto o de Yang e Regis (2011) identificaram relações positivas e significativas com a eficiência técnica das firmas. Os resultados das estimações evidenciados na Tabela 14 mostram que no Brasil esta relação ainda não é identificada. Seguindo o raciocínio exposto por Yang e Regis (2011), acredita-se que estes achados podem ser decorrentes da cultura ainda não amplamente difundida, nas empresas analisadas, de utilizar este tipo de incentivo (ver Tabela 3), que não geraria o efeito motivacional esperado no curto prazo.

Por outro lado, o nível de remuneração (especificado na equação 19) foi estatisticamente significativo a $1 \%$ (amostra $1=0,0201$; amostra $2=0,0229$; amostra 3 =0,0025), semelhantemente aos resultados encontrados por Baek e Pagán (2002), o que permite inferir que, no que concerne aos incentivos pecuniários concedidos aos executivos de firmas listadas na BM\&FBOVESPA, apenas o volume total pago influencia o desempenho, não importando os tipos de incentivos pecuniários

\footnotetext{
${ }^{19} \mathrm{O}$ detalhamento de cada tipo de remuneração foi apresentado no Quadro 3.
} 
propiciados. Cabe ressaltar que o valor absoluto do estimador do nível de incentivo para a amostra 3 foi baixo, evidenciando que apesar da variável ser significativa, seu impacto na eficiência técnica é bastante reduzido.

O estudo de Yang e Regis (2011) indica que a estrutura de compensação seria determinante da eficiência técnica das firmas, em detrimento da estrutura de propriedade medida pelo controle estatal. Os resultados obtidos nesta tese concordam parcialmente com os de Yang e Regis (2011), pois tanto a estrutura de propriedade quanto a de compensação não apresentaram relação significativa com a eficiência técnica das firmas brasileiras.

O objetivo da inserção da variável dummy acerca do controle estatal nas firmas listadas na BM\&FBOVESPA ( C $_{\text {ClEst }}$ it $)$ foi controlar possíveis efeitos decorrentes de restrições ao valor máximo pago a executivos de organizações governamentais, dado que tais incentivos possuem limitação legal no Brasil, no entanto, como já mencionado, os resultados não apresentam evidências de que este fato cause impacto na eficiência técnica das firmas testadas.

As variáveis dummy de controle setorial ( Dsetor $_{i t}$ ) foram estimadas apenas nos modelos que analisam o nível de incentivos, devido a problemas com multicolinearidade perfeita no modelo que trata dos tipos de incentivos. Para as amostras 1 e 2 as dummies setoriais foram significativas apenas para os seguintes setores: Construção (+), Minerais não Metálicos (+), Química (-), Telecomunicações (-) e Têxtil (+). Enquanto que para a amostra 3: Alimentos e Bebidas (+), Construção (+), Minerais não Metálicos (+), Química (-) e Têxtil (+). Por fim, ressalta-se que os setores que foram significativos nas três estimações também mantiveram o sentido da relação. 
Tabela 14 - Relação entre eficiência técnica e remuneração, por tipo de incentivo e nível de incentivo nas amostras 1, 2 e 3.2011 a 2014

\begin{tabular}{|c|c|c|c|c|c|c|}
\hline \multirow{2}{*}{ Variável } & \multicolumn{2}{|c|}{$\begin{array}{c}\text { Amostra } 1 \\
\text { (Todos os setores) } \\
\end{array}$} & \multicolumn{2}{|c|}{$\begin{array}{c}\text { Amostra } 2 \\
\text { (Sem o setor financeiro) }\end{array}$} & \multicolumn{2}{|c|}{$\begin{array}{c}\text { Amostra } 3 \\
\text { (Setor industrial) } \\
\end{array}$} \\
\hline & $\begin{array}{l}\text { Tipos de } \\
\text { Incentivo }\end{array}$ & $\begin{array}{l}\text { Nível de } \\
\text { Incentivo }\end{array}$ & $\begin{array}{l}\text { Tipos de } \\
\text { Incentivo }\end{array}$ & $\begin{array}{l}\text { Nível de } \\
\text { Incentivo }\end{array}$ & $\begin{array}{l}\text { Tipos de } \\
\text { Incentivo }\end{array}$ & $\begin{array}{c}\text { Nível de } \\
\text { Incentivo }\end{array}$ \\
\hline Remuneração fixa & 0,0048 & - & 0,0042 & - & 0,0059 & - \\
\hline Remuneração variável & $-0,0046$ & - & $-0,0052$ & - & $-0,0034$ & - \\
\hline Outras remunerações & $-0,0017$ & - & $-0,0029$ & - & $-0,0020$ & - \\
\hline Remuneração total & - & $0,0201 * * *$ & - & $0,0229 * * *$ & - & $0,0025 * * *$ \\
\hline Controle Estatal & 0,0189 & 0,0115 & $-0,0029$ & 0,0148 & $-0,0025$ & 0,0052 \\
\hline Finanças e seguros & - & 0,0755 & - & - & - & - \\
\hline Agropecuária e pesca & - & $-0,0727$ & - & $-0,0751$ & - & $-0,0318$ \\
\hline Alimentos e bebidas & - & 0,0954 & - & 0,0866 & - & $0,1252 *$ \\
\hline Comércio & - & 0,0679 & - & 0,0627 & - & - \\
\hline Construção & - & $0,1104 * *$ & - & $0,1100 * *$ & - & $0,1000^{*}$ \\
\hline Eletroeletrônicos & - & 0,0817 & - & 0,0796 & - & 0,1017 \\
\hline Energia elétrica & - & 0,0143 & - & 0,0128 & - & 0,0225 \\
\hline Máquinas industriais & - & 0,0680 & - & 0,0678 & - & 0,0370 \\
\hline Mineração & - & 0,0471 & - & 0,0209 & - & 0,1167 \\
\hline Minerais não metálicos & - & $0,1730 * * *$ & - & $0,1701 * * *$ & - & $0,2382 * * *$ \\
\hline Papel e celulose & - & 0,0722 & - & 0,0664 & - & 0,1352 \\
\hline Petróleo e gás & - & $-0,1033$ & - & $-0,0723$ & - & $-0,0946$ \\
\hline Química & - & $-0,1969 *$ & - & $-0,2058 *$ & - & $-0,2179 *$ \\
\hline Siderurgia e metalurgia & - & 0,0417 & - & 0,0465 & - & $-0,0077$ \\
\hline Software e dados & - & 0,0682 & - & 0,0807 & - & 0,0912 \\
\hline Telecomunicações & - & $-0,4884 * * *$ & - & $-0,4855 * * *$ & - & - \\
\hline Têxtil & - & $0,1249 * *$ & - & $0,1246 * *$ & - & $0,1398 * *$ \\
\hline Transporte e serviços & - & 0,0461 & - & 0,0401 & - & - \\
\hline Veículos & - & 0,0012 & - & $-0,0049$ & - & 0,0432 \\
\hline Imobiliária & - & $-0,0119$ & - & $-0,0342$ & - & - \\
\hline Constante & $0,6948 * * *$ & $0,3676 * * *$ & $0,3609 * * *$ & $0,3332 * * *$ & $0,6360 * * *$ & $0,5384 * * *$ \\
\hline $\begin{array}{l}\text { Observações } \\
\mathrm{R}^{2}\end{array}$ & $\begin{array}{c}429 \\
0,0073 \\
\end{array}$ & $\begin{array}{c}956 \\
0,0277 \\
\end{array}$ & $\begin{array}{c}398 \\
0,0138 \\
\end{array}$ & $\begin{array}{c}856 \\
0,0308 \\
\end{array}$ & $\begin{array}{c}172 \\
0,4319 \\
\end{array}$ & $\begin{array}{c}172 \\
0,4319 \\
\end{array}$ \\
\hline $\begin{array}{l}\text { Teste Sargan-Hansen } \\
X^{2} \\
p \text {-value }\end{array}$ & $\begin{array}{l}17,191 \\
0,0018\end{array}$ & $\begin{array}{c}0,572 \\
0,7513\end{array}$ & $\begin{array}{c}20,24 \\
0,0004\end{array}$ & $\begin{array}{c}0,183 \\
0,9125\end{array}$ & $\begin{array}{l}16,798 \\
0,0021\end{array}$ & $\begin{array}{c}0,941 \\
0,6246\end{array}$ \\
\hline
\end{tabular}

Fonte: Elaboração própria com base nos dados do Economática ${ }^{\circledR}$ e Formulário de Referência.

Nível de significância: $* * *<1 \%$; $* *<5 \%$; $* 10 \%$. 


\subsection{Sensibilidade da Remuneração aos Incentivos}

Esta seção objetiva testar a Hipótese 3 que investiga se os incentivos pecuniários pagos a executivos possuem relação significativa e positiva com a eficiência técnica da firma. Neste sentido, foi elaborada a Tabela 15 que apresenta uma estatística descritiva da variação da remuneração média total e tamanho das firmas, variáveis de interesse da equação 20. Antes de começar a interpretar os resultados, é importante lembrar que as proxies de variação da remuneração e de tamanho têm seus dados transformados em logaritmos naturais.

Através das informações da Tabela 15 pode-se inferir que para as amostras 2 e 3 a variação da remuneração não aparenta possuir persistência ao longo do tempo, conforme observada em Conyon (1997), pois o desvio-padrão desta variação é maior entre os anos, do que entre os indivíduos. Porém, observa-se uma redução do desviopadrão entre os anos considerando apenas as indústrias (amostra 3) e um aumento considerando apenas a amostra 1. Estes dados podem representar o viés do setor financeiro dentro da amostra ou mesmo uma inversão na tendência da persistência.

Quanto ao tamanho das firmas, medido pelo ativo total, verifica-se que a distinção entre as firmas tende a permanecer com o passar dos anos em todas as amostras $($ amostra 1: geral $=1,8170$ e entre indivíduos $=1,8130 ;$ amostra 2 : geral $=$ 1,6737 e entre indivíduos $=1,6685$; amostra 3: geral $=1,7213$ e entre indivíduos $=$ 1,7163), haja visto que o desvio padrão geral é muito próximo do desvio padrão entre indivíduos, enquanto que o desvio padrão entre os anos é significativamente menor. 
Tabela 15 - Sumário da variação da remuneração total e tamanho das firmas das amostras 1, 2 e 3. 2012 a 2014

\begin{tabular}{|c|c|c|c|c|c|c|}
\hline \multicolumn{2}{|l|}{ Variável } & Média & $\begin{array}{l}\text { Desvio } \\
\text { Padrão }\end{array}$ & Mínimo & Máximo & Observações \\
\hline \multicolumn{7}{|c|}{ Amostra 1 - Todos os setores } \\
\hline \multirow{3}{*}{$\begin{array}{l}\text { Variação da } \\
\text { remuneração total em } t\end{array}$} & Geral & 0,0007 & 1,2442 & $-3,8994$ & 4,8163 & $\mathrm{~N}=717$ \\
\hline & Indivíduos & & 0,9926 & $-3,1834$ & 3,0958 & $\mathrm{n}=239$ \\
\hline & Anos & & 0,7521 & $-2,5230$ & 2,7127 & $\mathrm{~T}=3$ \\
\hline \multirow{3}{*}{$\begin{array}{l}\text { Variação da } \\
\text { remuneração total em } t-1\end{array}$} & Geral & $-0,0006$ & 1,2438 & $-3,8994$ & 4,8163 & $\mathrm{~N}=717$ \\
\hline & Indivíduos & & 0,6918 & $-2,2620$ & 1,8481 & $\mathrm{n}=239$ \\
\hline & Anos & & 1,0343 & $-3,3820$ & 3,5665 & $\mathrm{~T}=3$ \\
\hline \multirow{3}{*}{ Tamanho } & Geral & 15,1023 & 1,8170 & 10,3927 & 21,0862 & $\mathrm{~N}=717$ \\
\hline & Indivíduos & & 1,8130 & 10,5334 & 21,0405 & $\mathrm{n}=239$ \\
\hline & Anos & & 0,1540 & 13,5605 & 15,9556 & $\mathrm{~T}=3$ \\
\hline \multicolumn{7}{|c|}{ Amostra $2-$ Sem o setor financeiro } \\
\hline \multirow{3}{*}{$\begin{array}{l}\text { Variação da } \\
\text { remuneração total em } t\end{array}$} & Geral & 0,0222 & 0,4276 & $-2,4873$ & 3,1594 & $\mathrm{~N}=642$ \\
\hline & Indivíduos & & 0,1993 & $-0,7336$ & 1,1533 & $\mathrm{n}=214$ \\
\hline & Anos & & 0,3784 & $-2,5661$ & 2,0617 & $\mathrm{~T}=3$ \\
\hline \multirow{3}{*}{$\begin{array}{l}\text { Variação da } \\
\text { remuneração total em } t-1\end{array}$} & Geral & 0,0453 & 0,4025 & $-2,4873$ & 2,9058 & $N=642$ \\
\hline & Indivíduos & & 0,1896 & $-0,5973$ & 0,9162 & $\mathrm{n}=214$ \\
\hline & Anos & & 0,3551 & $-1,8448$ & 2,2609 & $\mathrm{~T}=3$ \\
\hline \multirow{3}{*}{ Tamanho } & Geral & 14,8827 & 1,6737 & 10,3927 & 20,5030 & $N=642$ \\
\hline & Indivíduos & & 1,6685 & 10,5334 & 20,4829 & $\mathrm{n}=214$ \\
\hline & Anos & & 0,1608 & 13,3410 & 15,7361 & $\mathrm{~T}=3$ \\
\hline \multicolumn{7}{|c|}{ Amostra 3 - Setor industrial } \\
\hline \multirow{3}{*}{$\begin{array}{l}\text { Variação da } \\
\text { remuneração total em } t\end{array}$} & Geral & 0,0157 & 0,4460 & $-2,4873$ & 3,1594 & $\mathrm{~N}=516$ \\
\hline & Indivíduos & & 0,2072 & $-0,7336$ & 1,1533 & $\mathrm{n}=172$ \\
\hline & Anos & & 0,3951 & $-2,5727$ & 2,0552 & $\mathrm{~T}=3$ \\
\hline \multirow{3}{*}{$\begin{array}{l}\text { Variação da } \\
\text { remuneração total em } t-1\end{array}$} & Geral & 0,0341 & 0,4137 & $-2,4873$ & 2,9058 & $\mathrm{~N}=516$ \\
\hline & Indivíduos & & 0,1969 & $-0,5973$ & 0,9162 & $\mathrm{n}=172$ \\
\hline & Anos & & 0,3640 & $-1,8560$ & 2,2497 & $\mathrm{~T}=3$ \\
\hline \multirow{3}{*}{ Tamanho } & Geral & 14,7869 & 1,7213 & 10,3927 & 2,5030 & $N=516$ \\
\hline & Indivíduos & & 1,7163 & 10,5334 & 20,4829 & $\mathrm{n}=172$ \\
\hline & Anos & & 0,1695 & 13,2451 & 15,6402 & $\mathrm{~T}=3$ \\
\hline
\end{tabular}

Fonte: Elaboração própria com base nos dados do Economática® e Formulário de Referência.

A estimação do modelo descrito na equação 20 , que investiga a influência da eficiência técnica na variação da remuneração, passou inicialmente por testes de pressupostos para verificar sua consistência. Para ambas as amostras 2 e 3 o teste de Hausman indica que o modelo preferido é o de efeitos fixos, enquanto que para a amostra 1 é o de efeitos aleatórios. O teste VIF não evidencia presença de 
multicolinearidade em nenhuma das amostras. Além disso, o modelo foi estimado com uso da matriz Newey-West, robusta a heteroscedasticidade. ${ }^{20}$

A Tabela 16 descreve a sensibilidade da variação da remuneração total à eficiência técnica nas amostras 1, 2 e 3. Os resultados mostram que não se pode aceitar a Hipótese 3 da pesquisa na qual os incentivos pecuniários pagos aos executivos possuem relação estatisticamente significativa e positiva com a eficiência técnica da firma, dado que seus coeficientes estimados não foram significativos (amostra 1 = 0,0444; amostra $2=-0,1240 ;$ amostra 3: -0,7204).

A não identificação de relação entre o desempenho organizacional, medido pela eficiência técnica, e a variação da remuneração total reflete o impacto da remuneração fixa na motivação dos executivos discutida na seção 4.3. Se os gestores possuem como principal forma de incentivo a remuneração fixa que, por sua vez, não apresenta uma relação estatisticamente significativa com o desempenho organizacional (Tabela 14), e, admitindo que esta forma de incentivo contempla um compartilhamento de riscos entre agente e principal, então é de se esperar que a variação da remuneração total tenha uma relação de menor significância estatística com a eficiência técnica da organização.

Deve-se considerar, contudo, que os resultados demonstrados na Tabela 14 e na Tabela 16 podem ser decorrentes de má especificação do modelo (possível falta de variáveis explicativas que melhor representem o comportamento da variação da remuneração total), embora sejam consistentes com os de Dalmacio, Rezende e Slomski (2009) que afirmam que na maioria dos setores do mercado brasileiro o desempenho das firmas estaria mais associado ao desempenho do seu respectivo setor, sugerindo que as firmas não incorporariam o desempenho organizacional na fórmula de incentivos aos executivos.

A priorização dada à remuneração fixa também pode ser percebida como um entendimento geral de que a fórmula de incentivos não precisaria dar um maior enfoque no desempenho organizacional. Se isto é um fator real, então a motivação do agente em atingir o resultado esperado não estaria sendo uma preocupação do principal acerca de possíveis conflitos de agência ou assimetrias informacionais. Se por um lado uma remuneração fixa alta, em comparação com os demais tipos de remuneração, poderia ser um fator útil para reter talentos no curto prazo, por outro lado pode gerar desmotivação

\footnotetext{
${ }^{20}$ Ver APÊNDICE C - TESTES DOS PRESSUPOSTOS DAS EQUAÇÕES 20 E 21.
} 
no longo prazo, o que comprometeria a relação entre a utilidade esperada e a efetivamente obtida pelo agente.

Assumindo então que a eficiência técnica não tenha influência sobre a remuneração dos gestores, seria possível inferir que a definição da fórmula de incentivo aos executivos tem sido mais influenciada por fatores distintos do próprio desempenho da firma. A Tabela 16 mostra que a variação da remuneração em t-1 tem relação significativa a $1 \%$, porém com sinal negativo (todos os setores $=-0,4833$; sem o setor financeiro $=-0,5376$; setor industrial $=-0,5594)$. Isto indica que se o agente obteve uma alta variação da remuneração em $\mathrm{t}-1$, esta variação tende a ser controlada em $\mathrm{t}$ reduzindo a variação da remuneração neste último período.

O estudo de Conyon (1997) evidenciou resultados opostos para firmas listadas na Bolsa de Londres, identificando uma relação positiva entre a variação da remuneração em t e sua defasagem em 1 período e interpretando estes resultados como uma persistência da remuneração. Partindo-se deste raciocínio pode-se afirmar, então, que nas firmas listadas na BM\&FBOVESPA não há tal persistência e que isso pode ser fruto da própria cultura de incentivos praticada no mercado brasileiro.

Ressalta-se ainda que na análise dos resultados estimados para a amostra completa a variável tamanho foi significativa $(0,2967)$, indicando uma possível interferência do setor de finanças e seguros na amostra. Observe que o setor de finanças e seguros foi significativo a $5 \%(-0,5555)$ na amostra 1 , mas que quando foi retirado da amostra (amostra 2), a variável tamanho deixou de ser significativa. 
Tabela 16 - Sensibilidade da variação da remuneração total ao desempenho organizacional das amostras 1,2 e 3.2012 a 2014

\begin{tabular}{|c|c|c|c|}
\hline Variável & $\begin{array}{c}\text { Amostra 1 } \\
\text { (Todos os setores) } \\
\end{array}$ & $\begin{array}{c}\text { Amostra } 2 \\
\text { (Sem o setor financeiro) }\end{array}$ & $\begin{array}{c}\text { Amostra } 3 \\
\text { (Setor industrial) }\end{array}$ \\
\hline Eficiência Técnica & $-0,0444$ & $-0,1240$ & $-0,7204$ \\
\hline Variação da remuneração em $t-1$ & $-0,4833 * * *$ & $-0,5376 * * *$ & $-0,5594 * * *$ \\
\hline 2013 & $-0,0036$ & 0,0097 & $-0,0163$ \\
\hline 2012 & 0,0038 & 0,0034 & $-0,0396$ \\
\hline Tamanho & $0,2967 * * *$ & 0,1840 & 0,1255 \\
\hline Finanças e seguros & $-0,5555 * *$ & - & - \\
\hline Agropecuária e pesca & $-0,0197$ & - & - \\
\hline Alimentos e bebidas & $-0,0665$ & - & - \\
\hline Comércio & 0,1953 & - & - \\
\hline Construção & $-0,3920 *$ & - & - \\
\hline Eletroeletrônicos & 0,0165 & - & - \\
\hline Energia elétrica & $-0,7779 * * *$ & - & - \\
\hline Máquinas industriais & $-0,9623 * *$ & - & - \\
\hline Mineração & 0,3144 & - & - \\
\hline Minerais não metálicos & 0,3384 & - & - \\
\hline Papel e celulose & 0,2545 & - & - \\
\hline Petróleo e gás & $-0,4309$ & - & - \\
\hline Química & 0,0374 & - & - \\
\hline Siderurgia e metalurgia & $-0,0320$ & - & - \\
\hline Software e dados & 0,0748 & - & - \\
\hline Telecomunicações & $-0,6511$ & - & - \\
\hline Têxtil & $-0,5425^{* *}$ & - & - \\
\hline Transporte e serviços & 0,0565 & - & - \\
\hline Veículos & $-0,0380$ & - & - \\
\hline Imobiliária & 0,3682 & - & - \\
\hline Constante & $-4,2750 * * *$ & $-2,7569$ & $-2,2469$ \\
\hline Número de Observações & 717 & 642 & 516 \\
\hline $\mathrm{R}^{2}$ & 0,4603 & 0,2626 & 0,2780 \\
\hline $\mathrm{F}$ & - & 15,03 & 26,11 \\
\hline Prob $>$ F & - & 0,0000 & 0,0000 \\
\hline
\end{tabular}

Fonte: Elaboração própria com base nos dados do Economática ${ }^{\circledR}$ e Formulário de Referência. Nível de significância: $* * *<1 \%$; $* *<5 \%$; $*<10 \%$.

Outro fator que pode ter influenciado os resultados obtidos é a dificuldade de se ajustar a remuneração fixa à variação do desempenho organizacional (MERCHANT; STEDE, 2012), haja visto que este incentivo pode estar sujeito a restrições legais (por exemplo, a legislação trabalhista no Brasil regula a redução do salário de funcionários), e a possibilidade de fatores incontroláveis ocorrerem de forma a melhorar o desempenho organizacional incorporaria uma obrigação recorrente da firma.

Essa assimetria informacional tende a beneficiar mais os executivos à medida que seus conhecimentos, ou a área de atuação da firma, sejam mais específicos, dificultando que as empresas tenham comparações no mercado para seu desempenho, ou para o seu gestor (TAYLOR, 1994). Por outro lado, a variação da remuneração fixa poderia incorporar fatores de desempenho organizacional, conforme enfatizado por 
Deegan (1997), porém, nos mercados em que os gestores preferem este tipo de incentivo, como é o caso brasileiro (DALMACIO; REZENDE; SLOMSKI, 2009), espera-se que tal variação seja decorrente, dentre outros fatores, de acordos com sindicatos e ajustes da inflação e da média de mercado. Logo, fatores que não incorporam o desempenho organizacional, mas que funcionam como retenção de profissionais de maior qualidade (LAWLER, 1983).

Essa discussão não conclui que as empresas participantes da BM\&FBOVESPA não utilizam incentivos pecuniários como instrumentos motivacionais dos seus executivos, mas sim que é uma característica do mercado brasileiro a não utilização da remuneração fixa com o intuito de direcionar os esforços do agente, e sim outros objetivos como atração e retenção de indivíduos de quem se espera entregar maior valor agregado à organização. Consequentemente, as relações identificadas por Conyon (1997) no mercado britânico não ocorrem no mercado brasileiro. Isto, porém, não exclui o uso de outros incentivos pecuniários para fins de motivação.

Dados os resultados evidenciados na Tabela 16, realizou-se testes adicionais na tentativa de expurgar os efeitos que a remuneração fixa poderia exercer nas relações obtidas. Desta forma, a equação 20 foi reelaborada no intuito de capturar apenas os efeitos do desempenho organizacional sobre a remuneração variável haja visto que a literatura pressupõe uma relação estreita entre estas duas últimas variáveis (HEALY, 1985; DEEGAN, 1997; MERCHANT; STEDE, 2012). Para tanto, o seguinte modelo funcional foi proposto:

$R V_{i t}=\delta_{0}+\delta_{1} R V_{i t-1}+\delta_{2} E T_{i t}+\delta_{3}$ Dsetor $_{i t}+\delta_{4}$ DTempo $_{i}+\delta_{5}$ Tam $_{i t}+\varepsilon_{i t}$

Onde, $R V_{i t}$ é o logaritmo natural da remuneração variável da firma $i$ no período $t ; R V_{i t-1}$ é o logaritmo natural da remuneração variável da firma $i$ no período $t-1 ; E T_{i t}$ é o logaritmo natural da eficiência técnica estimada da firma $i$ no período $t$, Dsetor representa o vetor de variáveis dummies setoriais que assumem valor 1 para determinado setor e 0 para os demais; DTempo representa o vetor de variáveis dummies temporais para cada ano inserido na análise dos dados, assumindo valor 1 para determinado ano e 0 para os demais; e Tam $_{i t}$ é uma variável de controle que representa o porte da firma e é medida pelo logaritmo natural do ativo total da firma $i$ no ano $t$. 
A estimação do modelo predito na equação 21 tem seus resultados apresentados na Tabela 17. O teste de Hausman indica que não se pode rejeitar a hipótese de efeitos fixos para as três amostras, o teste VIF indica a não ocorrência de multicolinearidade, e o modelo foi estimado com matriz robusta a heteroscedasticidade e autocorrelação dos resíduos. A defasagem da remuneração variável fez com que os anos de 2010 e 2011 fossem excluídos da análise. Como existem firmas que não utilizam a remuneração variável no pacote de incentivos aos seus executivos (ver Tabela 3), o painel foi desbalanceado. Ademais, algumas variáveis foram omitidas em decorrência de colinearidade perfeita na estimação do modelo com efeitos fixos (Dsetor ${ }_{i t}$ e DTempo para 2011), enquanto que a variável tamanho $\left(\operatorname{Tam}_{i t}\right)$ apresentou valor VIF alto e foi excluída do modelo operacionalizado a fim de eliminar a multicolinearidade existente. Os testes de pressupostos de MQO são apresentados no Apêndice C.

A Tabela 17 descreve a sensibilidade da remuneração variável ao desempenho organizacional nas amostras 1, 2 e 3 . Os resultados mostram que apenas na amostra sem o setor financeiro a eficiência técnica da firma é significativa a 10\% (1,1888), logo, nestas firmas, a remuneração variável dos executivos seria influenciada pelo desempenho organizacional. O nível de significância relativamente baixo pode ter sido influenciado pelo fato de que a eficiência técnica representa também o desempenho de longo prazo enquanto que a remuneração variável é reconhecidamente ligada à motivação de curto prazo dos indivíduos (DEEGAN; 1997; AGUIAR, 2009; MERCHANT; STEDE, 2012).

Os resultados para a amostra 1 e para a amostra 3 não indicam relação entre a eficiência técnica e a remuneração variável (0,7065 e 1,6117, respectivamente), corroborando os resultados obtidos anteriormente na Tabela 16. Como a significância da relação na amostra 2 é baixa, e nas amostras 1 e 3 não foi identificada relação estatisticamente significativa, rejeita-se a hipótese 3 da pesquisa de que os incentivos pecuniários seriam sensíveis à eficiência técnica da firma.

De forma similar aos resultados obtidos na Tabela 16, a remuneração defasada possui relação significativa e negativa (amostra $1=-0,1967$; amostra $2=-0,1645$; amostra $3=-0,1310)$, o que representa o ajuste que os principais realizam após o pagamento da remuneração variável aos agentes com o intuito de controlar as variações das remunerações pagas aos executivos, exercendo então um controle discricionário dos incentivos. Deegan (1997) afirma que os ajustes objetivam controlar a assimetria 
informacional decorrente do nível de especificidade da função e conhecimento do negócio que os executivos detêm além dos demais interessados no desempenho organizacional. Logo, pode-se afirmar que não há persistência da remuneração dos executivos das empresas listadas na BM\&FBOVESPA, diferentemente do encontrado por Conyon (1997) no mercado britânico.

Tabela 17 Sensibilidade da remuneração variável ao desempenho organizacional das amostras 1, 2 e 3. 2012 a 2014

\begin{tabular}{lccc}
\hline \multicolumn{1}{c}{ Variável } & $\begin{array}{c}\text { Amostra 1 } \\
\text { (Todos os setores) }\end{array}$ & $\begin{array}{c}\text { Amostra 2 } \\
\text { (Sem o setor financeiro) }\end{array}$ & $\begin{array}{c}\text { Amostra 3 } \\
\text { (Setor industrial) }\end{array}$ \\
\hline Eficiência Técnica & 0,7065 & $0,8550^{*}$ & 1,6117 \\
Variação da remuneração em $t-1$ & $-0,19967^{* * *}$ & $-0,1645^{* * *}$ & $-0,1310^{* *}$ \\
2013 & $-0,0560$ & $-0,0771$ & $-0,0902$ \\
2012 & $-0,0653$ & $-0,0685$ & $-0,0382$ \\
Constante & $17,9389 * * *$ & $1,1888^{*}$ & $17,3492^{* * *}$ \\
\hline Número de observações & 516 & 446 & 361 \\
$\mathrm{R}^{2}$ & 0,0626 & 0,1147 & 0,0412 \\
$\mathrm{~F}$ & 5,41 & 8,94 & 2,42 \\
Prob > F & 0,0000 & 0,0000 & 0,0495 \\
\hline
\end{tabular}

Fonte: Elaboração própria com base nos dados do Economática® e Formulário de Referência. Nível de significância: $* * *<1 \%$; $* *<5 \%$; $*<10 \%$.

Percebe-se, ao final das análises, que as relações esperadas entre a eficiência técnica e os incentivos pecuniários pagos aos executivos não ocorrem em todas as formas propostas nos modelos utilizados neste estudo. Especificamente quanto ao efeito motivacional, identificou-se que apenas o nível dos incentivos pagos possui relação com a eficiência estimada enquanto que os tipos de incentivos não são significativos. A análise do fechamento do ciclo motivação-desempenho também não identificou nenhuma relação significativa entre a eficiência técnica estimada das firmas e os incentivos pagos, seja na forma da variação da remuneração total ou da remuneração variável. Entende-se, por fim, que a forma como a política de remuneração é praticada nas empresas listadas na BM\&FBOVESPA, utilizando maior foco na remuneração fixa, pode ter influenciado para que os resultados fossem distintos dos já encontrados em outros mercados, como o chinês e o britânico. 


\section{CONCLUSÕES}

A discussão acerca de remuneração a executivos no mercado brasileiro é um tema relativamente recente que ganhou força a partir da obrigatoriedade de prestação de informações por meio do Formulário de Referência da CVM ocorrida em 2009. Somese a isso, a disponibilidade de dados em mercados mais desenvolvidos que tem colaborado não apenas para o desenvolvimento de pesquisas acadêmicas, mas também para a própria regulação do mercado.

Nesse contexto, o presente trabalho baseou-se nos estudos de Jensen e Murphy (1990), Conyon (1997) e Baek e Pagán (2002), buscando aplicar métodos similares às empresas participantes do mercado brasileiro, além de agregar diferenciais que tais estudos não possuíam. Os diferenciais da presente tese residem na: (i) utilização da eficiência técnica estimada como medida de desempenho organizacional; (ii) análise de como o nível e os tipos de incentivos (seguindo a classificação proposta pela CVM) poderiam influenciar os resultados auferidos por uma firma em determinado ano, a partir do enfoque motivacional apresentado por Masson (1971) e Pennings (1993), e; (iii) estimação de uma fronteira estocástica de eficiência para as empresas listadas na BM\&FBOVESPA. A amostra do estudo foi composta inicialmente por 239 empresas em 5 anos, totalizando 1.195 dados (considerando todas as variáveis utilizadas), o que caracteriza um diferencial em relação aos estudos acerca da remuneração a executivos no mercado brasileiro, como os de Aguiar (2009), Krauter (2009) e Santos (2012).

O desenvolvimento metodológico foi baseado a partir de três pressupostos: i) o indivíduo é motivado e, em seguida, exerce o esforço para atingir determinado resultado; ii) diferentes tipos de incentivos geram diferentes motivações e, ao estarem disponibilizados conjuntamente, devem controlar de forma mais eficaz as ações do agente; e iii) individualmente, a eficiência técnica estimada é uma medida mais apropriada do que qualquer outro indicador de desempenho por conseguir incorporar prospectos razoáveis do desempenho de longo prazo (BAEK; PAGÁN, 2002) e determinar intrinsecamente os valores de equilíbrio de um conjunto de variáveis endógenas, como produtividade, lucratividade e preço da ação (YANG; RÉGIS, 2011).

Desta forma, o objetivo desta tese foi investigar a relação entre a eficiência técnica das firmas e a motivação dos executivos através dos incentivos concedidos. Para 
estimar a eficiência técnica de cada firma foi aplicado o modelo de fronteira estocástica de eficiência desenvolvido por Baek e Pagán (2002) a partir das definições gerais estabelecidas por Battese e Coelli (1995). A proxy utilizada para capturar tais recursos foi a receita líquida anual.

Para a Hipótese 1, referente às firmas aumentarem sua eficiência técnica ao passar dos anos, a estimação da fronteira de eficiência permitiu constatar que as firmas investigadas têm aumentado sua eficiência técnica ao longo dos anos, indicando que a Hipótese 1 não deve ser rejeitada. Outro achado relevante desta análise está na relação das variáveis de interesse com o nível de eficiência de cada firma. Tanto o capital quanto a mão-de-obra apresentaram relações lineares com a produção de receita, porém, a mão-de-obra teve sinal negativo. Complementarmente, apenas a mão-de-obra contém relação não-linear com o produto gerado, logo a relação linear com sentido invertido pode ser decorrente de uma curva de aprendizagem.

Para a Hipótese 2, que analisa o efeito motivacional que os tipos e nível de incentivos pecuniários exercem sobre os executivos, foram utilizados incentivos defasados em relação ao desempenho organizacional, além de algumas variáveis de controle (dummies de setor, dummies de tempo e tamanho da firma). Os testes complementares indicaram que a inclusão do setor de Finanças e Seguros e do setor industrial poderia enviesar os resultados, culminando com o desenvolvimento das análises para três amostras distintas, com base nos setores de atuação das companhias. Como a fronteira estocástica foi elaborada, inicialmente, para empresas industriais, e os testes de média indicaram diferença entre a eficiência de empresas industriais e de uma amostra maior incluindo setores de serviços e comércio, decidiu-se analisar tanto a amostra completa com todos os setores (amostras 1) quanto as amostras sem o setor financeiro (amostra 2) e apenas com indústrias (amostra 3). Os resultados indicaram que a utilização do controle estatal como variável de controle não apresentou resultados significativos. Inicialmente, acreditou-se que as limitações quanto ao teto de remuneração existentes no setor público brasileiro pudessem exercer algum efeito, no entanto, este pressuposto foi refutado nas análises subsequentes. Quanto ao controle setorial, apenas quatro setores mostraram-se relevantes para as três amostras analisadas: Construção (+), Minerais não Metálicos (+), Química (-) e Têxtil (+)

Ainda acerca da análise da Hipótese 2, os tipos de incentivos, como variável motivadora, acompanharam a classificação prevista no Formulário de Referência da 
CVM, a saber: Remuneração Fixa, Remuneração Variável e Outras Remunerações e Benefícios. Destas, apenas a última contempla incentivos que, de acordo com a literatura, deveriam exercer motivação para resultados organizacionais de longo prazo. Inicialmente, foi desenvolvida uma análise de dados em painel com os tipos de incentivo sendo variáveis preditivas do desempenho organizacional, entretanto, nenhuma variável obteve resultados estatisticamente significativos. Logo, rejeita-se a Hipótese 2 de pesquisa de que a diversificação dos incentivos possui relação positiva e significativa com o desempenho organizacional

Os resultados acerca da relação da eficiência técnica com o nível de incentivo, medido pela remuneração total média auferida pela Diretoria Executiva da firma, evidenciaram resultados semelhantes para as variáveis de controle (dummies de setor, dummies de tempo e tamanho da firma), porém significativos para o nível de incentivos. Pode-se concluir, no que tange aos incentivos pecuniários, que apenas o nível de incentivos pago tem exercido efeito motivacional. Este achado pode ser decorrente de uma característica das fórmulas de remuneração concedidas pelas empresas investigadas, que priorizam o uso da Remuneração Fixa, o que gera um descolamento entre o desempenho organizacional e a remuneração paga. Desta forma, a não diversificação mais ampla dos tipos de incentivo acaba mitigando seu efeito motivacional, que fica concentrado apenas no nível de incentivos.

Para a Hipótese 3, que trata da sensibilidade dos incentivos à eficiência técnica, teve-se como base os estudos de Healy (1985), Aggarwal e Samwick (1999), Habib e Ljungqvist (2005) e Krauter (2013). Esta etapa representa o fechamento do ciclo motivação-desempenho descrito no modelo conceitual desenvolvido nesta tese. Sendo assim, buscou-se identificar como outras variáveis poderiam explicar a variação da remuneração dos executivos de um ano para outro.

Foram estimados dois modelos onde a única diferença entre eles foi a proxy utilizada na variável dependente (incentivos a executivos). No primeiro modelo a variável dependente foi estimada utilizando a variação da remuneração total defasada, já no segundo modelo a proxy foi a remuneração variável paga. As variáveis independentes consideraram como única medida de desempenho organizacional a eficiência técnica das firmas e como variáveis de controle foram utilizadas dummies temporais e porte da firma. Os resultados obtidos evidenciaram que não se pode afirmar que a variação da remuneração total seja influenciada pela eficiência técnica da firma. 
Embora este resultado indique um menor poder preditivo da variável (eficiência técnica), o mesmo pode estar representando, na verdade, características do mercado brasileiro já apontadas por Dalmacio, Rezende e Slomski (2009) de que as fórmulas de incentivo acordadas entre executivos e firmas participantes da BM\&FBOVESPA tendem a não considerar o efeito do desempenho organizacional e que o uso da remuneração fixa não tem objetivos motivacionais. Complementarmente, se a principal forma de remuneração é a fixa, pode-se esperar que os esforços do agente em alcançar o desempenho esperado pelos principais não seriam incorporados por meio do uso da remuneração fixa, mesmo sendo esta o principal incentivo pecuniário ofertado pelas firmas.

A análise da sensibilidade da remuneração variável à eficiência técnica na amostra sem o setor financeiro demonstrou que este incentivo possui relação estatisticamente significativa com a eficiência técnica das firmas. Isto indica que os fatores motivacionais estão sendo capturados nesta forma de remuneração. O nível de significância encontrado possibilita inferir que a eficiência técnica estimada não explica de forma forte a remuneração e que isso é decorrente da variável escolhida conseguir representar, também, a expectativa de desempenho de longo prazo da firma, rejeitandose, portanto, a Hipótese 3 da pesquisa que diz que os incentivos pecuniários pagos a executivos possuem relação significativa e positiva com a eficiência técnica da firma. Embora, os resultados encontrados não tenham se repetido para as amostras 1 (todos os setores) e 3 (setor industrial), não sendo identificada uma relação significativa entre a remuneração variável e a eficiência técnica.

Os resultados obtidos para as variáveis defasadas da variação da remuneração total e da remuneração variável evidenciaram que não há persistência dos incentivos, o que pode indicar uma forma de controle de altas remunerações pagas a executivos no mercado brasileiro. O pressuposto, então, seria o de que se o executivo obtivesse grande variação de remuneração de um ano para outro, as firmas tenderiam a tentar reduzir esta variação no ano seguinte. Este comportamento pode representar uma tentativa de ajustar a remuneração ao desempenho organizacional de forma mais discricionária, tendo em vista que as fórmulas de incentivo (na média) não contemplaria tal relação. Por outro lado, se um executivo não alcançasse uma variação alta de sua remuneração de um ano para outro, uma forma de tentar mantê-lo no quadro de funcionários seria aumentando seu nível de remuneração visando proteger a empresa contra ações do mercado de 
trabalho de executivos. Entretanto, este seria um ato discricionário não capturado na fórmula de incentivos.

Os testes das hipóteses de pesquisa permitem responder a questão-problema elaborada para esta tese no sentido que quanto aos efeitos motivacionais dos incentivos pecuniários não foi identificado impacto da diversificação dos tipos de remuneração e que o nível desta é um determinante do desempenho organizacional. Quanto à sensibilidade da remuneração ao desempenho, apenas para a amostra 2 identificou-se relação entre eficiência técnica e remuneração variável, porém em um nível estatístico baixo. Logo, não se pode afirmar que a remuneração seja sensível à eficiência técnica das firmas.

Como contribuição desta tese, destaca-se que os resultados alcançados oferecem uma percepção mais ampla e aprofundada da discussão acerca de remuneração a executivos no Brasil. As características identificadas dos incentivos pecuniários, juntamente com os testes econométricos e os achados de estudos anteriores, evidenciam que a utilização de fórmulas de incentivo a executivos como instrumento de governança corporativa ainda é restrita e não produz os efeitos esperados e descritos em mercados mais desenvolvidos, como dos EUA e Reino Unido. Isto pode ser decorrente da temática ser ainda recente para o mercado brasileiro e a disponibilização de dados acerca de remuneração a executivos ter iniciado apenas em 2009.

Outra contribuição da tese é o uso de uma métrica diferenciada de mensuração de desempenho, através da análise de eficiência técnica, que pode ser mais explorada no ambiente brasileiro, tanto pelo mercado quanto pela própria academia no âmbito das Ciências Contábeis dada a sua capacidade de refletir o desempenho organizacional, ao invés do uso tradicionais de indicadores contábeis.

É importante, também, destacar que existe uma limitação de estudos no Brasil acerca da relação entre incentivos a executivos e o desempenho organizacional. Acredita-se que tal fato ainda seja restringido pela qualidade e disponibilidade dos dados de remuneração.

Por fim, estes resultados podem servir de base para ampliar a discussão em novas pesquisas, como, por exemplo, na avaliação relativa de desempenho das firmas ao se isolar o efeito da influência dos gestores do efeito decorrente da dinâmica setorial. Outra possibilidade que daria maior robustez à discussão motivacional seria a inclusão 
de perkisites (incentivos não-pecuniários), ainda bastante restrita pela não disponibilidade de dados, e a necessidade de agregar a análise bases de dados que contemplem empresas de capital fechado. 


\section{REFERÊNCIAS}

AGGARWAL, R. K.; SAMWICK, A. A. Executive compensation, strategic competition, and relative performance evaluation: theory and evidence. The Journal of Finance, v, LIV, n, 6, p, 1999-2043, 1999.

AGUIAR, A. B. Sistemas de remuneração gerencial e orientação temporal dos gestores, 2009, 206 f, Tese (Doutorado) - Curso de Controladoria e Contabilidade, Departamento de Faculdade de Economia, Administração e Contabilidade. Universidade de São Paulo, São Paulo, 2009.

AGUIAR, A. B.; SOUZA, B. C. Tipos de remuneração gerencial: propósitos de incentivo x propósitos tributários. In: VI Congresso da ANPCONT. Anais eletrônicos... Florianópolis, 2012. Disponível em: http://congressos.anpcont.org.br/congressosantigos/vi/images/ccg\%2052.pdf Acesso em: 05/06/2013.

AIGNER, D.; LOVELL, C. A. K.; SCHMIDT, P. Formulation and estimation of stochastic frontier production function models. Journal of Econometrics, v, 6, p, 2137, 1977.

ALLPORT, G. W. The trend in motivational theory. American Journal of Orthopsychiatry, v, 23, n, 1, p, 107-119, 1953.

ANGELIS, D. D.; GRINSTEIN, Y. Relative performance evaluation in CEO compensation: evidence from 2006 disclosure rules. Working paper. 2011. Disponível em: http://papers,ssrn,com/sol3/papers,cfm?abstract_id=1710386 Acesso em 13/04/2013.

ANTHONY, R. N.; GOVINDARAJAN, V. Sistemas de controle gerencial, 12 ed, São Paulo: McGraw-Hill, 2008.

AMORNKITVIKAI, Y.; HARVIE, C. Finance, ownership, executive remuneration, and technical efficiency: a stochastic frontier analysis (SFA) of thai listed manufacturing companies. Australasian Accounting Business and Finance Journal. v. 5, n. 1, p. 35 $-55,2011$.

BAEK, H. Y.; PAGÁN, J. A. Executive compensation and corporate production efficiency: a stochastic frontier approach. Quarterly Journal of Business and Economics. v. 41, n. 1/2, p. $27-41,2002$.

BAKER, G. P.; JENSEN, M. C.; MURPHY, K. J. Compensation and incentives: practice vs theory. The Journal of finance. v. 43, n. 3, p. 593-616, 1988.

BANKER, R, D.; DATAR, S, M, Sensitivity, precision, and linear aggregation of signals for performance evaluation, Journal of Accounting Research, v, 27, n, 1, p, 21-39, 1989. 
BATTESE, G. E.; COELLI, T, J. A model for technical inefficiency effects in a stochastic frontier production function for panel data. Empirical Economics. v. 20, p. 325-332, 1995.

BEZERRA, F, A.; CORRAR, L. J. Utilização da análise fatorial na identificação dos principais indicadores para avaliação do desempenho financeiro: uma aplicação nas empresas de seguros. Revista Contabilidade \& Finanças. n. 42, p. 50-62, 2006.

BAKER, G. P.; JENSEN, M. C.; MURPHY, J. K. Compensation and incentives: practice vs. theory. The Journal of Finance. v. 43, n. 3, p. 593-616, 1988.

BANCO CENTRAL DO BRASIL - BACEN, Resolução 3.921 de 25/11/2010, Disponível em: http://www,bcb,gov,br/pre/normativos/busca/normativo,asp?tipo=Res\&ano=2010\&num ero=3921 Acesso em: 2/11/2013.

BEBCHUK, L. A.; FRIED, J. M. Executive compensation as an agency problem. Journal of Economic Perspectives. v. 17, n. 3, p. 71-92, 2003.

BONNER, S. E.; SPRINKLE, G. B. The effects of monetary incentives on effort and task performance: theories, evidence, and a framework for research. Accounting, Organizations and Society. v. 27, p. 303-345, 2002.

BROOKS, C. Introductory econometrics for finance. 2 ed. Cambridge: Cambridge University Press, 2008.

BRUCE, A.; SKOVORODA, R.; FATTORUSSO, J.; BUCK, T. Executive bonus and firm performance in the UK, Long Range Planning, v. 40, p. 280-294, 2007.

BUCK, T.; LIU, X.; SKOVORODA, R. Top executive pay and firm performance in China. Journal of International Business Studies. 39, p. 833-850, jul/ago, 2008.

CAMPBELL, D. Nonfinancial performance measures and promotion-based incentives. Journal of Accounting Research. v. 46, n. 2, p. 297-332, 2008.

CARTER, M. E.; LYNCH, L. J.; TUNA, I. The role of accounting in the design of CEO equity compensation. The Accounting Review. v. 82, n. 2, p. 327-357, 2007.

CATELLI, A.; GUERREIRO, R. Mensuração do resultado econômico. In: CATELLI, A. (coord.), Controladoria: uma abordagem da gestão econômica GECON, 2 ed, São Paulo: Atlas, 2010.

CHARNES, A.; COOPER, W. W.; RHODES, E. Measuring efficiency of decisionmaking units. European Journal of Operations Research. 2, 6, p. 429-444, 1978.

CHEN, M. Y. Managerial pay adjustments: decomposition and impact on firm productive efficiency. Economic Modelling, v, 27, p, 196 - 207, 2010.

CHIEN, A. C. Y. A remuneração dos executivos tem impacto no valor e desempenho das empresas brasileiras de capital aberto? 2012, 26 f, Dissertação 
(Mestrado) - Curso de Mestrado em Finanças e Economia Empresarial, Departamento de Escola de Pós-graduação em Economia, Fundação Getúlio Vargas, Rio de Janeiro, 2012.

COASE, R. H. The nature of the firm. Economica New Series. v. 4, n. 16, p. 386-405, 1937.

COFER, C. N. The history of the concept of motivation. Journal of the History of the Behavioral Sciences. V. 17, n. 1, p. 48-53, 1981.

COMISSÃO DE VALORES MOBILIÁRIOS, Deliberação CVM n ${ }^{\circ 562}$ de 17 de Dezembro de 2008, Disponível em: <www.cvm.gov.br/.../cvmwww/.../Atos_Redir.asp?...\%5Cdeli\%5Cdeli...> , Acesso em: 28 de Outubro de 2012.

Deliberação CVM no 600 de 07 de Outubro de 2009. Disponível em: <www.cvm.gov.br/port/snc/deli600.pdf>, Acesso em: 28 de Outubro de 2012.

Instrução CVM $\mathbf{n}^{\mathbf{0}} \mathbf{4 8 0}$ de 7 dezembro de 2009, Disponível em: <www.cvm.gov.br/asp/cvmwww/.../exiato.asp?File=\%5Cinst\%5Cinst4... > , Acesso em 28 de Outubro de 2012.

CONYON, M. J. Corporate governance and executive compensation. International Journal of Industrial Organization. v. 15, p. 493-509, 1997.

CORDEIRO, J. J.; MUKHERJEE, P.; KENT, D. D. Non-parametric assessment of CEO compensation practices. Management Research News. v. 29, n. 5, p. 242-251, 2006.

DALMACIO; F. Z.; REZENDE; A. J.; SLOMSKI, V. Análise sectorial das medidas de performance utilizadas nos contratos de remuneração dos gestores. Universo Contábil, v. 5, n. 3, p. 6-23, jul/set, 2009.

DECHOW, P. M.; SLOAN, R, G, Executive incentives and the horizon problem, Journal of Accounting and Economics. v. 14, p. 51-89, 1991.

DECI, E. L.; KOESTNER, R.; RYAN, R. M. A meta-analytic review of experiments examining the effects of extrinsic rewards on intrinsic motivations. Psychological Bulletin. v. 125, n. 6, p. 627-668, 1999.

DEEGAN, C. Efficient management remuneration plan design: a consideration of specific human capital investments. Accounting and Finance. v, 37, p. 1-40, 1997.

DEWHURST, M.; GUTHRIDGE, M,; MOHR, E, Motivating people: getting beyond money, McKinsey Quarterly Online, 2009, Disponível em:

http://www,mckinseyquarterly,com/Motivating_people_Getting_beyond_money_2460

Acesso em: 2/11/2013.

DIXON, J.; NANnI, A.; VOllmann, T. The New Performance Challenge, Business One, Irwin, Burr Ridge, IL, 1990. 
EISENHARDT, K. M. Agency theory: an assessment and review, Academy of Management Review. v. 14, p. 57-74, 1989.

FARMER, M.; ARCHBOLD, S.; ALEXANDROU, G. CEO compensation and relative company performance evaluation: UK evidence. Compensation \& Benefits Review. v. 45, n. 2, p. 88-96, 2013.

FERREIRA, L. O. G. Padrões e características da remuneração de executivos de empresas brasileiras de capital aberto. 2012. 105 f. Dissertação (Mestrado) - Curso de Programa Multi-institucional e Inter-regional de Pós-graduação em Ciências Contábeis (unb/ufpb/ufrn), Universidade de Brasília, Brasília, 2012.

FOSTER, G. Externalities and financial reporting. The Journal of Finance. v. 35, n. 2, p. 521-533, 1979.

FRANCO, F.; FORTUNA, M, O método de fronteira estocástica na medição de eficiência dos serviços hospitalares: uma revisão bibliográfica, Working Paper, Associação Portuguesa de Economia de Saúde, 2003.

FRYDMAN, C.; JENTER, D. CEO compensation. Working Paper, National Bureau of Economic Research. 2010. Disponível em: http://www.nber.org/papers/w16585 Acesso em: 20/02/2015.

GIBBS, M.; MERCHANT, K. A.; STEDE, W. A. V.; VARGUS, M. E., Determinants and Effects of Subjectivity in Incentives, The Accounting Review, 79, p, 409-436, 2004.

GUIDRY, F.; LEONE, A, J.; ROCK, S, Earnings-based bonus plans and earnings management by business-unit managers. Journal of Accounting and Economics. 26, p. 113-142, 1999.

GONG, G.; LI, L. Y.; SHIN, J. Y. Relative performance evaluation and related peer groups in executive compensation contracts. The Accounting Review. v. 86, n. 3, p. $1007-1043,2011$.

GROEN, B. A. C.; WOUTERS, M. J. F.; WILDEROM, Celeste P, M, Why do employees take more initiatives to improve their performance after co-developing performance measures? A field study, Management Accounting Research, v, 23, p, 120-141, 2012.

HABIB, M. A.; LJUNGQVIST, A, Firm value and managerial incentives: a stochastic frontier approach, The Journal of Business. v. 78, n. 6, p. 2053 - 2094, 2005.

HAGERMAN, R. L.; ZMIJEWSKI, M, E, Some economic determinants of accounting policy choice. Journal of Accounting and Economics. v. 1, p. 141-161, 1979.

HAIR, J. F.; BLACK, W. C.; BABIN, B. J.; ANDERSON, R. E.; TATHAM, R. L. Análise multivariada de dados, 5 ed. Porto Alegre: Bookman, 2006. 
HASSABELNABY, H, R.; SAID, A. A.; WIER. B. The retention of nonfinancial performance measures in compensation contracts. Journal of Managament Accounting Research, v, 17, p, 23-42, 2005.

HEALY, Paul M. The effect of bonus schemes on accounting decisions. Journal of Accounting and Economics, 7, p, 85-107, 1985.

HOLMSTROM, B. Moral hazard in teams. The Bell Journal of Economics. v. 13. n. 2, p, 324-340, 1982.

HOLTMANN, M, Principles for designing staff incentive schemes. 2002. Disponível em: http://www.microfinancegateway.org/gm/document1.9.26843/22624_ST_Incentive_Design.pdf Acesso em: 20/05/2013.

INDJEJIKIAN, R. J.; NANDA, D. Executive target bonuses and what they imply about performance standards. The Accounting Review. v. 77, n, 4, p, 793-819, 2002.

INSTITUTO BRASILEIRO DE GOVERNANÇA CORPORATIVA - IBGC. Código das Melhores Práticas de Governança Corporativa. 2009. Disponível em: <www.ibgc.org.br/Download.aspx?Ref=Codigos $\&$ CodCodigo $=47$ Similares $>$, Acesso em: 28 de Outubro de 2012.

JENSEN, M. C.; MECKLING, W. H. Theory of the firm: managerial behavior, agency costs and ownership structure. Journal of Financial Economics. v. 3, p, 305-360, 1976.

JENSEN, M. C.; MURPHY, K. J. Performance pay and top-management incentives. The Journal of Political Economy. v. 98, n. 2, p. 225-264, 1990.

JOH, S. W. Strategic managerial incentive compensation in Japan: relative performance evaluation and product market collusion. Review of Economics and Statistics. v. 81, n. 2, p.303-313, 1999.

KAPLAN, R. S. Conceptual foundations of the Balanced Scorecard. Working Paper. 2010.

KAPLAN, R. S.; NORTON, D. P. The Balanced Scorecard: measures that drive performance. Harvard Business Review, janeiro - fevereiro, p. 71 - 79, 1992.

Putting the Balanced Scorecard to work. Harvard Business Review. v. 71, n. 5, p. 134-142, 1993.

The Balanced Scorecard - translating strategy in action. Boston: Harvard Business School Press: 1996a.

Linking the Balanced Scorecard to strategy. California Management Review, v. 39 , n. 1, p. $53-79,1996 b$.

Using the Balanced Scorecard as a strategic management system. Harvard Business Review. v. 74, n. 1, p. 75 - 85, 1996 c. 
The strategy focused organization: how Balanced Scorecard companies thive in the new business environment. Boston: Harvard Business School Press: 2000.

KASSAI, S. Utilização da análise por envoltória de dados (DEA) na análise das demonstrações contábeis. 2002. $350 \mathrm{f}$. Tese (Doutorado) - Curso de Controladoria e Contabilidade, Departamento de Faculdade de Economia, Administração e Contabilidade, Universidade de São Paulo, São Paulo, 2002.

KLEINGINNA, P. R.; KLEINGINNA, A. M. A categorized list of motivation definitions, with a suggestion for a consensual definition. Motivation and Emotion. V. 5, n. 3, p. 263-291, 1981.

KOENKER, R.; BASSETT, G. Regression Quantiles. Econometrica. v.46, p. 33-50, 1978.

KOETZ, C. M.; KOETZ, C. I.; MARCON, R. A influência do incentivo no comportamento oportunista de risco moral: uma análise experimental. Revista Eletrônica de Gestão Organizacional. v. 9, n. 3, p. 615-639, 2011.

KORMAN, A. K.; GLICKMAN, A. S.; FREY JR, R. L. More is no better: two failures of incentive failure. Journal of Apllied Psychology. v. 66, n. 2, p. 255-259, 1981.

KRAUTER, E. Contribuições do sistema de remuneração aos executivos para o desempenho financeiro: um estudo com empresas industriais brasileiras. 2009. $180 \mathrm{f}$. Tese (Doutorado) - Curso de Administração, Departamento de Faculdade de Economia, Administração e Contabilidade, Universidade de São Paulo, São Paulo, 2009.

Remuneração de executivos e desempenho financeiro: um estudo com empresas brasileiras. Revista de Educação e Pesquisa em Contabilidade. v. 7, n. 3, p. 259-273, 2013.

KUMBHAKAR, S. C. Production frontiers, panel data, and time-varying technical inefficiency. Journal of Econometrics, v. 46, p. 201-211, 1990.

KUMBHAKAR, S. C.; LOVELL, C. A. K. Stochastic frontier analysis. Cambridge: Cambridge University Press, 2000.

KUMBHAKAR, S. C.; WANG, H. HORNCASTLE, A. P. A practitioner's guide to stochastic frontier analysis using Stata. Nova Iorque: Cambridge University Press, 2015.

LAMBERT, R. A. Contracting theory and accounting. Journal of Accounting and Economics. v. 32, p. 3-87, 2001.

LAUTERBACH, B.; VANINSKY, A. Ownership structure and firm performance: evidence from Israel. Journal of Management and Governance. v. 3, p. 189-201, 1999. 
LAWLER, E. E. The strategic design of reward systems. 1983. Disponível em: file:///C:/Users/GEST-HP300-83/Dropbox/Lawler\%20-

$\% 20$ the $\% 20$ strategic\%20design\%20of\%20reward\%20systems.pdf Acesso em: $05 / 11 / 2015$.

LEE, Y. H.; SCHIMDT, P. A production frontier model with flexible temporal variation in technical efficiency. In: FRIED, H. O.; LOVELL, C. A. K.; SCHIMDT, S. S. (ed). The measurement of productive efficiency: techniques and applications. Oxford: Oxford University Press, 1993.

LEWELLEN, W.; LODERER, C.; MARTIN, K. Executive compensation and executive incentive problems: an empirical analysis. Journal of Accounting and Economics. V. 9, p. 287-310, 1987.

LIU, L. S.; STARK, A. W. Relative performance evaluation in board cash compensation: UK empirical evidence. The British Accounting Review. v. 41, p. 2130, 2009.

MARR, B.; SCHIUMA, G. Business performance measurement - past, present and future. Management Decision. v. 41, n. 8, p. 680-687, 2003.

MASSON, R. T. Executive motivations, earnings and consequent equity performance. Journal of Political Economy. v. 79, n. 1, p. 1278-1292, Nov - Dez, 1971.

MEDRANO, L. A. T. Modelos de fronteira de produção estocástica: uma abordagem dinâmica para múltiplos produtos. 2008. 139 f. Tese (doutorado). Programa de Pós Graduação em Estatística, Instituto de Matemática, Universidade Federal do Rio de Janeiro, 2008.

MEEUSEN, W.; VAN DEN BROECK, J. Efficiency estimation from Cobb-Douglas production functions with composed error. International Economic Review. v. 18, n. 2, p. 435-444, 1977.

MERCHANT, K. A.; STEDE, Wim A. Van der. Management Control Systems: Performance, Evaluation and Incentives. Harlow, England: $3^{\text {nd }}$ edition, Prentice Hall, 2012.

MICHAEL, J. Distinguishing between discriminative and motivational functions of stimuli. Journal of Experimental Analysis of Behavior. V. 37, p. 149-155, 1982.

MIGUEL, C. F. O conceito de operação estabelecedora na análise do comportamento. Psicologia: Teoria e Pesquisa. V. 16, n. 3, p. 259-267, 2000.

MIRANDA, L. C.; SILVA, J. D. G. Medição de desempenho. In: SCHIMIDT, P. Controladoria: agregando valor para a empresa. Bookman: São Paulo: 2002.

MORREL, D. L. Employee perceptions and the motivation of nonmonetary incentives. Compensation and Benefits Review. v. 43, n. 5, p. 318-323, 2011. 
MURPHY, K. J. Performance standards in incentive contracts. Journal of Accounting and Economics. v. 30, p. $245-278,2001$.

NEELY, A. The evolution of performance measurement research: developments in the last decade and a research agenda for the next. International Journal of Operations \& Production Management. v. 25, n. 12, p. 1264-1277, 2005.

NEELY, A.; ADAMS, C. The performance prism perspective. Journal of cost management. v. 15, n. 1, p. $7-15,2001$.

NEELY, A.; GREGORY, M.; PLATTS, K. Performance measurement system design: a literature review and research agenda. International Journal of Operations \& Production Management. 15, 4, p. 80-116, 1995.

PAKDEL, B. The historical context of motivation and analysis theories individual motivation. International Journal of Humanities and Social Science. V. 3, n. 18, p. 240-247, 2013.

PENNINGS, J. M. Executive reward systems. Journal of Management Studies. V. 3. n. 20, p. 261-280, 1993.

PEREIRA, L. A. S. Análise da eficiência técnica da produção leiteira dos agricultores familiares nos núcleos rurais de Rondonópolis - MT. 2011. 84 f. Dissertação (Mestrado). Mestrado em Agronegócios e Desenvolvimento Regional, Faculdade de Economia, Universidade de Mato Grosso, 2011.

PETERSON, S. J.; LUTHANS, F. The impact of financial and nonfinancial incentives on business-unit outcomes over time. Journal of Applied Psychology. v. 91, n. 1, p. 156-165, 2006.

ROOJEN, M. V. Humean motivation and Humean rationality. Philosophical Studies. v. 79, n. 1, p. 37-57, 1995.

ROSS, S. A. The economic theory of agency: the principal's problem. The American Economic Review. Vol. 63, n. 2, p. 134-139, 1973.

RYAN, R. M.; DECI, E. L. Self-determination theory and the facilitation of intrinsic motivation, social development, and well-being. American Psychologist. v. 55, n. 1, p. 68-78, 2000.

SANTOS, L. P. G. O uso do lucro econômico na formulação de contratos de incentivo contingentes ao desempenho e o problema do horizonte: uma análise experimental. 2012. 145 f. Tese (Doutorado) - Curso de Controladoria e Contabilidade, Departamento de Faculdade de Economia, Administração e Contabilidade, Universidade de São Paulo, São Paulo, 2012.

SCOTT, W. R. Financial accounting theory. 5a ed, Toronto: Pearson, 2011.

SECURITIES EXCHANGE COMISSION - SEC. Final rule: Executive compensation and related person disclosure (Release No, 33-8732A). 2006. 
Disponível em: http://www.sec.gov/rules/final/finalarchive/finalarchive2006.shtml Acesso em 23/05/2014.

SEIFORD, L. M.; THRALL, R. M. Recent developments in DEA - the mathematical programming approach to frontier analysis. Journal of Econometrics. v. 46, p. 7-38, 1990.

SCHAFFER, M. E.; STILLMAN, S. xtoverid: Stata module to calculate tests of overidentifying restrictions after xtreg, xtivreg, xtivreg2 and xthtaylor. 2010. Disponível em http://ideas.repec.org/c/boc/bocode/s456779.html Acesso em: 12/01/2016.

SILVA, F. A.; RIBEIRO, D. M.; MATIAS, M. A. O modelo de remuneração de administradores de bancos brasileiros. VII Congresso da ANPCONT. Anais... Fortaleza, 2013.

SLOAN, R. G. Accounting earnings and top executive compensation. Journal of Accounting and Economics. v. 16, p. 55-100, 1993.

SMITH, P. Data envelopment analysis applied to financial statements. International Journal of Management Science. v. 18, n. 2, p. 131 - 138, 1990.

SUNDER, S. Theory of accounting and control. Cincinnati: International Thomson Publishing, 1997.

TATICCHI, P.; TONELLI, F.; CAGNAZZO, L. Measuring Business Excellence. v. 14, n. 1, p. 4-18, 2010.

TAYLOR, S. L. Executive share options: an economic framework. Australian Accounting Review. v. 4, n. 2, p. 13 - 21, 1994.

THORE, S.; KOZMETSKY, G.; PHILLIPS, F. DEA of financial statements data: the U. S. computer industry. The Journal of Productivity Analysis. v.5, p. 229 - 248, 1994.

TODOROV, J. C.; MOREIRA, M. B. O conceito de motivação na psicologia, Revista Brasileira de Terapia Comportamental e Cognitiva. V. VII, n. 1, p. 119-132, 2005.

U.K. SECRETARY OF STATE. The Directors' Remuneration Report Regulations 2002. 2002. Disponível em: http://www.legislation.gov.uk/uksi/2002/1986/made e Acesso em: 23/05/2013.

VASCONCELOS, A, F.; MONTE, P. A. A remuneração de executivos e o desempenho financeiro de empresas brasileiras. ReCont, v. 4, n. 1, p. 1 - 17, 2013.

VANCE. D. E. Financial analysis and decision making: tools and techniques to solve financial problems and make effective business decisions. New York: McGraw-Hill, 2003.

VENKATRAMAN, N.; RAMANUJAM, V. Measurement of business performance in strategy research: a comparison of approaches. The Academy of Management Review. v. 11, n. 4, p. 801-814, 1986. 
Measurement of business economic performance: an examination of method convergence. Journal of Management. v. 13, n. 1, p. 109-122, 1987.

VENTURA, A. F. A. Remuneração executiva, governança corporativa e desempenho: uma análise nas empresas listadas na BM\&FBOVESPA. 2013. 72 f. Dissertação (Mestrado) - Curso de Programa Multiinstitucional e Inter-regional de Pósgraduação em Ciências Contábeis da Universidade de Brasília, Universidade Federal da Paraíba e Universidade Federal do Rio Grande do Norte (unb/ufpb/ufrn), Universidade de Brasília, João Pessoa, 2013.

WATTS, R. L.; ZIMMERMAN, J. L. Towards a positive theory of the determination of accounting standards. The Accounting Review. v. 53, n. 1, p. 112-134, 1978.

Positive accounting theory. New Jersey: Prentice-Hall, 1986.

WOOLDRIDGE, J. M. Introdução à econometria: uma abordagem moderna. Tradução da $4^{\mathrm{a}}$ edição norte-americana. São Paulo: Cengage Learning, 2010.

YANG, C. Y.; REGIS, P. Executive compensation and firm efficiency in China. In: Conference of Interdisciplinary Business \& Economics Research. 2011. Acesso em: 24/12/2013.

ZMIJEWSKI, M. E.; HAGERMAN, R. L. An income strategy approach to the positive theory of accounting standard setting/choice. Journal of Accounting and Economics. v. 3, p. 129-149, 1981. 


\section{APÊNDICE A - MATRIZ DE COVARIÂNCIA DOS COEFICIENTES DA EQUAÇÃO 12}

Tabela A 1 - Matriz de covariância dos coeficientes da equação 12

\begin{tabular}{|c|c|c|c|c|c|c|c|c|c|c|c|c|c|}
\hline & Capital & Mão-de-obra & Capital^2 & Mão-de-obra^2 & Capital x MO & Fin. e seguros & Agrop. & $\mathrm{A} \& \mathrm{~B}$ & Comércio & Construção & Eletroeletr. & E. elétrica & Mineração \\
\hline Capital & 0,0235 & & & & & & & & & & & & \\
\hline Mão-de-obra & $-0,0177$ & 0,0289 & & & & & & & & & & & \\
\hline Capital^2 $^{\wedge 2}$ & $-0,0012$ & 0,0012 & 0,0001 & & & & & & & & & & \\
\hline Mão-de-obra^2 ${ }^{\wedge}$ & $-0,0002$ & 0,0001 & 0,0000 & 0,0001 & & & & & & & & & \\
\hline Capital x MO & 0,0014 & $-0,0020$ & $-0,0001$ & $-0,0001$ & 0,0002 & & & & & & & & \\
\hline Fin, e seguros & 0,0040 & $-0,0029$ & $-0,0002$ & 0,0001 & 0,0001 & 0,0127 & & & & & & & \\
\hline Agropecuária & $-0,0024$ & 0,0010 & 0,0001 & 0,0002 & $-0,0003$ & 0,0046 & 0,0462 & & & & & & \\
\hline $\mathrm{A} \& \mathrm{~B}$ & $-0,0020$ & 0,0035 & 0,0001 & $-0,0001$ & $-0,0001$ & 0,0029 & 0,0029 & 0,0116 & & & & & \\
\hline Comércio & $-0,0018$ & 0,0012 & 0,0001 & 0,0000 & $-0,0001$ & 0,0027 & 0,0031 & 0,0035 & 0,0091 & & & & \\
\hline Construção & $-0,0025$ & 0,0035 & 0,0001 & 0,0000 & $-0,0002$ & 0,0040 & 0,0037 & 0,0034 & 0,0031 & 0,0094 & & & \\
\hline Eletroeletrônicos & $-0,0025$ & 0,0014 & 0,0001 & 0,0000 & $-0,0001$ & 0,0027 & 0,0032 & 0,0035 & 0,0034 & 0,0032 & 0,0225 & & \\
\hline Energia Elétrica & $-0,0018$ & 0,0002 & 0,0001 & 0,0002 & $-0,0002$ & 0,0049 & 0,0042 & 0,0031 & 0,0032 & 0,0036 & 0,0033 & 0,0072 & \\
\hline Mineração & $-0,0017$ & 0,0049 & 0,0001 & 0,0000 & $-0,0003$ & 0,0054 & 0,0037 & 0,0047 & 0,0036 & 0,0041 & 0,0036 & 0,0040 & 0,0294 \\
\hline Minerais não metálicos & $-0,0007$ & 0,0001 & 0,0000 & 0,0001 & $-0,0001$ & 0,0027 & 0,0032 & 0,0029 & 0,0030 & 0,0030 & 0,0031 & 0,0031 & 0,0027 \\
\hline Papel e celulose & $-0,0018$ & 0,0009 & 0,0001 & 0,0002 & $-0,0002$ & 0,0050 & 0,0042 & 0,0033 & 0,0033 & 0,0037 & 0,0034 & 0,0043 & 0,0044 \\
\hline Petróleo e gás & $-0,0025$ & 0,0024 & 0,0001 & 0,0002 & $-0,0003$ & 0,0049 & 0,0044 & 0,0030 & 0,0030 & 0,0040 & 0,0031 & 0,0042 & 0,0040 \\
\hline Química & $-0,0017$ & 0,0001 & 0,0001 & 0,0003 & $-0,0003$ & 0,0050 & 0,0044 & 0,0030 & 0,0032 & 0,0035 & 0,0033 & 0,0044 & 0,0042 \\
\hline Siderurgia e metalurgia & $-0,0021$ & 0,0035 & 0,0001 & 0,0001 & $-0,0003$ & 0,0036 & 0,0036 & 0,0031 & 0,0030 & 0,0037 & 0,0030 & 0,0034 & 0,0037 \\
\hline Software e dados & $-0,0004$ & $-0,0014$ & 0,0000 & 0,0001 & 0,0000 & 0,0055 & 0,0043 & 0,0027 & 0,0029 & 0,0036 & 0,0030 & 0,0042 & 0,0036 \\
\hline Telecomunicações & $-0,0019$ & 0,0036 & 0,0002 & 0,0002 & $-0,0005$ & 0,0044 & 0,0035 & 0,0040 & 0,0032 & 0,0032 & 0,0032 & 0,0041 & 0,0062 \\
\hline Têxtil & $-0,0001$ & $-0,0011$ & 0,0000 & $-0,0001$ & 0,0002 & 0,0018 & 0,0024 & 0,0032 & 0,0032 & 0,0026 & 0,0032 & 0,0026 & 0,0026 \\
\hline Transporte e serviços & $-0,0017$ & 0,0004 & 0,0001 & 0,0000 & $-0,0001$ & 0,0031 & 0,0033 & 0,0034 & 0,0033 & 0,0031 & 0,0034 & 0,0034 & 0,0035 \\
\hline Veículos e peças & $-0,0018$ & 0,0007 & 0,0001 & 0,0001 & $-0,0001$ & 0,0034 & 0,0035 & 0,0033 & 0,0033 & 0,0032 & 0,0033 & 0,0035 & 0,0036 \\
\hline Imobiliária & $-0,0008$ & 0,0003 & 0,0000 & 0,0001 & 0,0000 & 0,0047 & 0,0039 & 0,0027 & 0,0028 & 0,0037 & 0,0029 & 0,0037 & 0,0033 \\
\hline
\end{tabular}




\begin{tabular}{|c|c|c|c|c|c|c|c|c|c|c|c|}
\hline \multirow[b]{2}{*}{ Variáveis } & \multirow[b]{2}{*}{$\begin{array}{c}\text { Minerais não } \\
\text { metálicos }\end{array}$} & \multirow[b]{2}{*}{$\begin{array}{l}\text { Papel e } \\
\text { celulose }\end{array}$} & \multirow[b]{2}{*}{$\begin{array}{l}\text { Petróleo e } \\
\text { gás }\end{array}$} & \multirow[b]{2}{*}{ Química } & \multicolumn{7}{|c|}{ (continuação) } \\
\hline & & & & & $\begin{array}{l}\text { Siderur. e } \\
\text { metalurgia }\end{array}$ & $\begin{array}{c}\text { Software e } \\
\text { dados }\end{array}$ & Telecom. & Têxtil & $\begin{array}{c}\text { Transporte e } \\
\text { serviços }\end{array}$ & Veículos & Imobiliária \\
\hline Minerais não metálicos & 0,0390 & & & & & & & & & & \\
\hline Papel e celulose & 0,0031 & 0,0193 & & & & & & & & & \\
\hline Petróleo e gás & 0,0030 & 0,0042 & 0,0298 & & & & & & & & \\
\hline Química & 0,0028 & 0,0044 & 0,0044 & 0,0305 & & & & & & & \\
\hline Siderurgia e metalurgia & 0,0030 & 0,0035 & 0,0039 & 0,0036 & 0,0123 & & & & & & \\
\hline Software e dados & 0,0030 & 0,0042 & 0,0043 & 0,0042 & 0,0034 & 0,0269 & & & & & \\
\hline Telecomunicações & 0,0003 & 0,0034 & 0,0050 & 0,0114 & 0,0044 & 0,0030 & 0,2446 & & & & \\
\hline Têxtil & 0,0031 & 0,0026 & 0,0022 & 0,0023 & 0,0025 & 0,0024 & 0,0015 & 0,0080 & & & \\
\hline Transporte e serviços & 0,0030 & 0,0035 & 0,0032 & 0,0037 & 0,0030 & 0,0032 & 0,0046 & 0,0031 & 0,0130 & & \\
\hline Veículos e peças & 0,0031 & 0,0036 & 0,0034 & 0,0036 & 0,0031 & 0,0033 & 0,0034 & 0,0030 & 0,0034 & 0,0124 & \\
\hline Imobiliária & 0,0030 & 0,0037 & 0,0041 & 0,0036 & 0,0035 & 0,0041 & 0,0026 & 0,0024 & 0,0029 & 0,0031 & 0,0163 \\
\hline
\end{tabular}




\section{APÊNDICE B - ESTIMAÇÃO DA FRONTEIRA DE EFICIÊNCIA COM USO DA FUNÇÃO COBB-DOUGLAS}

Tabela B1 - Estimativa para os parâmetros da função Cobb-Douglas da fronteira estocástica (Battese e Coelli, 1995) em painel das firmas da amostra 1, 2 e 3. 2010 a 2014

\begin{tabular}{l|cc}
\hline \multirow{2}{*}{ Variável } & \multicolumn{2}{|c}{ Função Cobb-Douglas } \\
\cline { 2 - 3 } Capital & Coeficiente & Erro Padrão \\
Mão-de-obra $_{\text {Capital }^{2}}$ & $0,7532^{* * *}$ & 0,0206 \\
Mão-de-obra $^{2}$ & $0,1258^{* * * *}$ & 0,0210 \\
Capital x Mão-de-obra & - & - \\
Finanças e seguros & - & - \\
Agropecuária e pesca & - & - \\
Alimentos e bebidas & $-1,0912^{* * *}$ & 0,1062 \\
Comércio & $-0,9351^{* * *}$ & 0,2158 \\
Construção & $0,3475^{* * *}$ & 0,1108 \\
Eletroeletrônicos & $0,6354^{* * *}$ & 0,0949 \\
Energia elétrica & $-0,4382^{* * *}$ & 0,0992 \\
Mineração & $0,3810^{* *}$ & 0,1526 \\
Minerais não-metálicos & $-0,0121$ & 0,0827 \\
Papel e celulose & $-0,3262^{*}$ & 0,1821 \\
Petróleo e gás & 0,1060 & 0,1988 \\
Química & $-0,7539^{* * *}$ & 0,1395 \\
Siderurgia e metalurgia & $0,5012^{* * *}$ & 0,1756 \\
Software e dados & $1,2016^{* * * *}$ & 0,1718 \\
Telecomunicações & $-0,1425$ & 0,1099 \\
Têxtil & $-0,0183$ & 0,1555 \\
Transporte e serviços & $1,7641^{* * *}$ & 0,5036 \\
Veículos e peças & $-0,0943$ & 0,0886 \\
Imobiliária & $-0,0613$ & 0,1149 \\
Constante & 0,0202 & 0,1108 \\
\hline$\eta$ & $-1,0354 * * *$ & 0,1252 \\
$\sigma^{2}$ & $2,5153^{* * *}$ & 0,2017 \\
$\gamma$ & $0,1407^{* * * *}$ & 0,0102 \\
$\sigma_{u}^{2}$ & 251,0814 & 274,8403 \\
$\sigma_{v}^{2}$ & 0,9994 & 0,0007 \\
\hline & 250,9317 & 274,8404 \\
& 0,1496 & 0,0069 \\
\hline
\end{tabular}

Modelo Time-varying decay

(Normal-Truncado)

Número de observações $=1195$

Número de grupos $=239$

Log de probabilid. $=-821.1952$

Prob $>$ chi2 $=0.0000$

Wald chi2(21) $=6396.15$

Fonte: Elaboração própria com base nos dados do Economática® e Formulário de Referência.

Nível de significância: $* * * 1 \%$; $* *<5 \%$; $<10 \%$. 


\section{APÊNDICE C - TESTES DOS PRESSUPOSTOS DAS EQUAÇÕES 20 E 21}

\section{Equação 20}

Amostra 1 - todos os setores

Tabela C1 - Teste Hausman de especificação para sensibilidade da remuneração ao desempenho organizacional para a amostra 1. 2012 - 2014

\begin{tabular}{l|c|c|c|c}
\hline & $(\mathrm{b})$ & $(\mathrm{B})$ & \multicolumn{2}{c}{$(\mathrm{b}-\mathrm{B})$} \\
\cline { 2 - 5 } & Fixos & Aleatórios & Diferença & Erro Padrão \\
\hline Eficiência técnica & $-0,2382$ & $-0,0415$ & $-0,1967$ & 0,2997 \\
Variação da remuneração total em $t-1$ & $-0,4903$ & $-0,4843$ & $-0,0060$ & 0,0077 \\
2013 & $-0,0156$ & $-0,0035$ & $-0,0121$ & 0,0188 \\
2012 & $-0,0207$ & 0,0034 & $-0,0242$ & 0,0404 \\
Tamanho & 0,3534 & 0,2654 & 0,0880 & 0,1629 \\
\hline
\end{tabular}

Fonte: Elaboração própria com base nos dados do Economática ${ }^{\circledR}$ e Formulário de Referência.

Prob $>$ chi2 $=0,239$

Tabela C2 - Teste VIF para sensibilidade da remuneração ao desempenho organizacional para a amostra 1. $2012-2014$

\begin{tabular}{l|c|c}
\hline \multicolumn{1}{c|}{ Variável } & VIF & $1 / \mathrm{VIF}$ \\
\hline Tamanho & 9,91 & 0,100916 \\
D_eltric & 2,1 & 0,47713 \\
D_fin_seg & 2,02 & 0,496052 \\
D_2012 & 2 & 0,501188 \\
D_2013 & 1,98 & 0,505129 \\
Telog & 1,94 & 0,515181 \\
D_const & 1,54 & 0,648779 \\
D_com & 1,54 & 0,650131 \\
D_textil & 1,53 & 0,655116 \\
D_telcom & 1,45 & 0,690598 \\
D_AB & 1,4 & 0,712312 \\
D_SidMet & 1,4 & 0,714093 \\
D_transp & 1,39 & 0,718082 \\
D_veic & 1,32 & 0,754857 \\
D_Imob & 1,29 & 0,775732 \\
D_Quimica & 1,24 & 0,807726 \\
D_PetGas & 1,18 & 0,844038 \\
D_papel & 1,18 & 0,846555 \\
D_minerac & 1,12 & 0,891534 \\
D_maq_ind & 1,12 & 0,894006 \\
D_Eletroni & 1,12 & 0,895096 \\
D_Softw & 1,11 & 0,902232 \\
D_agr_pes & 1,06 & 0,942879 \\
D_Min_n_met & 1,05 & 0,948152 \\
VarRTlag1 & 1,03 & 0,967935 \\
\hline Mean VIF & 1,76 &
\end{tabular}

Fonte: Elaboração própria com base nos dados do Economática ${ }^{\circledR}$ e Formulário de Referência.

Pesaran's test of cross sectional independence $=-1.118, \operatorname{Pr}=1.7365$ 
Amostra 2 - Sem o Setor Financeiro

Tabela C3 - Teste Hausman de especificação para sensibilidade da remuneração ao desempenho organizacional para a amostra 2. 2012 - 2014

\begin{tabular}{l|c|c|c|c}
\hline & $(\mathrm{b})$ & $(\mathrm{B})$ & \multicolumn{2}{|c}{$(\mathrm{b}-\mathrm{B})$} \\
\cline { 4 - 5 } & Fixos & Aleatórios & Diferença & Erro Padrão \\
\hline Eficiência técnica & 0,7071 & 0,0824 & 0,6247 & 1,2970 \\
Variação da remuneração total em $t-1$ & $-0,5400$ & $-0,3256$ & $-0,2144$ & 0,0186 \\
2013 & 0,0384 & 0,0283 & 0,0100 & 0,0368 \\
2012 & 0,0637 & 0,0156 & 0,0482 & 0,0775 \\
Tamanho & 0,1922 & $-0,0127$ & 0,2048 & 0,0982 \\
\hline
\end{tabular}

Fonte: Elaboração própria com base nos dados do Economática ${ }^{\circledR}$ e Formulário de Referência. $\operatorname{chi} 2(5)=135,79$

Prob $>$ chi $2=0,0000$

Tabela C4 - Teste VIF para sensibilidade da remuneração ao desempenho organizacional para a amostra 2. $2012-2014$

\begin{tabular}{l|c|c}
\hline Variável & VIF & 1/VIF \\
\hline Tamanho & 3,22 & 0,3105 \\
2012 & 1,98 & 0,5050 \\
2013 & 1,97 & 0,5073 \\
Eficiência técnica & 1,44 & 0,6967 \\
Variação da remuneração total em $t-1$ & 1,02 & 0,9820 \\
\hline VIF Médio & 1,93 & \\
\hline
\end{tabular}

Fonte: Elaboração própria com base nos dados do Economática ${ }^{\circledR}$ e Formulário de Referência.

Pesaran's test of cross sectional independence $=-0.597, \operatorname{Pr}=1.4492$ 
Amostra 3 - Setor industrial

Tabela C5 - Teste Hausman de especificação para sensibilidade da remuneração ao desempenho organizacional para a amostra 3. 2012 - 2014

\begin{tabular}{l|c|c|cc}
\hline & $(\mathrm{b})$ & $(\mathrm{B})$ & \multicolumn{2}{|c}{$(\mathrm{b}-\mathrm{B})$} \\
\cline { 5 - 6 } & Fixos & Aleatórios & Diferença & Erro Padrão \\
\hline Eficiência técnica & $-0,7204$ & 0,0607 & $-0,7811$ & 0,5716 \\
Variação da remuneração total em $t-1$ & $-0,5594$ & $-0,3284$ & $-0,2310$ & 0,0211 \\
2013 & $-0,0163$ & 0,0195 & $-0,0358$ & 0,0159 \\
2012 & $-0,0396$ & 0,0092 & $-0,0488$ & 0,0390 \\
Tamanho & 0,1255 & $-0,0230$ & 0,1485 & 0,1085 \\
\hline
\end{tabular}

Fonte: Elaboração própria com base nos dados do Economática ${ }^{\circledR}$ e Formulário de Referência. $\operatorname{chi} 2(5)=138,40$

Prob > chi $2=0,0000$

Tabela C6 - Teste VIF para sensibilidade da remuneração ao desempenho organizacional para a amostra 3. $2012-2014$

\begin{tabular}{lcc}
\hline Variável & VIF & 1/VIF \\
\hline Tamanho & 3,55 & 0,2819 \\
2012 & 1,97 & 0,5073 \\
2013 & 1,97 & 0,5083 \\
Eficiência técnica & 1,77 & 0,5645 \\
Variação da remuneração total em $t-1$ & 1.01 & 0,9895 \\
\hline VIF Médio & 2,05 \\
\hline
\end{tabular}

Fonte: Elaboração própria com base nos dados do Economática® e Formulário de Referência.

Pesaran's test of cross sectional independence $=-0,824, \operatorname{Pr}=1,5903$ 


\section{Equação 21}

Amostra 1 - Amostra completa, com todos os setores

Tabela C7 - Teste Hausman de especificação para sensibilidade da remuneração ao desempenho organizacional para a amostra 1. 2012 - 2014

\begin{tabular}{l|c|c|cc}
\hline & $(\mathrm{b})$ & $(\mathrm{B})$ & \multicolumn{2}{|c}{ (b-B) } \\
\cline { 4 - 5 } & Fixos & Aleatórios & Diferença & Erro Padrão \\
\hline Eficiência técnica & 0,7065 & 0,0844 & 0,6221 & 0,4303 \\
Variação da remuneração total em $t-1$ & $-0,1997$ & 0,7825 & $-0,9822$ & 0,0449 \\
2013 & $-0,0560$ & $-0,0824$ & 0,0264 & - \\
2012 & $-0,0653$ & $-0,1658$ & 0,1004 & 0,0066 \\
\hline
\end{tabular}

Fonte: Elaboração própria com base nos dados do Economática® e Formulário de Referência.

chi2(4) $=478,46$

Prob $>$ chi $2=0,0000$

Tabela C8 - Teste VIF para sensibilidade da remuneração ao desempenho organizacional para a amostra 1. $2012-2014$

\begin{tabular}{|c|c|c|}
\hline Variável & VIF & $1 / \mathrm{VIF}$ \\
\hline Rvardef & 3,41 & 0,2935 \\
\hline D_2013 & 2 & 0,5001 \\
\hline D_2012 & 1,98 & 0,5048 \\
\hline $\mathrm{Te}$ & 1,61 & 0,6192 \\
\hline VIF Médio & 2,25 & \\
\hline
\end{tabular}

Fonte: Elaboração própria com base nos dados do Economática® e Formulário de Referência. 
Amostra 2 - Amostra sem o Setor Financeiro

Tabela C9 - Teste Hausman de especificação para sensibilidade da remuneração ao desempenho organizacional para a amostra 2. 2012 - 2014

\begin{tabular}{l|c|c|cc}
\hline & $(\mathrm{b})$ & $(\mathrm{B})$ & \multicolumn{2}{|c}{$(\mathrm{b}-\mathrm{B})$} \\
\cline { 4 - 5 } & Fixos & Aleatórios & Diferença & Erro Padrão \\
\hline Eficiência técnica & 1.188399 & 0.108169 & 1.08023 & 0.649156 \\
Variação da remuneração total em $t-1$ & -0.30982 & 0.746229 & -1.05605 & 0.048513 \\
2013 & -0.07227 & -0.12463 & 0.052362 &. \\
2012 & -0.02314 & -0.1612 & 0.138059 &. \\
\hline
\end{tabular}

Fonte: Elaboração própria com base nos dados do Economática ${ }^{\circledR}$ e Formulário de Referência. chi2(4) $=474,05$

Prob > chi $2=0,0000$

Tabela C10 - Teste VIF para sensibilidade da remuneração ao desempenho organizacional para a amostra 2. $2012-2014$

\begin{tabular}{|c|c|c|}
\hline 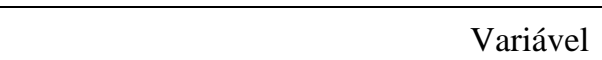 & VIF & $1 / \mathrm{VIF}$ \\
\hline Rvardef & 2,61 & 0,3837 \\
\hline te & 1,64 & 0,6093 \\
\hline D_2013 & 1,50 & 0,6687 \\
\hline D_2012 & 1,48 & 0,6752 \\
\hline VIF Médio & 1,81 & \\
\hline
\end{tabular}

Fonte: Elaboração própria com base nos dados do Economática® e Formulário de Referência. 
Amostra 3 - Amostra restrita ao setor industrial

Tabela C11 - Teste Hausman de especificação para sensibilidade da remuneração ao desempenho organizacional para a amostra 3. 2012 - 2014

\begin{tabular}{l|c|c|c|c}
\hline & $(\mathrm{b})$ & $(\mathrm{B})$ & \multicolumn{2}{|c}{ (b-B) } \\
\cline { 4 - 5 } & Fixos & Aleatórios & Diferença & Erro Padrão \\
\hline Eficiência técnica & 1,6117 & 0,0834 & 1,5283 & 1,0976 \\
Variação da remuneração total em $t-1$ & $-0,1310$ & 0,7376 & $-0,8685$ & 0,0532 \\
2013 & $-0,0902$ & $-0,1733$ & 0,0831 & - \\
2012 & $-0,0382$ & $-0,1602$ & 0,1220 & 0,0438 \\
\hline
\end{tabular}

Fonte: Elaboração própria com base nos dados do Economática® e Formulário de Referência. $\operatorname{chi} 2(4)=266,1$

Prob $>$ chi $2=0,0000$

Tabela C12 - Teste VIF para sensibilidade da remuneração ao desempenho organizacional para a amostra 3. 2012 - 2014

\begin{tabular}{l|c|c}
\hline Variável & VIF & 1/VIF \\
\hline Rvardef & 3,57 & 0,2799 \\
D_2013 & 2 & 0,5001 \\
D_2012 & 1,97 & 0,5085 \\
Te & 1,69 & 0,5930 \\
\hline VIF Médio & & 2,3100 \\
\hline
\end{tabular}

Fonte: Elaboração própria com base nos dados do Economática® e Formulário de Referência. 